Portland State University

PDXScholar

Dissertations and Theses

Dissertations and Theses

Summer 8-28-2013

\title{
Building Bridges with Social Capital in the European Union
}

Peter Andrew Noordijk

Portland State University

Follow this and additional works at: https://pdxscholar.library.pdx.edu/open_access_etds

Part of the Other International and Area Studies Commons, Other Public Affairs, Public Policy and Public Administration Commons, Social Policy Commons, and the Social Welfare Commons Let us know how access to this document benefits you.

\section{Recommended Citation}

Noordijk, Peter Andrew, "Building Bridges with Social Capital in the European Union" (2013). Dissertations and Theses. Paper 1091.

https://doi.org/10.15760/etd.1091

This Dissertation is brought to you for free and open access. It has been accepted for inclusion in Dissertations and Theses by an authorized administrator of PDXScholar. Please contact us if we can make this document more accessible: pdxscholar@pdx.edu. 
Building Bridges with Social Capital in the European Union

by

Peter Andrew Noordijk

A dissertation submitted in partial fulfillment of the requirements for the degree of

Doctor of Philosophy

in

Public Affairs and Policy

Dissertation Committee:

Birol Yesilada, Chair

David Kinsella

Melody Valdini

Shawn Smallman

Portland State University

2013 
(C) 2013 Peter Andrew Noordijk 


\begin{abstract}
A culture of accommodation and tolerance is a necessary part of establishing and preserving a functional multi-national and multi-ethnic European Union. Civil society organizations and their associated social capital have been shown to foster civic capacity and achievement of public policy goals. However, social capital that is based on group identity can also contribute to a sense of intolerance towards out-groups, undermining the stated tolerance objectives of the social pillar of the European Union. States with a strong presence alongside civil society are expected to be curb the development of the exclusionary bonding form of social capital in favor of bridging social capital which will improve progress toward policy goals.
\end{abstract}

This study tests the link between government capacity, social capital and tolerance using data from the 1990-2009 waves of the World Values Survey and European Values Study. Using path analysis and multi-level models of the relationships between political capacity, social capital and intolerance, the model establishes that government capacity enhances bridging social capital and which increases social tolerance. The study fills a gap in understanding how government capacity and policy can result in improved social capital even with greater diversity. A proposed relationship between political capacity and bonding forms of social capital was not supported. 


\section{Acknowledgements}

I would like to thank my love, Sunny Petit, whose support, patience and impatience saw this process through to completion. Thank-you to my chair and dear friend, Dr. Birol Yesilada who has also provided guidance and support throughout. Thanks to my parents who have offered hours of childcare. And to Hendrik Noordijk and Daphne Petit, who have carried me along in their own way. Grote dank to Hans Sakkers, Peter Brouwer and public officials in Utrecht and Rotterdam who helped me gain insight into their efforts at managing the challenges of integration at the ground level.

Finally, my deep appreciation goes out to my committee members, Doctors David Kinsella, Melody Valdini, and Shawn Smallman, for all their help. 


\section{Table of Contents}

Abstract

Acknowledgements

List of Tables

List of Figures

Chapter 1: Introduction

1.3 Hypotheses Related to Research Question 5

1.4 Plan of Dissertation 6

Chapter 2: State of the Problem and Review of the Literature 9

2.1: Status of Fundamental Rights in the European Union and the Open

Method of Coordination

2.2: Intolerance in Europe 14

2.3 The Measurement Problem for Intolerance 27

2.4 Civil Society and Social Capital 38

2.5 Bonding and the Dark Side of Social Capital 47

2.6 Social Trust and Civic Attitudes 53

2.7 Measuring Social Capital 56

2.8 Political Opportunity Structures and Tolerance 58

2.9 Association of Religiosity With Tolerance 62

2.10 The Interaction of Government Capacity, Social Capital, and Public Policy 68

2.11 Relative Political Capacity 73

2.12 Conclusion of Literature review and Discussion of the Problem 79

Chapter 3: Methodology, Models, and Data

3.1 Path and Hierarchical Models to test the Relationships Between Intolerance, State Capacity and Social Capital 84

3.2 Identifying and Testing Variables for the Models 87

3.4 Intolerance 88

3.5 Social Capital 94

3.6 Trust in Institutions $\quad 99$

3.7 Religiosity 101

3.8 Minority Ethnic and Religious Group Status 104

3.9 Education 104

3.10 Individual Political Position 105

3.11 Relative Political Extraction 105

3.12 Moving Average of Participation of Right-wing Groups in Government. 108

3.13 Ratio of Local to National Discretionary Spending 109

Chapter 4: Analysis

111

4.1 Intolerance In Europe Over Time

111

4.2 Demographic Correlates of Intolerance

113 
4.5 Path Model Examining Relationships between RPE, Social Capital and Intolerance

4.6: Testing Hypotheses with Multi-level Models.

4.7: Multi-level examination of Bridging Social Capital 137

4.8 Summary and Conclusion of Analysis

Chapter 5: Two Dutch Cases.

144

Chapter 6: Discussion and Conclusion

171

6.1: Implications of Results for Policy

176

6.2: Next Steps for Research and Practice

178

Sources Cited

181

Appendix A: Calculating Intolerance Measures

193

Appendix B: Membership Questions and Recoding

198

Appendix C: Social Capital

200

Memberships Responses Compared.

200

Importance of Family and Friends

207

Appendix D: Estimating Religiosity

212

Appendix E: Calculating RPE

215

Appendix F: Missing Data In the Model

217

Appendix G: Data Assumptions and Model Concerns for Multi-Level Models

222

Appendix H: Table of Intolerance 224

Appendix I: Intraclass Correlation 225

Appendix J: Notes and Figures From Analysis 227

Appendix K: Group-level Scatterplot of Intolerance by GDP/Cap 233

Appendix L: Participatie Ladder Levels 


\section{LIST OF TABLES}

Table 2.1: Reported Racist Crime Selected Countries and Years 29

Table 3.1: Social Capital Loadings $\quad 97$

Table 3.2: Public Institutions Confidence Correlations 100

Table 3.3: Descriptive Statistics for Religion Measures. 101

Table 4.1: Correlates of Intolerance: Demographics, National Characteristics

Table 4.2: Relative Political Extraction on Bridging Social Capital for Path Model

Table 4.2: Intolerance Single-level Regression for the Path Analysis 120

Table 4.3: Hierarchical Model 1986-2007 Data 126

Table 4.4: Models with 2008-2009 Cases Added, Models A through C 134

Table 4.5: Hierarchical Random-Intercept Regression on Bridging Social Capital 


\section{List of Figures}

Figure 2.1: Trust in Police by Ethnic Identifiers in European States. Data from European Union Minorities and Discrimination Survey (2009) 31

Figure 2.2: Confidence in Police by Majority Religious Status 33 Figure 2.5: Regression Equations for Relative Political Capacity from Arbetman and Kugler (1997)

Figure 3.1: Conceptual Paths of Political Capacity to Intolerance (author's diagram)

Figure 3.2: Example of Hierarchical Model

Figure 3.3: Cluster Analysis of Intolerance Indicators (WVS-EVS)

Figure 3.4 :Summative Intolerance Scale Distribution (WVS-EVS 1990-2008)

Figure 3.5: Social Capital Factor Maps (WVS-EVS)

Figure 3.12: Average Level of Religiosity by Country (WVS-EVS)

Figure 3.13: Relative Political Extraction of Selected Countries 1988-2007108

Figure 4.1: Summed 4-Item Intolerance in Europe 1989-2009

Figure 4.2: Path Analysis of RPE to Intolerance, Single-level Regression 121 


\section{CHAPTER 1: INTRODUCTION}

In 1997, Article 13 of the Treaty of Amsterdam gave the European

Community the right to "take legislative action to combat discrimination based on sex, racial or ethnic origin, religion or belief, disability, age or sexual orientation."

This declaration of the right to action placed an additional responsibility on

European member states to proactively meet the human rights objectives to which they had agreed in both the Maastricht treaty in 1992, and as members of the Council of Europe and signatories to the European Convention on Human Rights. The Treaty of Amsterdam, however, obliges the Union to penalize member states found to be in violation of the requirements to protect fundamental human rights (Ram 2003; FRA 2007b).

On February 15, 2007 the Justice and Home Affairs Council of the European Union made permanent an agency to monitor and provide technical assistance in meeting the social harmonization goals of Pillar III (The E.U.M.C., the Predecessor of the F.R.A. 2007). Social rights items, as outlined in the Amsterdam Treaty, are the protection of human rights, the promotion of democratic values, and to combat ethnic, racial, gender, and religious discrimination. Promotion of these rights and values is part of the Aquis Communitaire and the obligation of member states (Wood and Yeşilada 2002; Van Oudenaren 2005). As Europe adds new members with vastly divergent recent cultural, political, and ethnic 
composition as well as different levels of development and civil society traditions, the problems of harmonizing outcomes in an issue that touches on mass-belief systems and economic experience are exacerbated. The many states of the European Union are tasked with achieving the social tolerance goals of the Union, but are accorded deference in how to achieve those goals because of the unique structure of the Union. The emphasis on national sovereignty over issues of "home affairs" like immigration and social tolerance, means that the Union's mechanisms for promoting inclusion are limited to policy diffusion and monitoring - there is little scope for punishment, and even monitoring functions like review of national laws by the Fundamental Rights Agency have been challenged (Kjaerum 2009). The challenge is to find the conditions that have led to success in extending social tolerance to traditional out-groups. One of the main areas associated with successful public policy in general, and in this area specifically, has been strong a strong reserve of social capital.

The central hypothesis is that higher government capacity leads to reduced intolerance by fostering the development of a particular form of social capital, bridging social capital, and through the direct mechanism of repressing expressions of intolerance. Social capital can be thought of as networks of relationships that individuals are able to access to meet their needs. It can be 
conceptualized as having two main forms, bridging and bonding social capital networks.

Bridging social capital is associated with reduced intolerance expressed towards groups of outsiders. This works through several mechanisms. Civil society institutions can generate social capital that can foster either in-group bonding or between group bridging relationships, depending on their structure and purpose. The first mechanism is improved civic capacity as bridging capital is associated with more effective communities with a more effective political and civil society policy nexus (Putnam, Leonardi and Nanetti 1993; Putnam 1994). The development of bridging capital leads to an indirect path of improving tolerance by expanding the community's ability to solve problems thereby reducing competition for resources, and a direct path of government ability to suppress intolerant acts or organizations. A second mechanism that is also a direct path is also at work, this is the contact path. As actors from "outgroups" interact in civil society, refereed contact with minorities reduces the xenophobic nature of the majority community.

In contrast, bonding social capital is conceived as very tight networks that do not extend outside of an individual's social identity group. Bonding social capital is marked by an in-group or family focus of the network, and organizations that are provide resources to group members. Weak government participation in 
society limits the ability of individuals to access services outside of their "self-help" organizations, reinforcing the centrality of the identity group and stunting the development of broader networks of contacts.

The political capacity of governments, should constrain the type of social capital civil society groups (such as religious groups) generate. The combination of strong political capacity and a government interest in promotion of tolerance is expected to be associated with more bridging capital. The government will be able to constrain expressions of intolerance, and facilitate implementation of policy. Also, stronger governments reduce the competition for resources, or narrow-self help nature of some tightly bonded identity or family based bonding capital structures. Higher government capacity, should lead to more bridging forms of social capital, and therefore, more civic capacity and less intolerance. Societies with strong governments and strong social capital are expected to generate more successful tolerance outcomes than those with other combinations of government capacity and social capital.

The research questions are several-fold: Is bridging-social capital associated with better (lower) intolerance rates? Does relative political capacity lead to improved social tolerance? Does relative political capacity provide conditions for intensified bridging forms of capital? and finally, what conditions mediate any relationship between government capacity and intolerance. 


\subsection{Hypotheses Related To Research Question}

Hypothesis 1: Increased relative political capacity will be associated with lower levels of Intolerance in the European Union and accession states.

Hypothesis 2: Relative political capacity will reduce Intolerance by encouraging bridging forms of social capital and constraining bonding forms.

Hypothesis 2.1: Bridging social capital (Trust-based) is associated with reduced Intolerance.

Hypothesis 2.2: Increased relative political capacity will intensify bridging forms of social capital.

Hypothesis 2.3: Increased relative political capacity should constrain bonding forms of social capital, and constrain the relationship with Intolerance.

Hypothesis 3: More local allocation of state resources will foster stronger community engagement. Controlling for other factors, local expenditure should be associated with both increased social capital, and reduced intolerance.

Hypothesis 4: Government intention (measured by right-wing participation) interacted with relative political capacity should have a stronger effect on intolerance than relative political capacity measured alone.

In addition to analyzing the relationships between extractive capacity and intolerance through the mechanism of social capital, local government policies in two Dutch cities, Rotterdam and Utrecht, are discussed in light of their intentional 
promotion of social capital as an instrument for achieving better social integration and tolerance.

\subsection{Plan Of Dissertation}

Chapter two, following this introduction, provides a review of the literature that informs this analysis and highlights the data challenges and underpins sources of the research questions. In the literature review, social tolerance as a policy goal of the European Union is established. The limits placed on available public policy tools in the European model of governance are also reviewed in chapter two. There is also a discussion and overview of the challenge in defining and measuring intolerance in a multi-year and multi-national comparison. The different forms of social capital and their relationships to intolerance and civic capacity are reviewed, as well as the interaction between government capacity and the forms of social capital. Finally, a comparative measure of government capacity, or penetration in society that can be used to test the relationships proposed is discussed.

Chapter three (methodology) introduces the models that will be used to test the hypotheses. In chapter three, the different variables and their characteristics are also developed. A discussion of the challenge faced by missing data, and the technique used to address this issue is presented. 
Chapter four presents the analysis of three types of models used to investigate the relationships between political capacity, social capital, and intolerance. A path model is constructed to investigate the direct and indirect relationships between political capacity and intolerance, specifically focusing on bridging social capital as a mediator between political capacity and intolerance. Several multi-level regressions are then used to explore the relationships more indepth and analyze interactions between the effects of social capital and political capacity on intolerance. Other covariates are also introduced to control, or as elements of interest. Participation in government of right-wing parties and the ratio of local to total spending are included as estimates of government intention, and potential policy effectiveness respectively.

Chapter six presents a more in-depth look at the national and local policy contexts for two Dutch cities that intentionally incorporate social capital as part of their strategy to address social intolerance. The national policy context of the Netherlands is informative because it is one of the early migration destination countries, and one of the first to begin analyzing social phenomenon to construct national policy to address intolerance towards minorities. In the Netherlands, the implementation of social policy occurs primarily at the municipal level, and the examination of municipal policy in two major Dutch cities illustrates that cities consciously use social capital enhancing programs to meet social tolerance goals. 
The cities also participate in policy diffusion networks that help identify and spread best practices. The emergence of several of these programs has paralleled this research project.

This analysis contributes specifically to the present problems facing the European Union as it adapts to its newly dynamic and multi-cultural nature. The analysis contributes to synthesizing the fields of Political Science and Public Administration by integrating comparative politics concepts of relative political capacity and the ability of the state to promote specific social objectives. Understanding the relationship between state political capacity and intolerance in a cross-nationally comparable way provides an important tool in understanding conditions for successful policy implementation. 


\section{Chapter 2: State of the Problem And ReView of the Literature}

\section{1: Status Of Fundamental Rights In The European Union And The Open Method Of Coordination}

The European Union must be considered a multi-cultural polity, if it is to be considered a polity at all. The Aquis Communitaire, now represented by the Lisbon treaty, contains human rights guarantees referenced by the Maastricht Treaty in 1992, which incorporated both the Council of the European Union's Charter of Fundamental Rights of the European Union, and the Council of Europe's Convention for the Protection of Human Rights and Fundamental Freedoms (Charter of Fundamental Rights of the European Union 2009; Convention for the Protection of Human Rights and Fundamental Freedoms as Amended by Protocol No. 11 2009). The Charter requires that all states adopt a much more coordinated effort at decreasing intolerance and increasing forms of social inclusion. Despite having only created the Charter of Fundamental Rights of the European Union in 2000, and only giving it legally binding effect in 2009, the European Union member states have been obligated to perform their responsibilities under the Council of Europe's Convention on Human Rights. As all the members of the European Union share prior treaty obligations to protect human rights, the opinion of the European Court of Justice, proscribed the 
Commission from promulgating laws that could impinge on Human Rights under the Rome Convention (Commission 2009). In response to the European Court Justice Rulings, in 1977 the Commission, the Parliament, and the Council of Ministers issued a joint declaration vowing to protect human rights. Subsequently, through a series of declarations, treaties and institutions, The European Union has paid special attention to the problem intolerance throughout the series of recent expansions since the early 1990s.

The pursuit of social tolerance and the responsibility to combat racism and xenophobia, as well as discriminatory violence, are policy areas that bridge both the former Pillar I and Pillar III areas as defined by the Maastricht Treaty. As the competency of much of the issue falls in the Pillars of the European Union that are defined by inter-governmentalism not pooled sovereignty, therefore an institutional response to the issues that is uniform across the European Union is impossible. Even after the ratification of the Lisbon treaty, the issues of social intolerance still fall primarily in the competency domain of national governments (Fight against Racism and Xenophobia 2010).

European institutions like the European Union and the Council of Europe and the European Court of Human Rights have all started down a path of standardizing expectations of how minorities are to be treated. However, Koenig and others note that there has been an element of a European identity backlash of 
the sort anticipated by Ignatieff (1993) in his book about identity, "Blood and Belonging". Koenig (2007) finds that as the European Institutions have been pushing standards of treatment, the relationship between religious institutions and the state have evolved into something with salience to establishing national identity. That is, he observes that "traditional" religions of certain states have become an important national marker in an increasingly harmonized Europe, with the effect of marginalizing minority religious groups.

The single best manifestation of the public policy regime being offered to address the issue was the creation, in coordination with the Council of Europe, of a plurilateral institution to monitor, research and coordinate national policy responses to intolerance, the European Union Monitoring Center to Combat Racism and Xenophobia. This organization and its methods were early model of what was to become known as the Open Method of Coordination, where the state of a public policy problem is assessed for each member, then benchmarks are set, and a network for policy exchange is created. A means for "shaming and naming" countries that are not meeting benchmarks or implementing changes is the principle method of coercion (Nedergaard 2007; Velluti 2007; de Ruiter 2008). The $\mathrm{OMC}$ is a coordination-style of governance, with partners from the different governments, the Union, and non-governmental groups networked together in a form of institutionalized policy-diffusion. 
The Open Method of Coordination is a system of coordinated intergovernmentalism, it is marked by the following characteristics. Quoted from Radulova (2007), page 369 ; "In its fully-fledged form, the method involves the following processes : - fixing guidelines for the Union combined with specific timetables for achieving the goals which they set in the short, medium and long terms; - establishing, where appropriate, quantitative and qualitative indicators and benchmarks against the best in the world and tailored to the needs of different member states and sectors as a means of comparing best practice;

- translating these European guidelines into national and regional policies by setting specific targets and adopting measures, taking into account national and regional differences;

- periodic monitoring, evaluation and peer review organized as mutual learning processes."

The European Union Monitoring Center (EUMC) predated the establishment of the OMC but bears many of its hallmarks. The EUMC was a center jointly supported by the European Union and the Council of Europe, which recruited national partners, both official and non-governmental, to assess the current state of intolerance and to offer and implement policy solutions. It was conceived as collaborative, a center to collect information on the states of intolerance in each of the member states, it collected information on the "best practices" in data tracking, and in policy, and provided a forum for the diffusion of policy back to national partners (The Eumc, the Predecessor of the Fra 2007). As in other Open Method of Coordination structures, the EUMC worked extensively with national 
partners (National Focal Points) and non-governmental agencies in a network structures. Like other OMC structures, the EUMC, and its successor, the FRA, have no power to implement or enforce policy

As the EUMC began to conduct studies on the type and nature of social intolerance in EU member states, it was apparent that the development of benchmarks was impossible. There were many different legal traditions, different record keeping, and no uniform data from country to country, or even within countries. Also, as noted in the annual reports from the Fundamental Rights Agency and contributors such as Dijkstra, Geuijen and De Ruijter (2001), there is a big distance between paper rights and the actual experiences of discrimination on the ground in EU member states (European Union Agency for Fundemental Rights Annual Report 2008). Also, the requirements for citizenship to member states determine the rights of immigrants, some countries are jus sanguine (bloodbased), and others jus solis (birthplace) based citizenship states. The European Union's extension of citizenship to minority immigrant populations, is therefore, contingent on the state in which immigrants reside.

The trends observed by the Fundamental Rights Agency of the EU are not terribly encouraging in light of the different polices, or lack of policies of member states. The FRA report from 2007 shows that ethnic or religious minorities are substantially less likely to be employed or employed at their level of qualifications 
compared to their peers (FRA 2007a). They also note that many EU countries, including Bulgaria, Denmark, Greece, France, Italy, Austria, Portugal, Romania and Finland did not have legislation, or institutions to monitor and prosecute discrimination against individuals until the implementation of the Racial Equality Directive of the Amsterdam Treaty (Trends and Developments 1997-2005Combating Ethnic and Racial Discrimination and Promoting Equality in the European Union 2007).

The European Union has taken the issues of social tolerance seriously since the 1977 joint statement. However, as the issues surrounding intolerance are centered in areas outside the scope of the community method, and outside the competency of the Union, the responses to the problems of racism and other forms of social intolerance, had been left largely to the member states. It is not until more recently, the late 1990s and onward, has there been a coordinated and institutionalized response to the phenomenon of social intolerance.

\section{2: Intolerance In Europe}

Intolerance in Europe has been a subject of broad study, but unfortunately, little systematic measurement. Studies have largely found the expected directions of correlation of intolerance by education level, age and conservatism; less of the first, and more of the last two are correlated with intolerance with some qualitative 
differences in national contexts. However, the record on religiosity and intolerance is mixed and more strongly related to qualitative characteristics of religion and national context. Also, the rate of in-migration is not clearly associated with intolerance as might be assumed. Migrants seem to move to the wealthier countries with greater job opportunities. Those countries also seem to have more tolerant populations than poorer ones.

Studies on correlates to racism in different European countries find a variety of observations. In general, education is inversely correlated with ethnic or religious intolerance. However the education effects vary in a number of different studies, as data from surveys and qualitative research indicate that educational practices in some Central and Eastern European (CEE) states actually reinforce racial and religious bigotry against Roma and religious out-groups or historical national rivals (Hello, Scheepers and Gijsberts 2002; Mudde 2005). A number of theories on the genesis of anti-immigrant and anti-minority attitudes and behaviors postulate a material basis for intolerance (Coenders, Lubbers and Scheepers 2005d).

Additionally to competition for scarce resources, loss of status for groups sharing demographic features with immigrants, or who believe they have lost status because of social shifts also drives the perception of threat from unfamiliar "others" (Norris 2005). Observations that opposition to immigrants is apparent in 
both groups perceiving direct competition for jobs, such as the less educated, lower skilled workers, and self-employed people seems to lend support to both notions of threat (Coenders, Lubbers and Scheepers 2005a; Coenders, Lubbers and Scheepers 2005b).

However, several studies show that even controlling for income, education, and employment status, other factors, such as age, political self-placement, forms of religious adherence, authoritarian personalities and the presence of racist political parties or actors in society all correlate with intolerance towards minorities (Altemeyer 1996; Coenders, Lubbers and Scheepers 2004). At least in the European cases, contact between groups, as in urban settings or in integrated cities, an element of social capital, seems to reduce the intolerance impulse (Coenders, Lubbers and Scheepers 2005c). It is clear that there are motivations beyond simply economic threat for intolerance.

Another study of immigration into European Union states analyzed migration with respect to several hypothesis; (a) migration is largely from colanguage states or former colonies of European powers, (b) migration is generally driven by economic factor, particularly labor market demand, (c) finally that migration is driven by the generosity of social welfare benefits. The authors find that there is support for the labor market factor and the prior colonial experience thesis but not for the benefit generosity hypothesis popular with right-wing 
politicians (Hooghe, Reeskens, Trappers and Meuleman 2008). In a slight contradiction to Hooghe's findings, and a caution for using support for restrictive immigration as proxy for racism, Coenders et al, found that while overall racist attitudes were lower in Western Europe than in the southern or CEE states, attitudes towards repatriation policies were somewhat stronger (Coenders, Lubbers and Scheepers 2008a). This may be a reflection of the increased salience of repatriation policies in states with recent immigrants flow, whereas Southern and Eastern Europe have been primarily transit states, so they have fewer people to consider threats worthy of repatriating .

Another study that offers an interesting twist on the observations of the impact of immigrant or minority populations on attitudes towards out-groups. Semyonov and co-authors (Semyonov, Raijman and Gorodzeisky 2008) find expected relationships between political position, social vulnerability, and destination country GDP. They find a positive correlation between recent immigration flows and negative perceptions of foreigners. Most interestingly, they find a very strong relationship between perceived immigration flows and negative attitudes towards immigrants. That is, regardless of reality, those who think flows are large, think foreigners are a cultural or economic threat, regardless of actual flow sizes. This means there is a real problem for using actual census or 
immigrant flow data combined with opinion surveys as there may not be a good relationship between actual and perceived conditions.

While relatively few of the recent accession states are included in this analysis, a number of studies have shown that the new batch of states have higher rates of intolerance than the established European Union members. This lack of progress towards minority rights in the accession countries is attributed to several factors relating to the idea of subsidiarity and the practice of the Open Method of Coordination (Rechel 2008). Rechel $(2008,179-181)$ claims that the lack of clear guidelines or laws on the implementation of minority rights in EU countries, combined with the lack of enforcement of recommendations in old EU countries, and the absence of pressure related to the rights of minorities as a condition to accession all combined to undermine EU influence on minority rights. The Acquis and a Council directive required the passage of national level legislation, but there has been little evaluation of the effectiveness or resources put into countering intolerance in accession states.

A study about national contexts and how issues are framed have examined what contributes towards hostile feelings towards immigrants. The analysis tested the effects of unemployment conditions in the host country during the survey period and during the respondent's coming of age. They also tested survey responses during periods of political framing of immigration issues that 
emphasized outgroups' failures to assimilate, and tested the effect of assimilation versus multicultural framing in laboratory groups (Coenders, Lubbers, Scheepers and Verkuyten 2008b). In both surveys and laboratory experiments, they found a strong correlation for intolerance when assimilation framing was both in the public domain and included in questionnaires. The implications of this study are stark and resonate with Tarrow's observations on framing as well as psychology observations on the availability bias. Political actors are able to use scape-goating or out-group framing to create a more intolerant social environment simply by activating that reference frame (Tarrow 1998).

Despite data indicating strong anti-Roma, religious, and sexual orientation intolerance in Eastern accession countries, Mudde (2005) notes that the new accession states are not "hotbeds of racist extremism'. Mudde notes that in 2004 only one of the Eastern accession states had an extremist party with a strong presence, compared to five of the older EU members. While Poland, Slovakia and Romania all have strong racist civil society organizations including nationalist groups and conservative Roman Catholic and Orthodox churches, only in Romania do they have a direct presence in parliament. He also notes that despite poor data keeping, several CEE states have sustained high rates of racist violence. Despite the clearly racist elements in civil society the attitude, and violence rates and success of rightest parties do note correlate very neatly in the CEE states. 
Mudde $(2005,171-182)$ seems to attribute this to both political structure barriers and perhaps to the relative absence of out-groups other than Roma. While Mudde explains that racism is not as bad as is feared in the CEE states, Ram (2003) finds that the accession process played a very important role in bringing the Czechs and Romanians to implement policy meant to harmonize their laws, institutions and societies with that of the core EU states in the area of minority rights. She finds that the progress in those two countries occurred despite active opposition of some domestic political actors and the negative example of some Western European EU member states. EU official pressure combined with interactions between domestic and foreign NGOs and EU support of human rights NGO all combined to place minority rights on the public agenda conditioning the political structures in a way that should provide opportunities for increased tolerance while stemming the ability of racist actors to gain wide audiences. Intolerant public attitudes,state capacity, political opportunity for intolerant organizations and resonant frames seem to come together more in the CEE states than in the Western and Northern European EU member states.

National identity and European identity reflected in surveys, and in naturalization laws also influence intolerance. Racist attitudes and violence are not restricted to the CEE states. In a well-balanced study of racism in Belgium, racist attitudes towards out-groups are documented in both of the main ethnic 
communities of Belgium (Mielants 2006). He finds that the inability of politicians to deal with immigrants stems from their unwillingness to realize that immigrants were no longer simply foreign workers destined to return home. Political action against the racist right-wing Dutch-speaking Vlaams Blok/Belang and the Francophone groups are mediated by Belgium's internal identity struggle. Perpetrators of racist violence are slow to be punished and racist attitudes are generally tolerated outside of official circles, also reflecting a lack of concern with dealing directly with racism problems facing Belgium - the seat of the EU (Mielants 2006, 321-324). Like the studies by Coenders, Lubbers, and Scheepersl, the anti-immigrant feelings sensitive to assimilation versus multiculturalism framing were particularly directed at immigrants and citizens from North African or Turkish ethnic origins instead of former colonial possessions (Coenders, et al. 2008a). A range of studies have shown an attachment to a European identity with citizenship based on legal, not ethnic lineage, identifiers, that is particularly strong among the more well-educated and those who identify more with the European Union. Another study finds that identification with European Union citizenship has a positive effect on tolerance attitudes towards immigrants among Belgian youth (Quintelier and Dejaeghere 2008). Interestingly, they find that intolerance levels are higher among Dutch speakers, then among French speaking youth. While the current case among Belgian adults indicates that the Dutch speaking youth will 
have higher levels of educational attainment and economic security. However, there have been very prominent Flemish political actors who have repeatedly used political scape-goating against immigrants and French-speakers in order to create a Flemish separatist movement, so negative images of "othered" groups may be more frequent in the homes of Flemish youth. The series of studies commissioned by the European Union Monitoring Center for Racism and Xenophobia, have traced a correlation between expectations of legal behavior as a qualification for citizenship with higher levels of education (Coenders, Lubbers and Scheepers 2005e). While Coenders et al associate this requirement to be an indicator of intolerance among more well-educated Europeans, my own past research found that there is an inverse relationship with other forms of multi-cultural resistance and the "legal citizenship" requirement among those who are well-educated. That finding is consistent with a jus solis and a naturalization conception of nationality and citizenship over one based on ethnicity or blood lines. Unfortunately, as noted in the annual reports from the Fundamental Rights Agency and studies such as Dijkstra et al, there is a big distance between paper rights and the actual experiences of discrimination on the ground in EU member states (Dijkstra, et al. 2001). Also, the requirements for citizenship to member states determine the rights of immigrants, some countries are jus sanguine, and others jus solis based citizenship states. The European Union's extension of citizenship to minority 
immigrant populations, is therefore, contingent on the state in which immigrants reside.

European institutions like the European Union and the Council of Europe and the European Court of Human Rights have all started down a path of standardizing expectations of how minorities are to be treated. However, Koenig and others note that there has been an element of a European identity backlash of the sort anticipated in Ignatieff's work's on ethnic nationalism in the face of economic and identity displacement caused by globalization (Ignatieff 1993). Koenig $(2007,921-923)$ finds that as the European institutions have been pushing Union-wide standards of treatment, the relationship between religious intuitions and the state have evolved into something with salience to establishing national identity. He observes that the traditional religions of certain states have become an important identity marker in an increasingly harmonized Europe, with the effect of highlighting historical majority religions and pushing minority groups to mobilize behind a religious identity. Furthermore, the European Institutions have reached directly to religious organizations as part of civil society in order to reach around the states, while several of the European states have historically used the power of governments precisely to supplant religious groups as providers of legitimate services (Rex 2000). 
Different immigration policies, traditions and political structures in EU member states have led to a variety of outcomes. Rex explores the forms of response that European states have adopted in dealing with immigration. Transnational immigrant populations are problematic for European governments formed around class compromise. New policies to deal with multi-ethnic inflows take few main forms. 1st, the exclusion of minorities and repatriation back to source countries. 2nd is to extend legal citizenship to native-born or naturalized minority group members but insist on social and cultural integration. 3rd is the guest-worker strategy or treating immigrants and their families as temporary. 4th is permitting group-based identity and multiculturalism. Rex (2000, 62-70) argues that allowing multiculturalism provides structures for services and communitygovernment integration. However right-wing politicians combat multiculturalism with deterministic arguments that place minorities as a threat to the state because they have static and incompatible values with the majority population. Entzinger (2000) sees the kernels of conflict in the treatment of minorities as groups, he observes that when states emphasize group rights, they also make it easier to target groups. Without strong state enforcement of individual rights, and the allocation of services through group organizations, using minority organizations to help execute policy may be problematic in the long-run as the attachment to the 
state as the legitimate venue for pressing claims is weakened as services are provided by organizations .

Koopmans(1999) and Norris(2005) each focus on the interaction of public demand for policy to deal with minorities with the political opportunity structures that are determined by the state as an explanation for the rise of right-wing parties. Koopmans and Stratham(2000) note in their study of continental and British responses to minority problems, The structure of the state and franchise extended to immigrants (citizen, group rights, or geographic concentration) informs the types of claims-making options available. The state is still the frame of reference and the target for claims-making by migrants and minorities, not transnational organizations. The European Union acts merely a coordinating committee not the focus of rights claims or for minority groups. German exclusion of citizenship leads to source country nationality-based claims-making and the prevalence of home-country based ethnic mutual support organizations, while British groups are identified by religion or social group or region, not source nationality as they are identified as British individuals.

The very different strategies states have for dealing with naturalizations, immigration flows is a product of structural conditions for claims-making and influences the political participation among immigrant communities (Ireland 2000). All of the European-Union states demonstrate varying degrees of poor outcomes 
for minorities indicative of stubbornly remaining racism in society. Fennema (2000) examined a number of the policies in several states and found varied usage of legal instruments to combat racism. He found that France, Belgium and England had all rarely used their anti-racist legislation to prosecute discrimination against individuals, or discrimination by political parties. Germany used its legal instruments to suppress leftist movements until after a series of deadly attacks on minorities in the early 1990s. The Dutch, despite having anti-discrimination laws on the books since 1972, primarily used the law to protect against political discrimination and left social issues like racial discrimination to be responded to through the use of a pillar model. They created semi-private social organizations and tried organize the ethnic community groups to essentially help themselves access the political system and integrate into Dutch society. The process has, unintentionally, led to community enclaves that replicate source country divisions, and separation from Dutch society at large (Ireland 2000)(Thranhardt 2000). Unlike many other states the Dutch governments, frequently assessed the success of the integration efforts through ongoing public policy analysis.

The Fundamental Rights Agency of the EU, reports on the recording, reporting and responding to problems of social integration in a systemic manner, are not terribly encouraging in light of the different polices, or lack of policies of member states. The FRA report from 2007 shows that ethnic or religious 
minorities are substantially less likely to be employed or employed at their level of qualifications compared to their peers (FRA 2007a). They also note that many of the EU countries, including Bulgaria, Denmark, Greece, France, Italy, Austria, Portugal, Romania and Finland, did not have any legislation, or institutions to monitor and prosecute discrimination against individuals pending the implementation of the Racial Equality Directive of the Amsterdam Treaty (FRA 2007b).

\subsection{The Measurement Problem For Intolerance}

It would be optimal if there were a dataset that accurately recorded acts of social intolerance. Consistently recorded and consistently published records would provide a means of external validation for the variables used to estimate attitudes of intolerance in this analysis. Unfortunately, such a dataset does not exist. The structure for addressing the problems of social intolerance and social exclusion in the European Union is the Open Method of Coordination, a method that requires the establishment of and comparison of policy progress towards a set of benchmarks. However, the most basic elements of comparison seem to be missing in all instruments except the occasional special Eurobarometer survey, the recent European Social Survey, and neither of those other surveys has maintained the same questions over several years yet. 
There have been some efforts to assess the state of European Union assessments of their problems with crimes of discrimination, and member state performance has been consistently poor. Not only do the EU states generally not keep standard or consistent records of reported hate crimes that are comparable between one another, by and large they fail to keep records that are comparable from year to year at home (Trends and Developments 1997-2005- Combating Ethnic and Racial Discrimination and Promoting Equality in the European Union 2007). Further complicating this measurement problem is the fact that as awareness of the problem grows among law enforcement and in the community at large; the frequency of reporting goes up as a proportion of population. This phenomenon creates a correlation between pro-active policy and the rate of reported hate crimes when reported crimes increase as a direct result of policy responses taking hold! Even in the United States, Congress directed the FBI to track Hate Crimes in 1990, and by 1995 the FBI only issued uniform reporting standards for hate crimes reported by only $18 \%$ of law enforcement entities (Uniform Crime Reports 2010).

Table 1.2 is derived from data collected by the Fundamental Rights Agency and extracted from the World Values Surveys. The table provides an overview of the changes in reported racist crime over time within countries compared to the 
changes in attitude over same period for the few countries that have World Values Survey data over the same range.

For a perfect instrumental variable of racism one would expect some level of monotonic change between those measures. Racist crime should go up when racist attitudes go up and vice-versa. However, of the five countries for which there are overlapping data, four have reversed relationships. Clearly there are factors contributing mightily to measurement error. We know that the wording and methodology of the World Values Survey instruments are consistent over the periods and between countries, although social conditions are not static (such as large riots in France the month prior to 2007 survey). We also know from the FRA reports and from national reports that there are problems with police recording of data within each country as well. Table 2.1 demonstrates why using reported crime is not going to be a successful measure of comparable progress towards social tolerance goals. Further detail of the complications of using various data sources other than the World Values Surveys are explained below.

Table 2.1: Reported Racist Crime Selected Countries and Years

\begin{tabular}{|c|c|c|c|c|c|c|c|c|c|}
\hline & 2000 & 2001 & 2002 & 2003 & 2004 & 2005 & 2006 & 2007 & $\begin{array}{l}\text { Average } \\
\text { Annual \% } \\
\text { Growth of } \\
\text { Intolerance } \\
\text { (WVS) }\end{array}$ \\
\hline Belgium & 757 & 751 & 727 & 848 & 1021 & 1224 & 1359 & 1289 & 7.60 \\
\hline $\begin{array}{l}\text { Czech } \\
\text { Rep }\end{array}$ & 364 & 452 & 473 & 335 & 364 & 253 & 248 & 196 & -8.80 \\
\hline Denmark & 28 & 116 & 68 & 53 & 37 & 87 & 96 & 35 & 3.20 \\
\hline
\end{tabular}




\begin{tabular}{|c|c|c|c|c|c|c|c|c|c|}
\hline Germany & & $14725(.14)$ & 12933 & 11576 & 12553 & 15914 & 18142 & \begin{tabular}{|l|}
17607( \\
$.22)$
\end{tabular} & $8.5(7.5)$ \\
\hline France & 903 & $424(.21)$ & 1317 & 833 & 1574 & 979 & $923(.6)$ & 707 & $-9.9(17)$ \\
\hline Ireland & 72 & 42 & 100 & 62 & 84 & 94 & 173 & 224 & 16.20 \\
\hline Austria & 450 & 528 & 465 & 436 & 322 & 406 & 419 & 752 & 7.30 \\
\hline Poland & 215 & 103 & 94 & 111 & 113 & 172 & 150 & 238 & $1.5(-7.5)$ \\
\hline Slovakia & 35 & 40 & 109 & 119 & 79 & 121 & 188 & 155 & 21.30 \\
\hline Finland & 495 & 448 & 364 & 522 & 558 & 669 & 748 & 698 & 4.90 \\
\hline Sweden & 2703 & 2785 & 2391 & 2436 & 2414 & 2383 & 2575 & 2813 & $0.5(-8.5)$ \\
\hline England & 47614 & 52638 & 54858 & 47810 & 53113 & 56654 & 59071 & 61262 & $3.6(-1.7)$ \\
\hline
\end{tabular}

Source data: European Union Agency for Fundamental Rights: Annual Report 2009. Pp24-25 "Reported Racist Crimes". WVS Combined wave 1980-2007, added means of two questions "Would you have a problem if an (immigrant) or (foreign worker) moved into your neighborhood?"

Trust in the police and judiciary also dictates whether individuals will be

willing to report crimes, further complicating the value of indicators even in countries like Great Britain, which have had a fairly consistent reporting standard over a number of years. According to some reports up to $85 \%$ of crimes against Muslim victims in the European Union member states go unreported. The recent MIDIS project commissioned by the Fundamental Rights Agency of the EU provides a broad range of fairly stark findings for the likelihood of reporting hate crimes .

The figures present data from the MIDIS report. The two tables present different responses from sub-groups of minorities in the EU, their trust of the police, and their reasons for not reporting assaults or threats of a discriminatory nature. What is noteworthy in these tables is the overall trust of police in most minority communities contrasted with the very high lack of trust among nonreporting victims of hate activities. The MIDIS studies (European Union Minorities 
and Discrimination Survey: Main Results Report 2009; European Union Minorities and Discrimination Survey. Data in Focus Report: Muslims 2009) also report the differential levels of trust in the police among different ethnic groups within countries. You can see from the two charts that the Roma at once trust the police least, and cite that lack of trust as a reason for non-reporting most consistently of the surveyed groups.

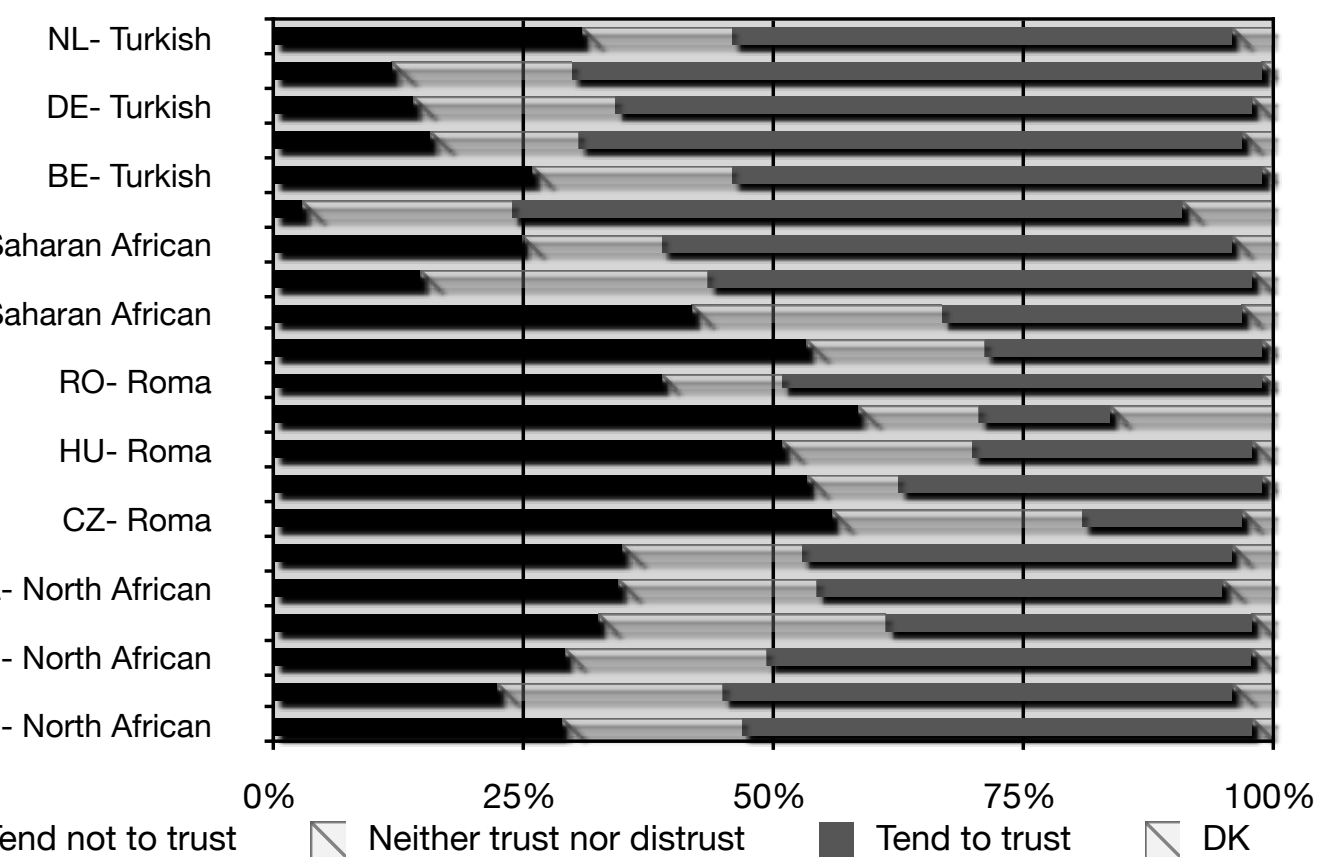

Figure 2.1: Trust in Police by Ethnic Identifiers in European States. Data from European Union Minorities and Discrimination Survey (2009)

To further illustrate the confounding effect of trust in the police on reporting rates, note the different mean scores in the figures below, the first illustrates differential scores between religious minority populations and majority, the second 
between muslim self-identifiers and majority (or non-religious) self-identifiers. Two important limitations to this data are that the religious minorities data include ethnic majority individuals who are of a minority religion such as Roman Catholics in the Netherlands, and does not capture ethnic minorities of the majority religion, such as gypsies in Hungary.

What the two tables below illustrate are the complicated nature of the relationship between minorities and the very people to whom they need for protection. The first shows the confidence of minority religion self-identifiers and the police, and the second the confidence of Muslim self-reporters and the police. In the tables below, the country name has an asterisk if the means difference is significantly greater than 0 .

Minority religious self-reporters and their confidence in the police varies greatly from state to state. There are a number of conflicting strains to explain this phenomenon. One is, that as an artifact of the data, the modal group of religious identifiers is used as the base category for determining majority status. This means that in several of the countries the "minority" group may actually be part of the ethnic majority. Non-reporters were also grouped into the majority group, which may be inappropriate for highly religious societies like Turkey, but it makes sense for most of the European countries, as many people are only nominally religious anyway. The imprecise nature of the groupings increases the 
unexplained variance and may mask some of the differences that are addressed

by the Midis study however, these classifications are comparable across countries.

They still capture the differences in attitudes toward the police, if in a less precise

manner. While it is difficult to identify any clear trends, the western wealthier states

(with more recent experience of immigration) do tend to show minorities who hold

the police in less esteem than their majority peers.

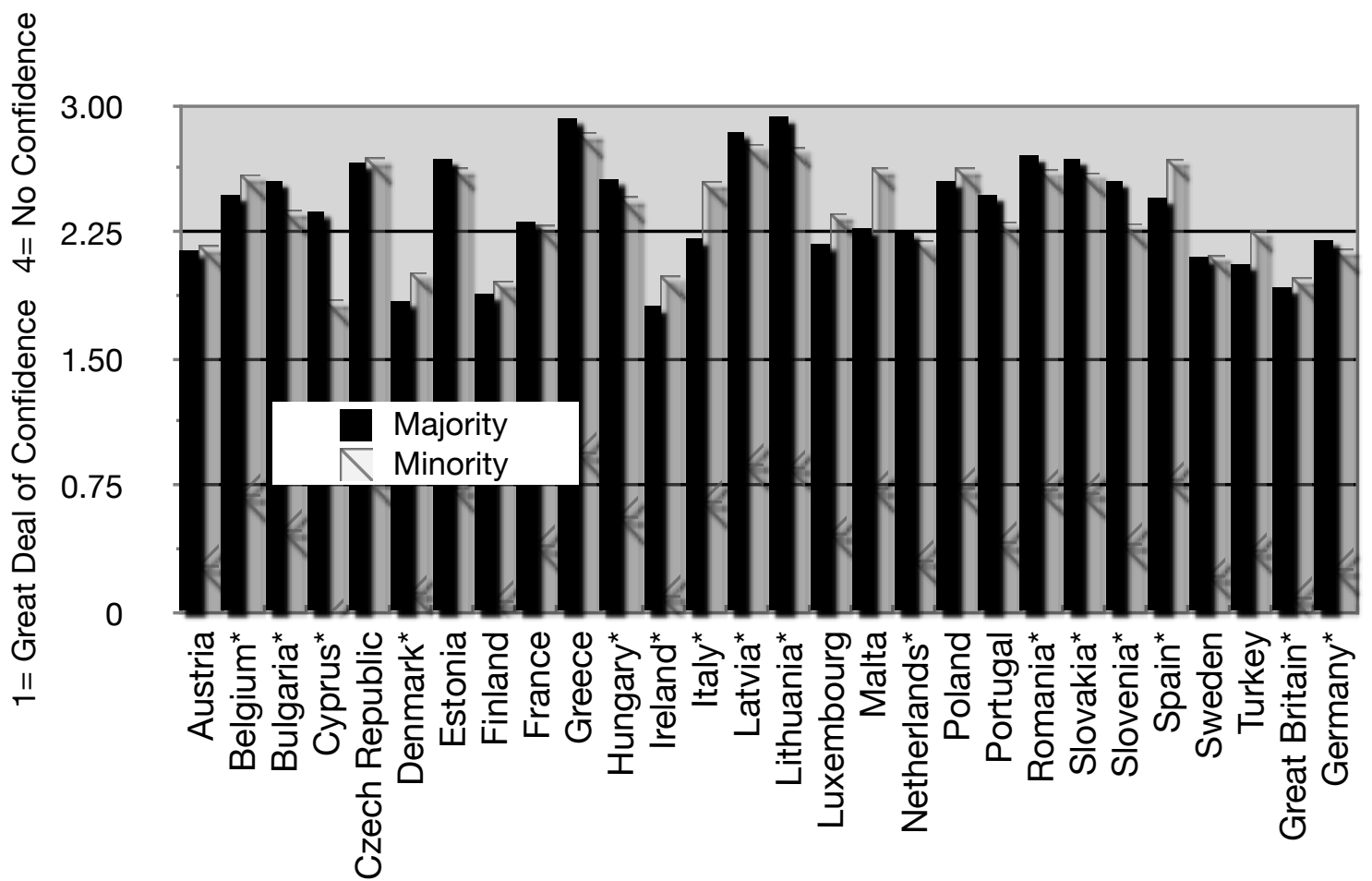

* Denotes difference significant from 0 at $p<.05$.

Notes: Data from combined WVS-EVS waves 1-5, World Values Survey 1981-2008 Official Aggregate. Question asks "How much confidence to you have in the following...Police? 1=Great Deal, 4=No Confidence." Minority religious status doesn't include ethnic minorities of majority religion (like Orthodox Christian Gypsies in Greece) and does include majority ethnicity persons of minority religious status (Roman Catholics in the Netherlands for example.)

Figure 2.2: Confidence in Police by Majority Religious Status 
The chart, "Confidence in the Police by Muslim Status" further highlights some of the differences of experience from state to state, and could provide some insights into the difficulty of measuring racism through crime. It has the added benefit of selecting a group that is in a distinct minority in most of the European countries (except Turkey and Cyprus.) The chart reinforces the observation of the minorities chart above, with some clear exceptions. In France, the Netherlands and Sweden, people have pretty strong confidence in the police, but Muslims have even more confidence than do majority religion (or secular) populations. The rest of the developed western states do not, however, have such a salubrious and counter-intuitive record.

The instances of high confidence in the police by both minority and majority status, illustrates an interaction effect that may create the appearance of high crime in countries of low reported intolerance for countries like Sweden or the Netherlands in which minorities are more willing to report incidents to police, while likely experiencing fewer incidents overall because the police are believed effective by people holding racist attitudes.

National RPE and confidence in the police have a strong relationship with a correlation of $-.13 p<.01$ (confidence in the police is scored from 1 to 4 where 1 is "a great deal".) This further reinforces the argument that countries, which have a stronger state presence in society, and are perceived as more capable, will have 
higher levels of reporting of hate crimes and lower attitudes of intolerance simultaneously.

There is no series of data on intolerance that is uniform between countries over time other than the WVS scales on neighbors. Reported crime data cannot be used because of the numerous problems in data collection, and local attitudes towards the police and local expectations of the treatment of minorities. The lack of externally valid data other than the World Values Survey leads to the requirement of constructing a scale of intolerance from the series available in the World Values Surveys. 


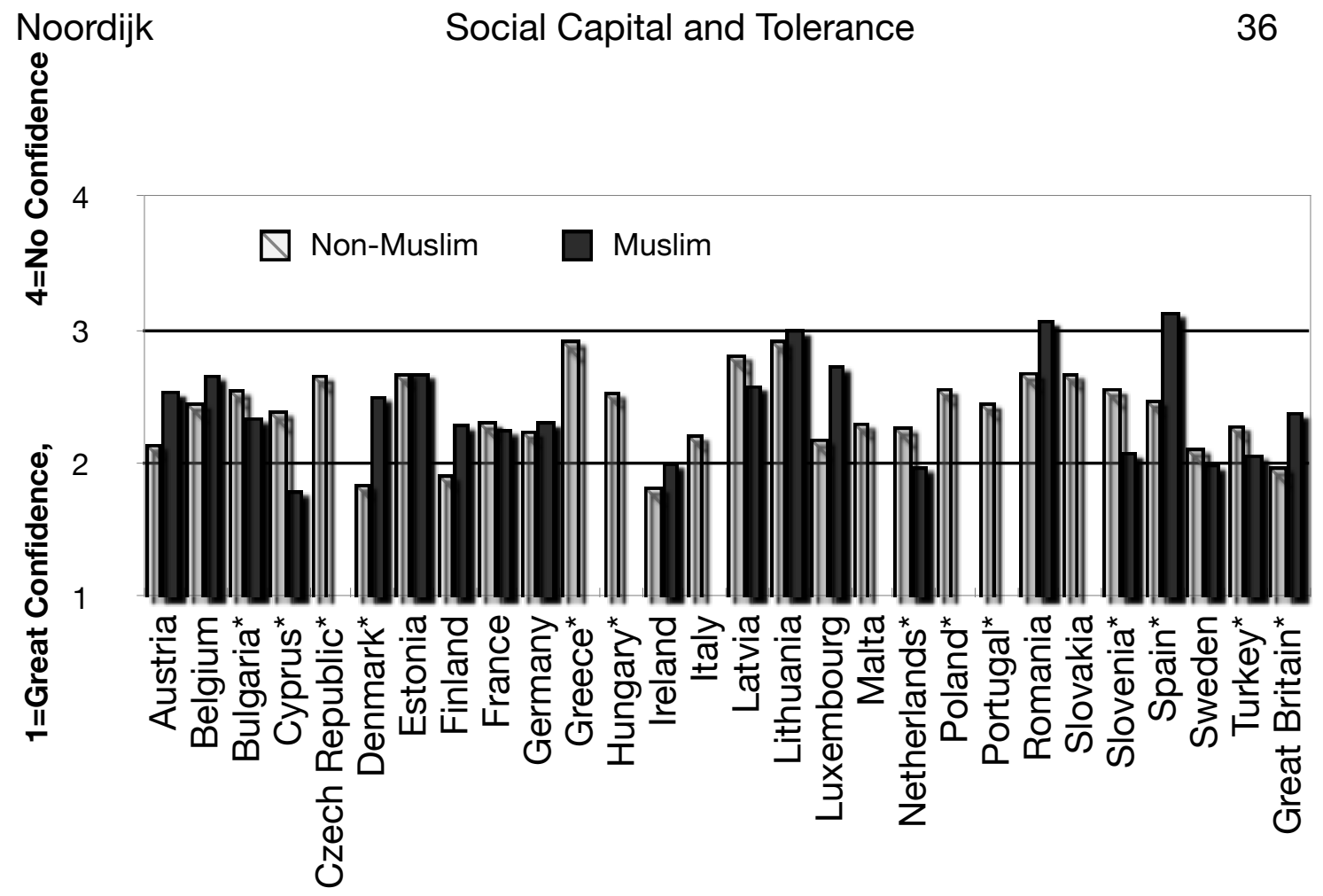

* Denotes difference significant from 0 at $p<.05$.

Notes: Question asks "How much confidence to you have in the following...Police? 1=Great Deal, 4=No Confidence." Data from World Values Survey 1981-2008 Official Aggregate

Figure 2.3: Confidence in Police by Muslim Status

One more item of note for the intolerance scale, especially in the context of Eastern and Southern Europe, including Italy, is intolerance towards Roma ethnic identifiers. The World Values Survey has conducted only limited surveys of attitude towards the Roma, but where it has, the results confirm recent analysis by the Fundamental Rights Agency. The Roma are one of the least tolerated groups in Europe. Unfortunately this item was only widely used in the 1999 European Values wave of the World Values Surveys and cannot be included in the intolerance variables. However, for the data that both sets exist we can estimate a 
correlation between our current measures and the gypsy variable by finding the Eta of the means difference between those citing gypsies as undesirable neighbors versus those who do not. Unsurprisingly, there is a large correlation present with an eta of .41 with the summed responses to the other five neighbor questions as a measure of Intolerance.

Table 2.3: Intolerance toward Roma

\begin{tabular}{|l|l|l|}
\hline & \multicolumn{2}{|c|}{ Neighbors: Gypsies } \\
\hline & \multicolumn{1}{|c|}{ Correlation Coefficient } & \multicolumn{1}{|c|}{$N$} \\
\hline $\begin{array}{l}\text { Neighbours: People of a different } \\
\text { race }\end{array}$ & $.306^{* *}$ & 14324 \\
\hline $\begin{array}{l}\text { Neighbours: People who have } \\
\text { AIDS }\end{array}$ & $.351^{* *}$ & 14324 \\
\hline $\begin{array}{l}\text { Neighbours: Immigrants/foreign } \\
\text { workers }\end{array}$ & $.336^{* *}$ & 14324 \\
\hline $\begin{array}{l}\text { Neighbours: Homosexuals } \\
\text { **Sig. (2-tailed) tau-B. Question asked if respondent would have a problem with listed neighbor. } \\
\text { Countries in the sample: Bulgaria (1999), Finland (2000), France (1999), , Italy (1999), Nethelands } \\
\text { (1999), Poland (1999), Romania (1999), Sovenia (1999), Spain (1999), Sweden (1999), Turkey } \\
\text { (2001), Great Britain (1999) } \\
\text { Source:World Values Survey 1981-2008 Official Aggregate }\end{array}$ \\
\hline
\end{tabular}

Understanding trends in intolerance is a challenge even using instruments designed expressly for that purpose. The European Union has only just developed such instruments, and instead has been forced to rely on non-comparable criminal justice data, or anecdotes from their national partner groups. The World Values/ European Values Surveys provide one instrument of measure consistent over several years both in structure and application in measuring a scale of intolerance. 
Establishing an instrument for measuring intolerance allows us to examine the correlates of intolerance and explore the effects of policies and intent in the European Union context.

Thus far, efforts to achieve EU goals have been largely left to the different member states. Only in the past 10 years has an institution existed to track, compare, evaluate and coordinate social tolerance policies between the states. Despite the inter-governmental nature of the problem, major institutions of Europe have encouraged efforts at social inclusion among their member states.

\subsection{Civil Society And Social Capital}

This section presents the background and state of the literature for different forms and measurement of social capital and its relationship with civic capacity. This study explores the role that state capacity plays in creating conditions for the emergence of bridging social capital instead of more intensely bonded networks. A strong state provides the conditions for increased bridging capital and stronger civic capacity in general.

Social capital is an essential component of any well-functioning government and must be present for democracies to function at all (Bermeo 2003). Social capital has a three-fold relationship with tolerance as a feature of society. First, as Stepan (2000) notes, tolerance of differences (political and 
otherwise) itself is a lynchpin of democracy. Second, common measures of social capital feature items such as trust of neighbors and society; intolerant individuals are expected to not show trust towards out groups. Finally, and most importantly, social capital is expected to increase the civic capacity of governments that are part of societies with strong social capital, with both government autonomy and officials' embeddedness in social capital networks (Evans 1995). The European Union members are required to be functioning democratic states, and each of those states face strains through expansion of the EU. Additionally, their demographic changes furthermore put explicit emphasis on achieving community objectives through partnerships between government and civil society. Those partnerships are expressly meant to both foster increased social capital infrastructure and embed national or European Union-level government actors in the societies.

There are a number of definitions of social capital available in sociology, economics, political science and public administration. While these definitions have variations in disparate fields, there is some harmonization on the concept and ways to try and measure it. There is agreement that social capital is composed of both trust networks, associations, and a set of norms or values carried by the individuals in society (Van Deth 2003). Social capital is capital in the sense that these networks provide some instrumentality for individuals in these 
associations or networks. The presence of dense, intersecting networks in society allows for individuals in a network to access resources in adjoining networks, whereas networks that reinforce existing relationships offer less opportunity for utilizing resources, and foster closed trust networks marked by tight social control. In order for individuals to tap resources beyond their immediate group, intersecting networks with norms of trust and cooperation must be present. Therefore social capital must have both dense networks and norms of trust or cooperation (Sobel 2002; Van Deth 2003). Conceptions of social capital have two main addresses that are not mutually exclusive. Social capital is at once an attribute of individuals and society (Van Deth 2003).

Putnam $(1993,167)$ describes social capital as, " the features of social organization, such as trust, norms, and networks that can improve efficiency of society by facilitating coordinated actions." Light describes social capital as trust relationships that are part of social networks. His concept of social capital, as Putnam's, is instrumental and intentional. Social capital can exist as both spontaneous and latent networks, but can be made instrumental and is convertible to tangible benefits (Hutchinson, Vidal, Putnam, Light, de Souza Briggs, Rohe, Gress and Woolcock 2004). Woolcock(1998) provides a broader description of social capital that includes some notion of civil government within the rubric of social capital. Woolcock's (1998) conception of social capital starts 
at the micro-level of interpersonal relationships within a social subset of individuals. The trust relationships, shared norms and networks among those individuals he calls individuals' micro-level embeddedness. He also notes another dimension of human capital, which is the link of an individual to other larger social networks (vertical "autonomous" capital) that extends to the macro level of society giving an individual access to other sources of social resources. Macro-level social capital is similar to civic capacity - it is the combination of the ability of the broader society to get things done (autonomy), and the networks of relationships that sub-groups have with larger society (embeddedness). The inclusion of the macro- and micro-levels of social capital integrate the concepts of civic capacity (the ability of social groups to identify and achieve goals) and civil governments as institutions that bridge groups, as well as the narrower conceptions of social capital described above (Woolcock 1998).

Portes (2000) also attributes Putnam with pushing the transition of social capital conceived as an attribute of individuals to one of society. He argues that a society has a "stock" of social capital that is generated by bridging associational memberships and norms of trust and cooperation (Putnam 1994; Putnam 2000). Newton (2001), however, goes further arguing that social capital is only conceptually plausible as an attribute of society. It is a measure of the stock or social trust, associational links, and possibly political trust in a society. While it 
may manifest in the ability of individuals to access resources, the stock of capital itself is a collective phenomenon. Newton tested his claims about social capital. He analyzed the correlations between associational memberships and forms of trust toward society and public institutions and found that the relationships only emerge systemically at the level of society and not as attributes of individuals. The associational memberships and social activities of individuals were generally unrelated to their indicators of social trust. Instead other factors like socioeconomic status, majority status and education had far higher correlations with elements of trust (Newton 2001). Conceptually there is a logic to social capital being conceived as an attribute of society as well as of individuals. An individual with few personal associational memberships, or even low levels of social trust, is still able to activate more "loose ties", or access more resources in a society with many interlocking connections and norms of trust, than the same individual in a society marked by tight non-intersecting associations and low-levels of trust. As referenced above, Newton's (2001) analysis of the linkages between associational membership and measures of trust found little connection at the individual level . However, Paxton (2007) operationalized a confirmatory factor analysis of attributes of social capital including associational memberships at the individual level . Controlling for national contexts in a multi-level analysis, Paxton found that organizational types with members who have multiple memberships also have 
increased levels of trust in other individuals more than other types of associations, while membership in some organizations (religious and unions) may actually reduce generalized trust (Paxton 2007). Van Deth and Zmarli (2010) also operationalized an analysis of associational types of individuals' memberships and found similar connections to Paxton's; associational types mattered for the types of trust (this time political trust) that individuals possessed (Maloney, van Deth and Rossdeutscher 2008).

Trust networks are described as tightly bonded networks of individuals such as religious sects that are costly to exit, have tight control over pooled resources, have very high stakes of exclusion for individual members and may have a mixture of vertical and horizontal linkages within and between related organizations (Tilly 2005). Tilly (2005) describes networks that have limited memberships and tightly connected nodes. His case of study is Eastern European Jewish immigrants in Johnstown Pennsylvania, but may as well be Bengali immigrants to England, or Indonesian immigrants to the Netherlands. These networks are dominated by identity and community focus and access to resources is achieved through group membership and performance of qualifying duties. There may be several organizations within this tight network, such as charitable groups, business associations, and women's groups. But they are marked by having high overlapping memberships and few links outside the 
community. These tightly bonded networks can provide resources like financing for businesses, economic assistance, or social functions, but they also are very circular and can foster suspicion of outsiders as a means of further enforcing the social ties (Almond, Appleby and Sivan 2003). Recent research (Iglic 2010) on the types of social capital associated with different groups has found some distinctions between types of association networks and their relationship to general or particularized forms of trust. Finally, the societal nature of social capital lies in the presumed intersection of the structural (intersecting networks) characteristics and the cultural aspect in solving collective action problems and producing public goods (Putnam and Bagnasco 1996; Van Deth 2003).

Social capital can also be seen as residing in individuals to instrumental purposes and is not necessarily a public good. The individual-centered conception of social capital relates to, but is distinct from social capital as a characteristic of a society, a public good, and not just its individual members. Social capital as an individual's asset means that the social capital stock of an individual is identified by their location in and size of their trust networks. That is their associations of individuals with whom they have sufficient social connections that they can count on society enforcing agreements (Portes 2000). The notion of social capital utilized by Putnam in, Making Democracy Work (Putnam, et al. 1993), and Bowling Alone (2000) is an attribute of the community as much as it is 
of individuals. The earlier notions of social capital offered by Bourdieu and Coleman put the instrumentality of social capital for individuals at the center of the concept, social capital was something individuals had, not societies (Portes 2000; Van Deth 2003). Individuals had trust networks, or weak and strong ties that they could activate in order to improve their own lot. But the notion of social capital as an individual's attribute introduces the possibility of individual social capital shortcircuiting the positive effects of community stocks of social capital. That is, we cannot merely add the social networks of individuals alone and arrive at an estimate of civic capacity (Coleman 1988).

While Kwon and Adler $(2002,18)$ describe social capital as the goodwill flowing between individuals, they state that social capital is manifest in the resources that relationships can bring to the individuals. Granovetter's (1983) description of social capital places emphasis on the advantages of weak ties, or the resources available through the broader and weaker social networks that individuals posses (Granovetter 1985). There are also extrinsic and internalized aspects to the concept of social capital. The extrinsic descriptions highlight the utilization of networks by individuals to garner resources or facilitate their personal objectives, but the intrinsic element of social capital is the set of internalized norms for cooperation and behavior that membership in groups and iterated relationships within social networks help to create (Adler and Kwon 2002). Social capital is also 
described (Portes 1998; Knoke 1999; Burt 2004) as processes through which individuals create and activate bonding and bridging networks by joining and using membership in organizations to expand their personal access to resources and information. Knack's (2002, 776-778) analysis of social capital's impact on the civic capacity of states operationalize two aspects of social capital separately. He uses both generalized trust, and memberships in associations as his measures of social capital. Knack also highlights that group membership need not lead to more trust at all as groups, like religious or ethnic affiliation organizations, garner bonding capital by burning bridges, which is why he insists on a multi-faceted measure of social capital.

To further illustrate the importance of social capital as an individual's attribute, imagine two people as part of society. One is a member of two associations, both nested in a sectarian context; a member of a Roman Catholic business association and part of a charitable association - also part of the Roman Catholic community (this would be reflective of the sectarian based associations that dominated the Netherlands until the middle of the twentieth century). The effect of membership in the bonding-type associations on the individual's social capital mean that he has many links to the same group of people but generates low levels of generalized trust-he does not trust outsiders and doesn't need to trust others within the group as he has many avenues of control and reciprocation 
and simply. Along with low-levels of generalized trust, the individual has a limited network of potential contacts as many of their links are redundant and all are within the same community. Consider another individual, also with two memberships: one in a secular social charity organization such as Rotary International, and another in a local education group (such as a parent teacher association). There may be some overlap of membership in the two groups, but the individual essentially spans two groups with different memberships and different second-order networks. This individual learns more generalized trust because she has fewer social control links to the individuals in her networks and instead must trust associates to act fairly. She also has a much broader potential network of "friends of friends." The interlinked nature of her memberships provides greater social capital in the form of both networks and generalized trust.

\subsection{Bonding And The Dark Side Of Social Capital}

Individual social capital and community-level capital can be at crosspurposes. While it is often the case that social networks can be useful to help reduce transaction costs (by providing a means of finding qualified job candidates or connecting individuals to government officials, for example) those relationships are not necessarily positive. However, individuals with connections may instead play a market-distorting role by controlling information or selecting members only 
from an "in" group (Portes 2000). This is the case of corruption in "strong society" countries lacking in a autonomous state apparatus. In this hypothetical, instead of fostering institutional trust and civic capacity the individuals with high levels of capital undermine the communities' stock of social capital. The cases in "Making Democracy Work" (Putnam and Bagnasco 1996) in Southern Italy, illustrate how extended family and patronage networks dictated access to resources and employment and fostered organized crime networks, providing substantial examples of social capital networks that have a malevolent effect on society .

Although the earliest definitions of social capital are based on observing the positive externalities achieved by networks of trust and associations, Durlauf and Fafchamps (2004) in their survey of the evolution of the concept note that not all versions of social capital are socially beneficial. Several early explorations of the concept at least mention that not all elements of social capital are necessarily positive (Granovetter 1983; Coleman 1988; Woolcock 1998), introducing the concept of social capital alongside examples of its darker forms. Other authors have explored the potential pitfalls of individuals being too embedded in a tight associational environment, either socially or between business and public-sector actors (Evans 1989; Portes 2000). Evans (1989) and Portes (2000) separately dealt expressly with malevolent forms of social capital networks designed to undermine fair allocation of resources and information. Portes (1998) argues that 
the dark side of social capital stems from networks that are too dense and stifle innovation or the ability of individuals to access resources outside their group. Social capital that is too rich in bonding capital and lacking bridging capital that can stifle success as much as absent capital. Evans (1995) also argues that civil societies' networks and their linkages to the state, or the absence of a strong autonomous state, can serve as networks of exploitation if the state is subject to capture by narrow groups. Knack (Knack 2002) also explicitly measures social capital as associations and generalized trust and volunteerism separately because some groups are so focused on exclusionary memberships, they undermine generalized social trust and civic capacity . Indeed, more recent work has also been dedicated to uncovering aspects of social capital that are less than salutary for the positive virtues expected.

van Deth and Zmerli(2010) provide a taxonomy of dark social capital in a recent introduction to an issue of American Behavioral Scientist. They argue that the conception of bridging versus bonding capital does not really explain why the anticipated negative consequences would emerge from bonding over development of bonding capital. They provide three types of organizations or negative effects that can be described as "dark social capital". They especially focus on organizations with negative norms or intent, reproduce negative norms, and can achieve evil aims more effectively when gaining skills and reducing costs 
of collective action with increased social capital. Especially when it is a tight network of bonding capital with multiple informal avenues for control of members .

The dense bonding environment of small inward-facing groups isolates individuals and limits the community's ability to solve problems. In her study of democracy and social capital, Paxton (2002) notes that the absence of bridging mechanisms can lead to intolerance and isolation in inward looking groups and is inversely related to civic attitudes. Government institutions can provide bridges in the absence of or in addition to overlapping memberships (Akkerman, Hajer and Grin 2004a). It is central to the argument in Kemmis' "Community and the Politics of Place" (Kemmis 1990) that a strong shared sense of broader identity can bridge smaller groups and create an environment for interlinking networks.

More recent work by Putnam (Putnam 2007) examining the impact of multiethnic communities on social capital, measures such as social trust finds the impact of minority presence on social capital is strongly negative. Even controlling for demographic variables, and census tract level variables, the finding is robust. In the United States, greater minority presence is associated with lower rates of social capital. The measurement of social capital is problematic as highlighted by the concept of trust used in the context of Putnam's 2007 paper. For a respondent in a densely populated neighborhoods which are often integrated, and low-income, and have lower rates of home ownership, the image of a neighbor 
encompasses many hundreds or thousands of people, most of whom they may not know personally. This does not mean they have low-levels of social capital or even generalized social trust - it means that they don't know all of their immediate neighbors, but they may have hundreds of trust network members in the broader community. Which leads to a second critique. The mentally available image of neighbor to someone in rural small communities is likely someone the respondent knows personally, so for them trust equals confidence in the sense described by Giddens (1990). There is little risk in trusting their neighbor because they are in a trust network. A more diverse, or high-turnover community or one with high population density evokes an image of neighbors who are strangers. In this sense trust in neighbors is a blind trust, it is a question about the nature of humanity, and in a dense population, or in a poor neighborhood with high crime rates, there are plenty of examples of risk and betrayal available in the recent experience of the respondent. But again, in aggregate they may have a more robust network, or even be more generous or optimistic person - they are simply required to have more blind trust in their neighbors, than is the respondent in $\mathrm{N}$. Dakota or even York, PA, two locations in their study.

A response paper testing Putnam's observations about the U.S. found stark differences between the U.S. results and regional variation in the European Union (Gesthuizen, Scheepers and van der Meer 2008). Of course, the national 
level variance in the European Union is much greater than that between states or cities in the U.S., but it is the reasons for variation that are very interesting. The primary national level-characteristics that seem to ameliorate the adverse effects of ethnic diversity on social trust and other indicators of social capital in Europe are the lower levels of income inequality in Western European states, and the length of time of democratic experience. Related to the democracy experience, more research indicated that respondents feelings of political efficacy were strongly tied to both indicators of social capital and ethnic tolerance (Hooghe, Reeskens, Stolle and Trappers 2006). Although Gesthuizen and her coauthors (Gesthuizen, et al. 2008) claim that the levels of social security of the states does not play a major role in preserving social capital, it seems that social transfers are one of the major mechanisms for eliminating the income inequalities associated with the sort of resource competition and with-in group help systems that are associated with lower bridging-social capital for diverse communities in Putnam's study and is an area worth testing because providing a safety net is one of the main functions, and instruments of control for tightly bonded social communities (Tilly 2005, 117-124).

The implications for policy from Putnam's paper certainly resonate both with the European Union's goals and observations from work on identities and authoritarian personality (Altemeyer 1996). Putnam's more recent work observes 
the possibility of reduced salience of ethnic identifiers through rigorous enforcement of non-discrimination policies, as in the U.S. military. He finds that social change in the U.S. incorporates diversity into identity over time, in a way that can be accelerated by policy emphasizing procedural democracy, and American membership based on civic identity not ethnic identity (2007).

\subsection{Social Trust And Civic Attitudes}

Regardless of whether one ascribes to an elites-driven, pluralist, or massmobilization theory of democratic persistence, the connections between culture and political practice are fairly direct. An active civil society that has many diverse organizations and networks of connections can facilitate governance and act as a break on power. If the culture supports trust and tolerance and is politically active, then the values of the broad base of society will be reflected in the form of governance and democracy secured from the bottom-up. If the political culture is such that there is weak or inactive civil society, then the linkages between the people will be through party structures and political agencies. In an environment of low social capital and traditional non-democratic civil society institutions, authority is respected and the fate of democracy lies in the loyalty of the political elites to democratic competition. 
Despite a rapidly changing world, the persistence of national or regional political culture cannot be ignored. An interesting study of the persistence of civic cultural norms and behaviors is provided by Rice and Feldman (1997). Using World Values Survey and General Social Survey data they analyzed the civic attitudes and behaviors reported by Americans against those of their countries of ethnic origin. The authors conducted their study on the premise that a civicminded political culture is foundational to the persistence of democracy. They were interested in the persistence of civic values as a sort of leading indicator of democratic decline of success. In defining their measures for civic culture, the authors (Rice and Feldman 1997) borrow from Putnam's 1993 analysis of Italian social capital and presage the observations on civic behavior in the Scandinavian Midwest from his, "Bowling Alone" (2000) which reflected their thesis. The authors found powerful durability of civic culture surviving the transition to America with a nearly unitary relationship between civic culture values in the source country and those of American descendants. The implications for the persistence of cultural values, and therefore democratic or authoritarian tendencies rooted in culture are profound. It seems that the idea that one can take the person out of the home culture, but cannot take the home culture out of the person is truer then often suspected. The implication of this for comparative political analysis is that 
measures of political culture may vary widely because of cultural artifact and will vary widely from state to state.

Particularly in societies that have an acceptance of authoritarian structures, the role of political and social elites cannot be underestimated. If individuals in more traditionalist societies are less likely to be politically engaged, then the elites to whom they are connected will be able to either bolster a functional democracy, or undermine the legitimacy of a state government that has little outside the support of elites. Civil society leadership, and the organizations those leaders head transmit values to their members. Those values can be tolerant of other groups, or enforce group identity by emphasizing the differences and inferiority or threat of Others' groups (Altemeyer, 1996).

Transferring the trust built into private trust networks to government requires that the link to government be one of contingent consent instead of a variety of other linkage types that are based on dominance or patronage networks (Tilly 2005). Only with the effective linkage between networks and public authority extending to diffuse members of trust networks will democratic governance be supported. The transfer is predicated on trust networks be linked to government and to one another (often) through government, and eventually generating norms of invested interest in the performance of government and the recognition of government as a legitimate venue for resolving community problems (Tilly 2005). 
This is, again, an expression of the "crowding in" observed by Albana and Barbera (2010) instead of the "crowding out" of social capital by a strong central state as described by Fukuyama (1995a, p102). Again, the impact on civic capacity caused by the interaction of state and society depends on the kind of government and the type of social capital.

\subsection{Measuring Social Capital}

The concept of social capital is difficult to measure. However, trust at the individual and social levels and individual enrollment and activity in civics-oriented organizations are most frequently used indicators. Social capital has several components; individual characteristics like trust between individuals, membership in different associations, and political engagement, as well as community characteristics marked by enlightened self-interest, bridging social capital and trust and expectations of institutions.

Some investigations have been able to use specially crafted survey tools crafted to measure civic behavior among small populations (Williams, Shinn, Nishishiba and Morgan 2002) or make use of existing population surveys to measure trust and associations (Paxton 1999). Norris also uses a social capital index taken from World Values Survey data that analyzes variables of individual social trust and the participation of individuals in associations (2002). She notes 
that the "big government" countries have higher levels of social capital, and that social trust is associated with economic development, not associational memberships. Her observations call into question the importance of associations to development and provoke questions as to whether latent informal networks and social trust levels are more important than activated networks. An alternative explanation is that some forms of association develop "strong society" ties that create "dense but segregated horizontal networks" that undermine the bridging capital important for the formation of horizontal networks (Putnam, et al. 1993). These observations emphasize the importance of both associational membership and generalized trust dimensions of social capital.

Paxton's is one of the more sophisticated efforts of measuring latent social capital in which she develops a three-part confirmatory factor analysis model of social capital (Paxton 1999). The first latent variable she measures is interpersonal trust. Then she creates an institutional trust variable that controls for covariance among indicators. Finally she creates a latent variable that combines personal associations and formal association to estimate the associational embeddedness of the individual. Using a factor model for estimating social capital is particularly beneficial because the technique allows for multiple levels of conceptualization and can highlight forms of association that undermine the trust features of social capital and vice-versa as well as control for covariant errors. Unfortunately, neither 
Norris nor Paxton examine their analysis to investigate the impact of particular associations on other variables of individual social capital to determine if there is a confounding indicator (Paxton 1999; Norris 2005). However several recent articles have addressed the importance of type of association and have found some relationships between associational type and social capital type.

Organizations that focus on the uniqueness of their group members and reinforce particularistic practices may build a strong small social network, but they weaken the ability of the broader society to pursue democratic practices. Very new work by Iglic has traced a relationship between political tolerance and associational memberships, religion-based organizations in Eastern and Southern Europe have a negative association with political and social tolerance as did charitable groups and (Iglic 2010).

Measurement of social capital must include organizational memberships, some measures of generalized trust and social outlook and ideally, an indicator of particularistic group composition, such as religiosity.

\subsection{Political Opportunity Structures And Tolerance}

Political opportunity structures in the various countries can both inform the types of political parties that are permitted to participate in national politics, as well as the locus of government civil society interaction. The section below on ethnic 
and racial intolerance introduces more detail about some of the opportunities for issue framing afforded right-wing parties in the countries studied. However, as a more general analysis, the stated goal of each of the member states - not mention their treaty obligation - is to reduce intolerance towards ethnic, religious or lifestyle minorities. The political opportunity structures afforded will also be affected by the level of government resources are committed to policy, what sort of political system is in place, and what parties have been in power during the period studied.

Although generally applied to political protest movements, the concepts of political opportunity structures can inform the role that the institutions of the state can play in structuring the forms of social capital in a community. Kitschelt (1986) describes political opportunity structures as the combinations of resources, institutional arrangements and repertoires of contention, or historical precedents, for pressing claims against authorities. The access of social movements to the political process, and to policy-makers and the way that such access is conditioned by institutional rules such as access points, election laws and regime type, further limits the forms that social movements can take in society. The coercive capacity of the state and elites' tolerances for certain types of framing of issues also provides an element of structural constraint on acceptable social capital forms. 
Kitschelt's (2000) argument that the political process conforms or constrains the kinds of social movements that are available to actors wishing to press claims depends on a functional state to sustain a constraining environment, the state must penetrate society, and be relatively autonomous of capture by any interest group in order to effectively shape the political opportunity structure. His study finds that a few macro-level characteristics can shed insight on the political opportunity structures facing civil society actors. The openness of the political system to claims, centrality of political structures, state participation in the economy, and capacity to implement policy are all primary features of the political opportunity structures (Kitschelt 1986; Kitschelt 2000). While some critics of the concept of political opportunity structures, such as Pippa Norris, consider the concept too vague to be useful, there are political scientists who still find Tilly's notion useful (Norris 2005)(Tilly 2005). Koopmans defends the notion of political opportunity structures while recognizing that they need to be defined in particular comparative contexts and cannot be a standard set of characteristics for all cases, lest they lose any meaning by being too general (Koopmans 1999). Koopmans identifies cultural factors as additional conditioning structures facing social movements (Koopmans and Statham 2000)). They argue that cultural factors have steered the framing of immigration issues in a direction that fosters right-wing politics in Germany and France. This is similar to Tarrow's social 
movement notion that concepts must achieve resonant framing of their claims, and that resonance lies in the familiarity and acceptability to society of the problem identification and proposed solutions offered by social movement leaders (Tarrow 1998). Tarrow uses Tilly's conception of political opportunity structures in identifying conditions when groups may be able to press claims and that mobilization may be most effective when there is divided government, or weakened repressive mechanisms. Additionally, outreach to international organizations can help bring resources to domestic groups or induce the government into placing the issues of groups onto the domestic agenda (Tarrow 2005).

All of the states examined have reasonably strong states, but their level of penetration into society varies, as do their political structures such as elections types, and the distance of policy formation and execution from the community, and institutional tolerance of extreme-fringe parties In order to capture a proxy for open opportunity structures, the ratio of how much non-social security government spending is conducted through regional and local authorities is included. The notion is that the closer the distance of critical spending decision makers to the communities, the more open the political structures and access points to community members. A positive relationship between the ratio of local spending authority and level of social capital in an open political opportunity 
structure would seem to meet the positive interaction criteria described by Akkerman, Hajer and Grin (2004b, 82-84). One caveat to this approach is that the European Union and several of the national governments also work directly with civil society groups to execute social policy, and this metric may miss that relationship. Personal communication with staff at the Fundamental Rights Agency of the European Union, and discussions with Peer Scheepers at The University of Utrecht informed me that nobody has tracked government spending on tolerance promotion (Grimheden 2007; Scheepers 2007). Gathering that information is well beyond the scope of this current study.

\subsection{Association Of Religiosity With Tolerance}

In light of the collapse of the Eastern Bloc and the European Union's expansion eastward and southward, the special case of religion as a civil society institution should be taken into consideration. As Linz and Stepan's typology of totalitarian states makes clear, the states of the former Eastern Bloc suffered from the states' flattening of civil society (Linz and Stepan 1996b). The only civil society institution to survive in much of Eastern Europe were the Roman Catholic and Orthodox churches. Where the church didn't survive they were one of the first institutions to return. In Western Europe, while church attendance is low, many of the countries still maintain official religions or have a long history of state-church 
cooperation in the provision of services as well as the construction of identity. A number of studies of religiosity and tolerance have been conducted on the effect of religion on intolerance towards other ethnic and religious groups.

One study tested the effect of religiosity on anti-Semitism to see if antiSemitism in the Netherlands was a product of exclusionary doctrine of Christianity. The authors found that there was a positive, albeit somewhat weak relationship between christian religiosity and religious anti-Semitism (Konig, Eisinga and Scheepers 2000). However, the authors found that Roman Catholic religiosity had a link to secular anti-Semitism while membership in the Protestant sects did not differ from average Netherlanders. The authors found a much more powerful nonreligious predictor of effect on anti-Semitism. They found that a variable on perspective, "narrow perspective," accounted for fifty-two percent of the relationship between christian beliefs and religious anti-Semitism, while religious beliefs accounted for less than fifteen percent. The implication of their analysis was that the relationship between Christian religiosity and anti-Semitism was driven by the third factor, narrow perspective. While the authors documented a positive and significant relationship between Christian beliefs and anti-Semitism, they established that the relationship was more of narrow perspective mediated slightly by values of a Christian religiosity. Their analysis notes the relationship 
between fundamentalist religiosity and authoritarian personalities, and narrow worldview that contribute towards antipathy for out groups.

Yet another study conducted in the Netherlands, hypothesized that religiosity should have a non-linear negative relationship with intolerance. The authors theorized that those who, "live" their faith will reject ethnic bias, while only those who claim an affiliation without being a core believer, or adhere to a particularistic faith will show positive correlations with intolerance (Scheepers, Gijsberts and Hello 2002). This difference between "identity" religiosity versus lived religiosity is analogous to the idea of religiosity versus narrow-perspective reviewed above. The authors conducted a multi-level regression analysis of types of religious beliefs and behaviors as well as protestant and Roman Catholic sects of Christianity. Their conclusions were that Christians tended to show more prejudice then non-religious people or persons of other faiths (however in the predominately Christian countries studied, other groups are the outgroups). They also found that ethnic intolerance was positively associated with religious attendance, but with the strong caveat that the kind of religiosity practiced mattered. They found a negative marginal relationship between intolerance and doctrinal beliefs and the importance of religion in respondents' lives, but a positive one between intolerance and religious particularism. The results seem to support a commonsense notion that those who practice a religion that values tolerance, will 
be more tolerant, but those who adhere to an exclusionary interpretation of their faith, will tend to be less tolerant. Their study showed the importance of using a multi-dimensional factor for religiosity, as the type of religiosity and the manner in which it is practiced changes the sign of the association with intolerance. The authors do caution that the non-Christian religious individuals in their study of European countries are members of outgroups, and therefore unlikely to express intolerance towards the minority group to which they belong. Finally, and significantly to this study, the authors found that the religious heterogeneity of the countries in the study had a strong positive effect on prejudice, as did economic conditions. Questions about ethnic bias may be more salient to those with outgroups toward whom misanthropic feelings can be directed. The findings of the multilevel study partially refute and partially support earlier studies on religiosity and bias in Europe.

A 1990 study of racism and religiosity in Holland found that their was some association with prejudice among casual church members and those who attended frequently but that the trend reversed among individuals who participated in church functions and associations. They also found that the positive association between nationalism and religious participation almost completely suppressed the relationship between faith and bias (Eisinga, Felling and Peters 1990). A 1999 follow-on study that extended the investigation to a 
cross-state comparisons concluded that nationalism had a much more powerful effect on bias, and that the relationship between religion and bias may be spurious to that of nationalism and prejudice (Eisinga and Billiet 1999).

The hypothesis that Roman Catholic Eastern European states possess a cultural propensity toward intolerance and authoritarian behavior, can be understood in light of the studies reviewed above. Indeed the relatively lower levels of economic security provided in the post-communist era would signal intolerance based on Inglehart's thesis of modernization and tolerance (Inglehart 1997). Also, the observations of Scheepers(Scheepers, Te Grotenhuis and Van Der Slik 2002) and others that christian beliefs and Roman Catholicism in particular, are associated with decreased levels of tolerance would also indicate that a comparison of the United States and Poland, would find Poland less tolerant. Finally a political culture dominated by years of Communist rule and the enforced conformity that was imposed, might also be expected to have eroded any residual culture of tolerance from before the Communist occupation. Scheepers and others observed that of the Eastern European countries, Poland was the only one that showed no association between faith and prejudice. Karpov's (Karpov 1999) comparison between Poland and the United States actually revealed that, after controlling for demographic and economic indicators, Polish sentiment was generally, if less consistently, as tolerant as that of America. 
The Polish case also indicates a Polish intolerance for anti-system militaristic behavior, having won their democracy, there seems to be a cultural propensity to try and keep it.

An effort to analyze the apparent relationship between nationalism and religious beliefs in the United States, created a survey with a battery of scales designed to investigate the conflation of religious doctrine with beliefs in the sacredness of the American symbols (Wimberley, Clelland, Hood and Lipsey 1976). Their study targeted fundamentalist Protestants who were thought most likely to possess a civil religious value system. Beliefs of presidential authority stemming from God, the sacredness of the flag, and the religious importance of the American example all showed correlated but independent loadings from strictly religious doctrinal beliefs in their latent variable model. Some fundamentalist Christian Americans were found to hold beliefs toward the country similar to those held towards God, with an emphasis on particularistic religious beliefs and civil values indicating a religious-nationalism axis in-line with the work by Altemeyer (Wimberley, et al. 1976; Altemeyer 1996). The observations by Eisinga and Billet (1999) that a third dimension of nationalism and narrow perspective have a stronger relationship to intolerance than religiosity per se seem consistent with the results of these earlier studies . Religion and religious organizations can provide motivation and structure for participation in organization 
activities that provide community services. However, religious participation is often associated with a narrower view of community- focused on co-religionists, and therefore also associated with intolerance.

\subsection{The Interaction Of Government Capacity, Social Capital, And Public Policy}

The interaction of government capacity and social capital is not a simple causal path. Government provides conditions for bridging forms of social capital. Bridging social capital makes government more accountable and effective by preventing capture by narrow interest groups, by providing civil society mechanisms for identifying problems and pressing claims against and monitoring the performance of government. Social capital offers at least two mechanisms to support better governance. One in which competent, honest and motivated civil service exists, a society with high social capital has an engaged civil society which can articulate social preferences while including a broader segment of the population. Secondly, an engaged populace performs good monitoring functions to prevent malgovernance (Evans 1989; Evans 1995).

In Making Democracy Work, (Putnam and Becker 1995) the conclusion is that the tight networks of associations and the interpersonal and institutional trust they help foster, create increased civic capacity. Government is able to more effectively develop and execute policy, leading, in turn, to increased institutional 
trust and participation. Akkerman (2004b) also investigated the role of interacting states and civil society with an eye both to effectiveness and increased forms of civil society participation. Their study of the Netherlands' implementation of central government directed local initiatives for citizen participation in government found a strong positive effect of institutionalized participation mechanisms.

Critiques of Putnam's positive attributions of the role of social capital pivots on the notions of the political opportunity structures available to members of society. The relationship between the state and social capital is not a simple oneway causal relationship as implied by Putnam's work in Italy, but it is a more interactive relationship (Tarrow 1996). Tarrow argues that the form of government and the type of interventions in society the government makes has as much to do with the generation of social capital and thence civic capacity as the other way around (Tarrow 1996; Knack 2002). As others have observed in the democratization literature, strong governments may not have an interest in an active a strong civil society (Linz and Stepan 1996a). They may be intervening to promote patronage relationships, flatten civil society or create strong bonding capital within groups, but only do so to keep those groups dependent on the state (Kitschelt 2000). Conservative social capital theorists argue, that a strong state serves to interfere with the formation of social capital and undermines the ability of members of society to organize and solve problems autonomously (Fukuyama 
2001). Their prescription for good policy formation and implementation is to reduce the strength and resources available to any single part of the state.

However, the observations of other analysts have been that the state does matter, that an effective state need not simply crowd-out social capital, but that the forms of the political structures created can strengthen social capital, and reward cooperative behavior. Work by Pippa Norris (1999) and has documented an apparent decline in some forms of social capital (institutional trust and participation in elections) but argue that despite these declines, the western democracies are still well above a threshold for good governance.

In order for the state to have a moderating effect on civil society, it must have penetration and integration yet some autonomy from civil society actors and civil society groups. Migdal's (Migdal 1988) seminal work on the competition between the state and traditional society structures in developing countries provides a very powerful insight on the mutual shaping effect the state and society can have on policy implementation. Migdal (1988) observes many cases in which the relationship between policy makers in the central state and the people for whom they are attempting reforms is moderated by an entrenched social structure in which powerful individuals, those with the most capital, social and otherwise, work to undermine or twist reforms in order to reinforce the existing political economy. Migdal (1988) also notes that previously strong state with functional 
systems can be weakened by sudden changes in the structures of production. This is similar to the arguments that the existing state connections with certain civil society actors are altered creating an opportunity for civil society actors to reshape social relationships and their relationship with the state. It is an opportunity for the central state to assert itself in addressing the problems associated with transitions, or to fade from relevance or autonomy in the lives of its citizens (Linz and Stepan 1996b; Linz and Stepan 1996a).

As the prior section on social capital briefly discussed, the relationship between the state and civil society need not be the zero-sum game that theorists in the de Tocqueville tradition anticipate. Later studies on civic engagement and social capital demonstrate that federal requirements for citizen participation led Portland, Oregon to create neighborhood associations as official adjuncts to city government. This official status for small civic groups directly linking citizens with their government appears to have led to citizen engagement in a wide variety of community organizations (Putnam, Feldstein and Cohen 2003). This is an example of how access points and government structure, in response to the subsidiarity requirements of the European Union treaties, can lead to improved civic capacity at the local level, where policy is implemented. Also discussed in section 2.4, not all studies of government-civil society interactions find a positive relationship between social capital and government policy; even in cases where 
the policy is explicitly meant to integrate civil society organizations into policymaking (Togeby 2004). With cautions that governments and civil society groups need "horizontal" interactions instead of hierarchical or patronage connections, several examples of a mutually beneficial relationship between government, society and civic capacity (Wallis and Dollery 2002; Akkerman, et al. 2004b). Their observations are slightly mixed but they share common observations that there needs to be a balance between access points for civil society members to press their interests, but also sufficient government autonomy to constrain capture by groups with narrow memberships and bonding capital which isolates other citizens.

A recent analysis provides even more support to the observations made by other work on social capital in Europe, that the "crowding out" hypothesis postulated by Fukuyama (1995b) and others (Gesthuizen, et al. 2008) is not only incorrect, but reverse (Albano and Barbera 2010). Albano and Barbera (2010) test directly the speculation that the establishment of a strong-state, particular of a social safety net, has a positive relationship with volunteerism and the bridging capital of individuals engaged in associational activities. This result provides encouragement to my thesis about the importance of state capacity in generating a positive spiral with social capital, particularly with bridging forms of social capital. 
There are a broad range of studies that have shown trends that counter the general assumptions of the main body of earlier social capital work. One is that social capital does not always have a positive effect on civic capacity- when groups work against each other either directly or through the state. Another, discussed previously, is that smaller is not always better. The novel element added to the literature by this paper is an effort to test and quantify the relationship between government capacity and social capital. This will rectify the different observations of diversity and social capital. It also will test the occasional proposition that negative or at best neutral effect government has on social capital- the presence of government at the macro level is associated with higher levels of social capital and numerous observations at the micro-level have recorded that government mediated interactions have improved both social capital and civic capacity.

\subsection{Relative Political Capacity}

To conduct the analysis of state success in moving toward a more tolerant society, measures of political capacity at the state level are used to try and account for Evans's theory. As all the EU states should have fairly high levels of government penetration in society, an interaction effect between state autonomy and social capital that will lead to more successful outcomes is expected. States 
with an ability to broadly extract resources from society must have a certain degree of penetration of their society. With that penetration of society comes the ability to suppress or co-opt organizations working at cross-purposes to the state, and cooperate with civil society organizations working in support of the state's goals. With the European Union's subsidiarity principle, as well as the recent focus on fostering civil society, states will locate their efforts closer to the communities affected.

Relative political capacity in the European Union for the period of this analysis can be taken from work performed by Arbetmann and Kugler (1997) and others to compare tax extraction and therefore bureaucratic reach among countries at similar levels of development. The model is an effort to estimate how deeply into society governments can reach. It should be a proxy for Evans' autonomous state, functionally combining autonomy and embeddedness. As a final note, the lack of state strength and state capacity is often cited as a threat to the establishment of democracy. However a study by Jose Cheibub (1998) found that democracies, especially immediately after transitions, are more effective at extracting taxes from civil society than authoritarian forms of government. An implication of this finding may be that the post-transitional phase of democratization provides a unique opportunity to establish the state and its functions as citizens are less reluctant to submit to the functions of the state. If 
that opportunity is realized by implementing parties, directed by their elites, then regardless of regime structure, democracy can be consolidated and strengthen the legitimacy of the state and the process.

The theoretical foundations of Arbetman and Kugler's (Arbetman 1997) model of relative political capacity lie in observations of the seeming invariance of extractive capability with regime type. The observation follows earlier work by Lipset (1959) and others who observed that contrary to the modernization theory assumption that a strong authoritarian state would have a better ability for stateled accumulation, democracies have performed the strong state role of taxation just as effectively as non-democracies, often even more efficiently (Diamond, Linz and Lipset 1990; Przeworski and Limongi Neto 1997). The construct of relative political capacity is meant to measure bureaucratic effectiveness in reaching into society, this is combined with the effectiveness of political parties in mobilizing system consensus and reducing the costs of political reach (Organski 1997). As noted by Dahl (1971) and refined by subsequent research, if the costs of oppression surpass the effectiveness of the oppressive mechanism, then elites may turn to democracy in order to reduce costs of resource extraction, or to mobilize their populations (Przeworski, Stokes and Manin 1999).

The theoretical foundation of measuring political capacity speaks directly to the creation of institutions that allow the state to penetrate and mobilize society or 
its resources. Organski (1997) describes the cycle as one in which political development leads to increased political capacity, that capacity is then turned to collecting resources and addressing social concerns, which also improves government capacity and reach. Implicit in this description is innovation in the interface of government and society - part of the model that would encompass national governments' efforts to incorporate civil society elements, and to foster social capital in addressing EU policy concerns such as intolerance and the attendant discrimination.

Although a precise estimation of government effectiveness is an ongoing effort (Kugler and Tammen 2012), there have been several attempts at improving the measurement. Measures of relative political capacity (RPC) as described in Arbetman and Kugler (1997) are derived from two components, relative political extraction (RPE) and relative political reach (RPR). As the names imply, these measures are comparative in nature, they measure the behavior of states against the expected behavior of their peer states. The relative political extraction component is a measure of the tax revenue/GDP of a particular country divided by the predicted tax/income ratio calculated from the regressing the tax ratio of other states controlled for level of development and a series of economic structure variables such as agricultural production, exports, and minerals exports. Relative political extraction is the ratio of reported government revenues over revenues 
expected by the model. RPE is the residual of the model (Arbetman and Kugler 1997).

The relative political reach element is calculated in a similar fashion to that of extraction, the difference being that relative political reach uses the ratio of labor market activity of a country over the activity level predicted by a regression equation derived from all countries in the sample; controlling for a variety of factors such as development level, economic structure, and unemployment rate (Arbetman and Kugler 1997).

The regression equations for the RPC measure are described below in Figure 2.5. Unfortunately, the data required to complete the full formula for RPR is incomplete for many of the Eastern and Southern European countries over the period of this study. Therefore the political capacity measure to be used in this analysis will be relative political extraction without including relative political reach. Relative political extraction is calculated using the methodology described by Arbetman and Kugler (1997) with latest relevant data from Eurostat, OECD and the World Bank. 


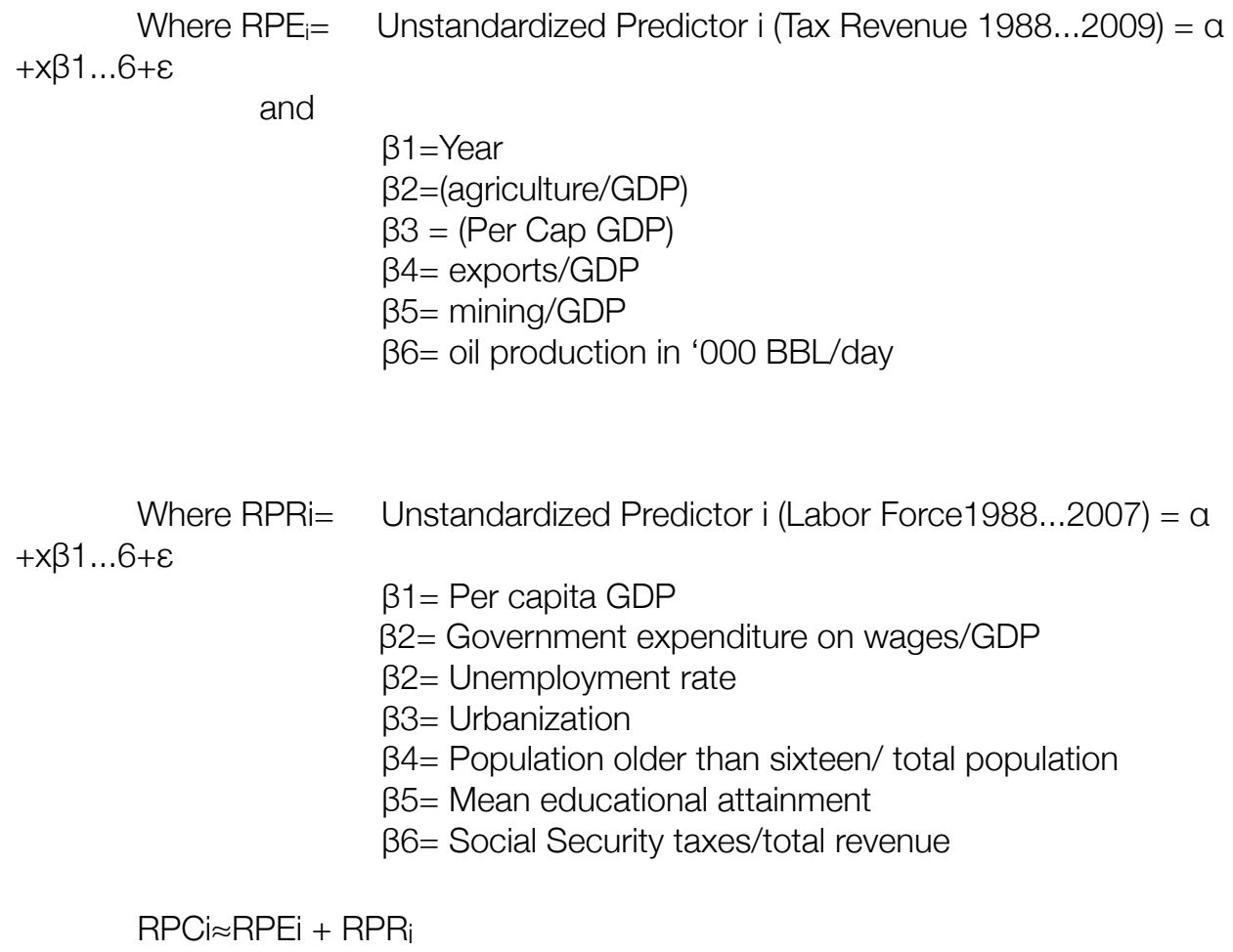

Figure 2.5: Regression Equations for Relative Political Capacity from Arbetman and Kugler (1997)

Even in the European Union members to be included in this analysis, there will be some variation in capacity observed, as different member states have different levels of social safety net, different rates of economic growth, different policies to connect with at-risk populations, and different abilities to make credible threats to sanction free-riding by double-dippers who collect social benefits, but also work on the side. Particularly in states with high-unemployment or high migrant populations, the ability or desire of the state to monitor, assist or sanction should be less than in states without large fractions of marginalized workers. 
Because the employment data in many of the eastern European accession states is volatile or unavailable for much of the period 1991-2001, RPE is used to estimate political capacity instead of the combined term.

\subsection{Conclusion Of Literature Review And Discussion Of The Problem}

This section has introduced the state of the conditions of the problem of social intolerance in the European Union in several dimensions. The state of the literature about the relationships of intolerance with a variety of personal and societal characteristics was introduced revealing some expected and counterintuitive relationships. The literature, including a quick overview of existent quantification of intolerance was also introduced, demonstrating the importance and difficulty in measuring intolerance, either as a concept, or as activities such as hate crimes or acts of discrimination.

The state of theoretical literature on the other important concepts in this study was also presented. The review covered the different conceptions and measures of social capital available including both theoretical and instrumental examples. Social capital has a number of distinct dimensions, it is a characteristic of individuals, and societies. It can be in-group focused, creating tight-knight saturated networks; it can also be more diffuse with multiple relationships bridging several kinds of groups. The importance and role of government capacity was 
also introduced, as well a discussion in how the relative capacity of governments might be measured.

While the literature contains discussions of a direct path that social capital plays in promoting social inclusion and tolerance, the link between social capital (particularly the bridging form of social capital) and the capability of government is not as thoroughly explored and rarely in a comparative context. The next chapter introduces the variables and models that will be used to test the questions introduced in chapter one. Putting the different threads of the literature together, the relationships between state capacity and intolerance as transmitted through a direct effect an indirect path through the forms of social capital that emerge under a more capable state will be tested. The expectation is that the bonding forms of social capital will be weakened and the bridging forms enhanced, resulting in improved intolerance outcomes for the community. 


\section{Chapter 3: Methodology, Models, ANd DATA}

This study will attempt to measure the impact that state political capacity

has on shaping social capital in a direction that sustains bridging capital and supports the policy goal of increased tolerance. Bridging social capital is the form that is marked by numerous weak ties and generalized social trust and is associated with an inclusive outlook towards other groups. Civil society institutions generate social capital, they create either in-group bonding or intergroup bridging relationships. The review of the literature provided a foundation for anticipating that bridging capital creates more effective communities with a more effective political and civil society policy nexus. The political capacity of governments, combined with an interest in tolerance promotion, should condition the type of social capital civil society groups (such as religious groups) generate. The combination of strong political capacity, and government interest in promotion of tolerance is expected to be associated with more bridging capital. Societies with strong governments and strong social capital are expected to be associated with more successful tolerance outcomes than those with other combinations of government capacity and social capital.

The model will take as its independent variable a measure that reflects the goals of the Pillar III harmonization agenda. Absent surveys such as the European Social Survey, and the World Values/ European Values Survey, there is no consistent measure of intolerance that is comparable between European 
countries. Therefore a scale derived from questions regarding the suitability of members of possible out-groups as neighbors will be used as a measurement of intolerance for individual respondents.

A hierarchical linear model, comprising important indicators of the concepts above, will be used to test the effects of individual and state-level characteristics on tolerance of diversity. The model will also test the relationships between and interactions of, social capital, state political capacity, religiosity and identity on attitudes towards others. These items will be measured for interactions and change over five waves of the World Values Survey, using factor analysis and hierarchical models to test changes within societies and the relationship with indicators. World Values Survey data from 1990-2009 will be used for individual level information on age, income, education level, political ideology, left-right political self-placement, dimensions of social capital and tolerance. National-level data for aggregate income, tax effort, right-wing government participation and social security expenditures are drawn from the World Bank's World Development Indicators, the European Commission's data agency, Eurostat, the OECD and from national statistical agencies.

In order to examine the specific hypothesized relationships between state political capacity, social capital and the policy objectives of tolerance, a series of models that control for relationships between demographic characteristics of 
individuals as well as the relationships observed in others' work to test components of the hypotheses will be used. In the discussion of variables below, the direct correlation between the main variables of social capital, religiosity, and RPE are examined. The relationships between social capital and relative political extraction as well as intolerance using a path analysis of ordinary least squares regression models is also tested. Finally, the relationships with hierarchical linear models that include variables at the individual level like demographic characteristics and the forms of social capital, with group-level variables that are measured within national milieus is explored.

The path model provides insight into the relationships between the different variables. It allows the partition of variance to gauge both direct and indirect effects of independent variables on the phenomenon of interest. This model allows an assessment of the effect that political capacity may have on the creation of different forms of social capital on education, and finally on intolerance itself.

The hierarchical models are used specifically, to account for the effect that state level characteristics, such as wealth, mean education level, religious makeup, recent experience with immigration, and social spending may have on the pressures of ethnic and economic competition that individual's experience. However, beyond those characteristics, the interaction between social capital, civil society institutions and a capable state are expected to have a greater effect on 
achieving the goal of tolerance beyond high-levels of social capital, or political capacity alone. As a mediator to the expected relationship between state capacity and social capital, the intensity and form of religiosity (personal versus institutional) as an element of social capital and identity is expected to have a relationship with tolerance that is also mediated by state capacity.

\subsection{Path And Hierarchical Models To Test The Relationships Between Intolerance, State Capacity And Social Capital}

The hypothesized relationships between intolerance, government capacity and social capital are characterized by multiple paths of effects between variables and by nesting in national contexts. The relationship between government capacity and intolerance is proposed as including an indirect path through social capital. Public policy execution in the European Union is an expressly context dependent process. The European Union follows a policy of subsidiarity which gives considerable latitude to the member states in determining how to achieve Union objectives, particularly on domestic policy issues like integration. Beyond the formally context driven nature of problem analyzed, the very characteristics and social phenomenon that are of interest, have unique national experiences that will modify the way phenomenon interact. The distinct national social and political contexts indicate that any analysis that does not explicitly recognize the nested nature of the problem of policy implementation in different national and social 
contexts, is going to suffer from unnecessarily large unexplained variance and lose a great deal of explanatory power. Because of these characteristics, the relationship is explored using the two main techniques of a path model and multilevel regression.

Figure 3.1 contains a diagram of the path between government capacity and intolerance including the indirect path through social capital. The diagram illustrates the proposed relationship between government capacity and social capital, where government capacity supports the emergence of bridging social capital. The path from bridging social capital and the direct path from government capacity to are expected to reduce intolerance.

In addition to the theoretical basis for an analytical model that incorporates context, the method of data collection and cases available are drawn from national samples rather than a simple random sample of the entire population of the European Union and candidate states. Therefore, the use of an analytical method that fails to incorporate the nested structure of both the phenomenon and the data would suffer validity problems (Snijders and Bosker 1999).

The primary hypotheses of this study, that the political capacity of government matters for the execution of policy and the presence and type of social capital matters for tolerance, and that the interaction of government presence and social capital (government constraining malignant versions of social 
capital and supporting bridging capital), require the ability to analyze cross-level interactions between context-conditioning national level characteristics like government capacity and individual-level characteristics such as social capital. The multi-level nature of the phenomenon highlights the limited utility of other analytical techniques like multiple regression with dummy variables as a proxy for national contexts (Bickel 2007).

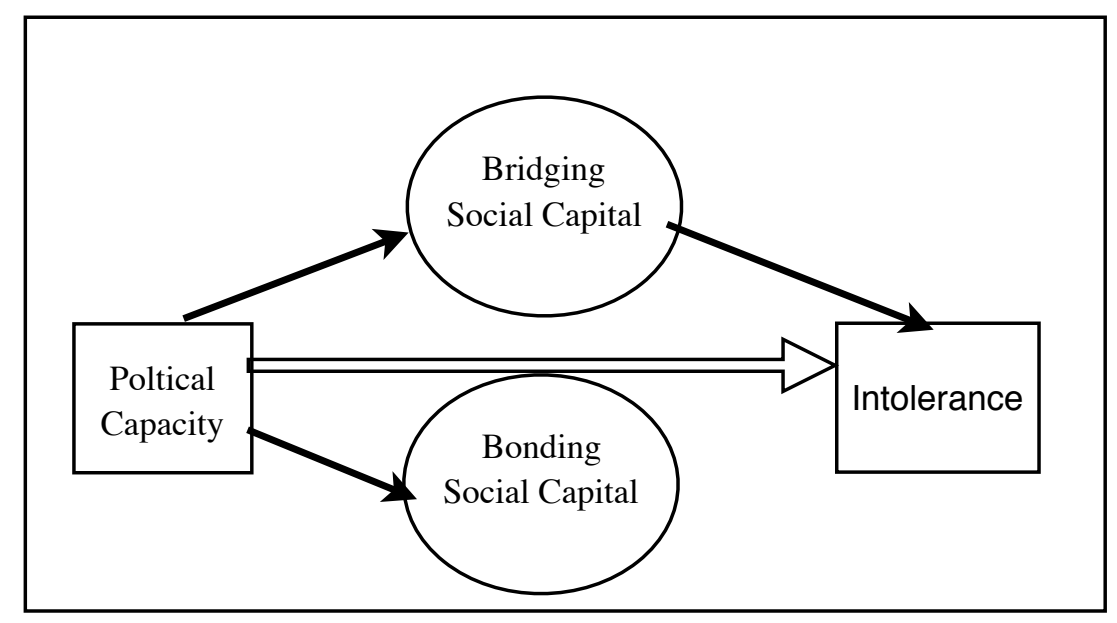

Figure 3.1: Conceptual Paths of Political Capacity to Intolerance (author's diagram)

The multi-level model itself is written below with lowercase variable names denoting individual level variables, and capitalized names denoting state-level variables. The terms individual-level, micro-level, and level one are all used interchangeably; macro-level, group-level, level-two and state-level are used to describe level-two variables. 


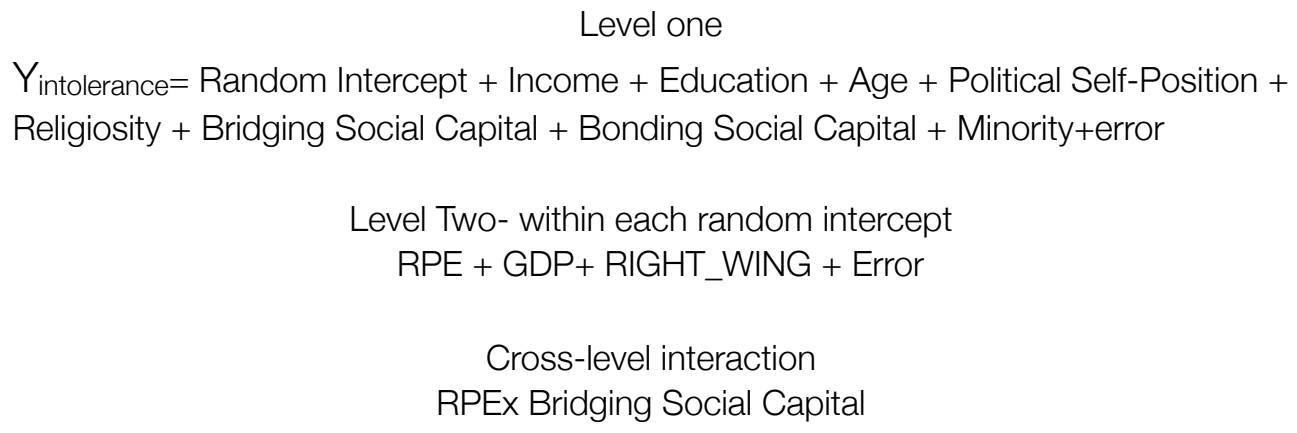

Figure 3.2: Example of Hierarchical Model

Appendix D contains more detailed description of the strengths and limitations of the types of analytical methods to be used in the analysis including the need for dealing with missing data and distributional requirements of the maximum likelihood estimators used in hierarchical regression.

\subsection{Identifying And Testing Variables For The Models}

Several of the concepts included in the model have multiple indicators and capture slightly different concepts. In order retain a fairly parsimonious model while preserving the information available and capturing important dimensions of the concepts that may be in the data, compound variables or scales were created to derive some of the variables for use in the model. There will be a three-stage test for each compound variable. The first test is whether it makes sense theoretically to use more than one indicator for the variable. If the indicator is unidimensional and captured by one question, then only one measured indicator will be used. However, in many cases it is useful to combine the different 
measures of a single concept together in order to have a more complete measure of the item. Second, if the concept is theoretically multi-dimensional, the hypothesized dimensions of the concept are present in the data with a factor analysis and hierarchical cluster analysis to establish the appropriate combinations for variables. If there is a compelling theoretical reason to combine dimensions under the first test, then that will override considerations of confirmatory techniques.

The sections below describe each of the variables in detail, the derivation of compound variables and factors, as well as information on means and distribution of other components of the independent and dependent variables.

\subsection{Intolerance}

Fitting a model with an estimator for intolerance using questions about intolerance attitudes available in the European and World Values Surveys is somewhat difficult as there are few variables that persist in the core questionnaire from wave-to-wave. Also difficult is tracking how well the estimates of intolerance generated by the variables in the survey correlate to acts of intolerance on the ground in each of the member countries. As reported by the Fundamental Rights Agency, for the period of this research, there is no consistent reporting system for intolerant behavior or crimes, and even less cross-nationally comparable data 
available (FRA 2007a). Therefore, the general intolerance indicators available to test in our study will be a scale composed of related questions about undesirable neighbors from the World Values Surveys.

The European and World Values Surveys contain a series of questions that ask the respondents to state if they "would have a problem" with each of a set of hypothetical neighbors. The characteristics of the "neighbors" in the survey vary from country to country except for a small group of potential neighbors that are carried through most countries most years. This subset of neighbors includes the potential out-groups of immigrants, foreign workers, homosexuals, AIDS sufferers, heavy drinkers and drug users. Other questions about religious and ethnic minorities are inconsistently available.

I conducted a number of analyses in order to identify patterns of intolerance in the scale of questions. First the scale of neighbors was analyzed using hierarchical cluster analyses with nearest neighbor estimators. The result shown in figure 3.3 illustrates the approximate distances of covariation each item has for individual respondents. 


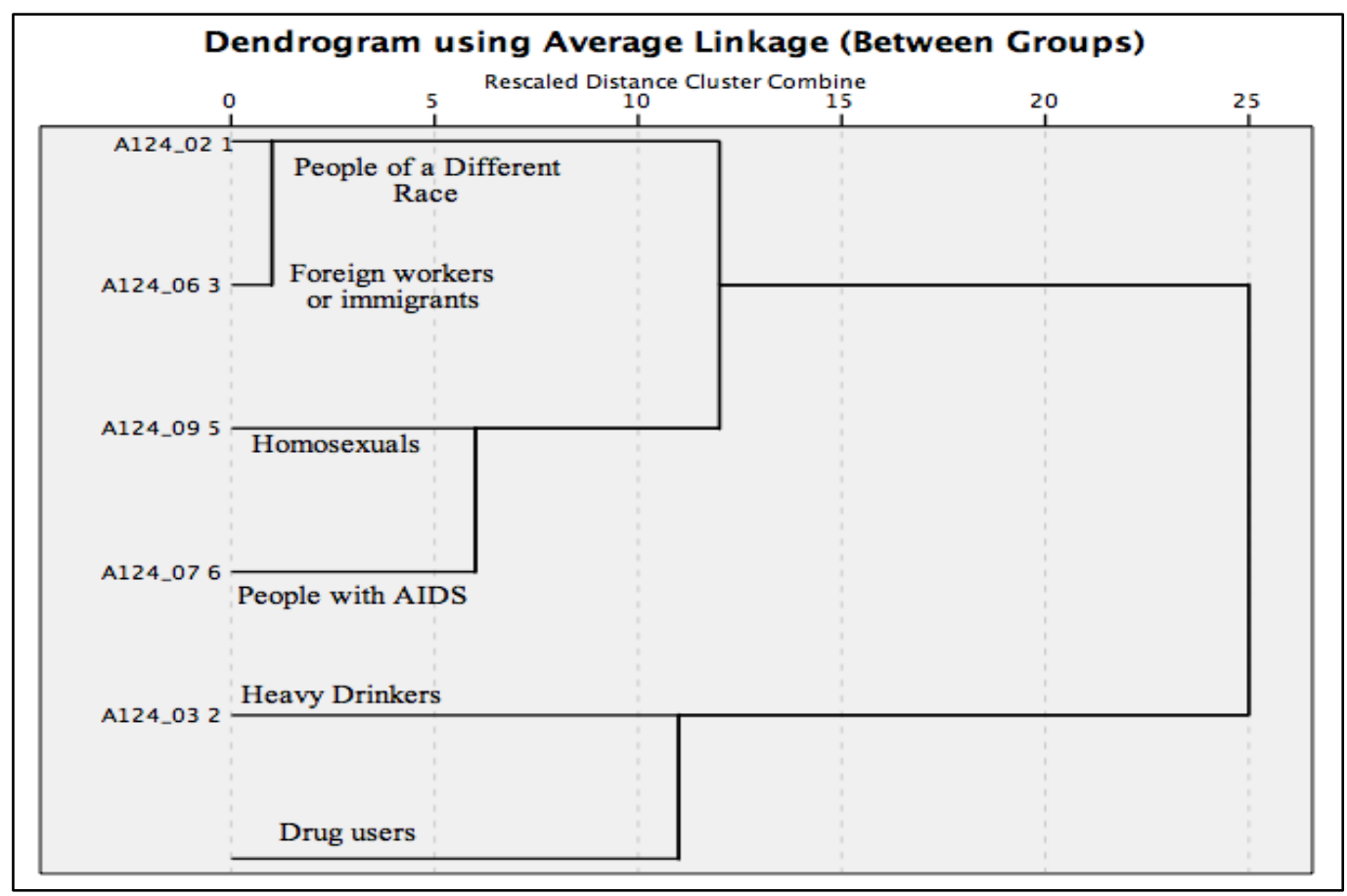

Figure 3.3: Cluster Analysis of Intolerance Indicators (WVS-EVS)

Intolerance toward neighbors who are immigrants or of a different race occur frequently in the same respondents. The are only two steps between the two indicators this cluster. Next, respondents appear to cluster AIDS sufferers and homosexuals together, then with the foreign worker/different race cluster at step twelve. The indication from the cluster analysis is that intolerance toward foreign workers and toward homosexuals/AIDS sufferers is closely related. Less tightly clustered are the two indicators of substance abuse behavior.

Based on the results of the cluster analysis several estimates of intolerance were calculated. One is an estimate of intolerance was calculated using factor analysis. One variable derived from the factor analysis is used for analysis. 
Details of the process to calculate Intolerance that is focused only on attributes are discussed in Appendix A

The identification of separate factors underlying intolerance in the European Union may have implications for policy as they can help policy-makers direct prescriptions at addressing the components of intolerance instead of the general concept of social intolerance. Some groups, such as recent immigrants or religious people, might well group drug or alcohol addiction in with homosexuality as undesirable behaviors to be avoided in neighbors, while there are others who may be perfectly tolerant of sexual orientation, or even of alcoholics, while being strongly racist or anti-immigrant- supporters of Pim Fortuyn or Geert Wilders in the Netherlands would well fall into this group.

In order to develop a single easy to interpret scale of intolerance in Europe, that captures intolerance as a more general phenomenon and consistent with the European Union's stated goals of social tolerance especially of race and lifestyle a simple summative index was created.

The 0-4 summative variable was created using the four questions that were most highly correlated in the polychoric correlations table and cluster analysis. For each neighbor from the list that was mentioned: "Immigrant", "Different Race", "AIDS", "Homosexual", a point was added to that individual's score. The frequency distribution of the resulting variable is shown below. 
As shown by figure 3.4, the resulting scale has a single-tailed distribution with a slightly high skewness. For the hierarchical regressions, the variable is transformed to further reduce skewness. The distribution below is a gamma distribution, but although a gamma-link hierarchical general linear model may provide greater statistical power and better estimates, the mean (1.03) and median (1) are close enough in this distribution that the loss of power is made up for by the ease of interpretation. 


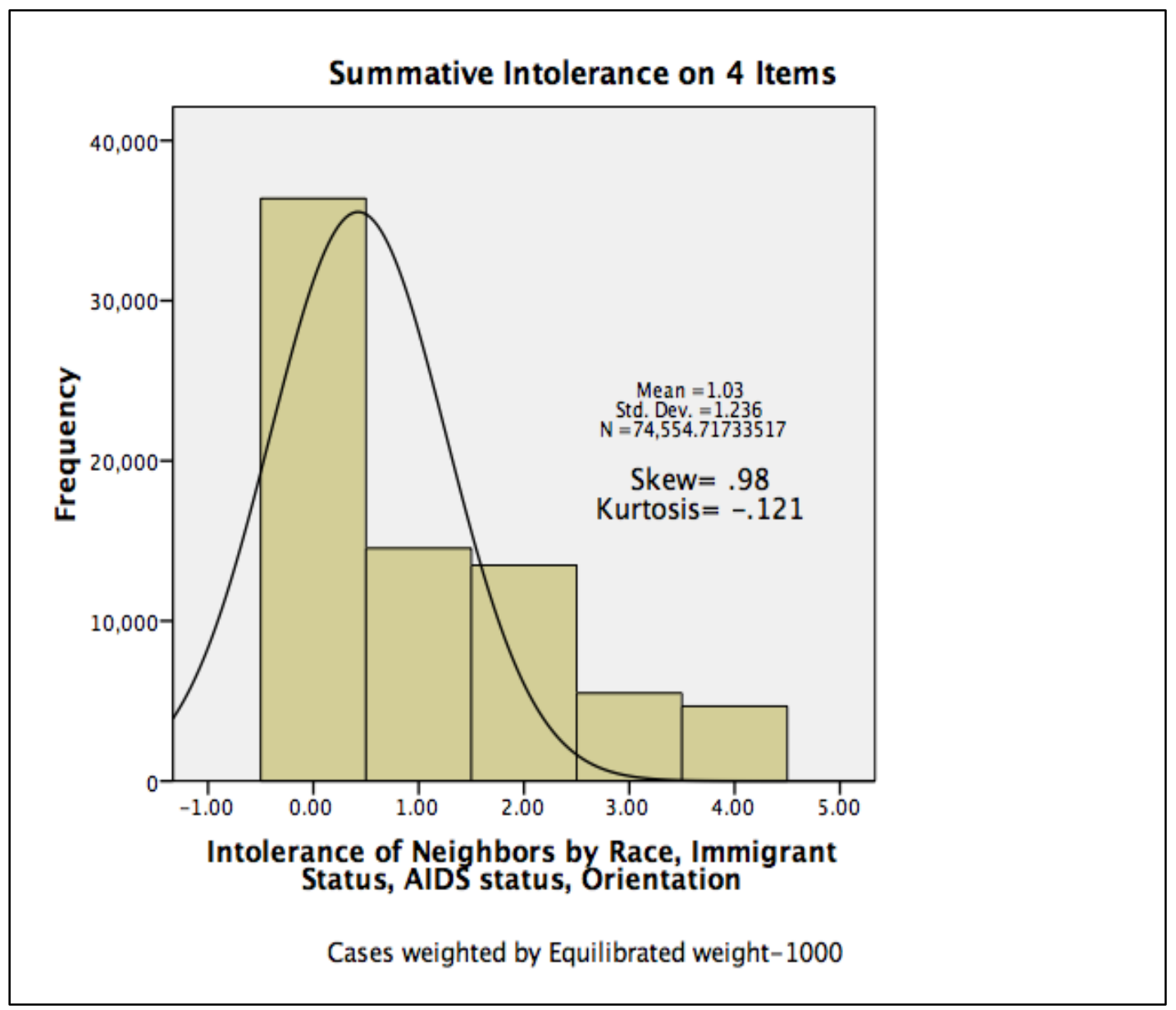

Figure 3.4 :Summative Intolerance Scale Distribution (WVS-EVS 1990-2008)

The separation of general intolerance and a measure that emphasizes the attributive aspects of intolerance allows investigation of intolerance that is specific to particular sub-groups apart from persons who have generally intolerant personalities. It may enable understanding of different kinds of intolerance that emerge at different economic or social development. 


\subsection{Social Capital}

Borrowing from analysis of social capital discussed in the literature review section about the concepts and measurement of social capital, a set of three social capital variables is crafted, composed of scales of variables linked to different dimensions of the concept; bridging social capital; containing metrics of generalized trust, friendships and memberships in organizations; bonding social capital is trust that is in-group focused, and not associated with active civic engagement or trust in government institutions. Finally, the model will also include a measure of religiosity because religion and religious association are major civil society actors and have a strong tie to other forms of associational memberships and intolerance.

\subsubsection{Bridging and Bonding Social Capital.}

The membership component of the bridging social capital is derived from a sum of membership questions available in the World Value sand European Values Survey. The items for memberships included are church or religious organization, sports or recreation organization, arts, music or education organization, labour union, political party, environmental organization, professional organization, and charitable organization. I created a summed scale of these items using the process described below. 
Unfortunately, the World Values Survey and European Values Survey use slightly different wording to ask respondents' memberships and activity in various organizations. As described in the literature review and introduction to this section, membership in organizations is thought to be a cornerstone of the conceptualization of social capital. The different wording used in the two waves makes it impossible to simply use the responses from each of the surveys in direct comparisons between states and the different versions of the survey. ${ }^{1}$ Appendix C contains details on recoding the surveys to amend the two versions and preserve the information contained in the surveys. I will review the relationships between the different aspects of social capital and the two different measures of associational activity.

In order to check how the membership items relate to one another I tested them using both cluster analysis. Examination of the dendrograms produced by hierarchical cluster analysis shows the different membership questions tending to cluster together except the variables for religious organization membership and union membership which lay outside the cluster of other organizations. It is inaccurate to describe union membership as voluntary for many countries - if you are a worker in certain industries you are also a union member by law. However,

\footnotetext{
${ }^{1} \mathrm{~A}$ table with the different wordings is in appendix 2
} 
that very fact of obligatory membership, may also mean that unions can be generators of relationships that are not self-selected.

Further inquiry into the nature of the relationships between the membership indicators using exploratory factor analysis reveals that the business associations cut across various groups such as unions and religious organizations. A subsequent factor analysis of memberships including items of abstract social trust, religion indicators, and the importance of family and friends showed no clear pattern other than that religious membership loads tightly on other religion indicators, and that the importance of family and friends measure slightly different constructs.

\subsubsection{Combined Social Capital Factors}

The memberships indicator was combined with three separate variables that measure trust in individuals and the importance of friends and family to establish factors for social capital. The questions query respondents on the importance of family in their lives, the importance of friends in their lives, their state of happiness, and whether or not they think most people can be trusted. The question on generalized trust, "Do you think most people try and take advantage of you, or that most people can be trusted" is a binary variable. The importance of family and importance of friends is a four-point ranked ordinal question. 
Table 3.1 presents the loadings of a factor analysis for four indicators of social capital that have been used in the literature and discussed in the preceding pages. The table below reports the factor loadings (factor matrix), the unique loadings (pattern matrix), correlations, and coefficients of two factors identifying different aspects of social capital. The factor that emerged are labelled bridging and bonding capital.

Table 3.1: Social Capital Loadings

\begin{tabular}{|c|c|c|c|c|c|c|}
\hline & \multicolumn{2}{|c|}{ Factor Loadings } & \multicolumn{2}{|c|}{ Unique loadings } & \multicolumn{2}{|l|}{ Coefficients } \\
\hline & Bridging & Bonding & Bridging $B$ & Bonding & Bridging & Bonding \\
\hline Most people can be trusted & 0.467 & -0.121 & 0.484 & -0.05 & 0.396 & 0.010 \\
\hline Important in life: Friends & 0.288 & 0.103 & 0.257 & 0.146 & 0.181 & 0.051 \\
\hline Importance of Family ${ }^{1}$ & 0.192 & 0.815 & 0 & 0.838 & 0.000 & 0.830 \\
\hline Memberships & -0.407 & 0.056 & -0.41 & -0.005 & -0.312 & -0.007 \\
\hline \multicolumn{3}{|l|}{$\begin{array}{ll}\text { Correlation } & 0.081\end{array}$} & \multicolumn{4}{|c|}{ Variance explained $79 \%$} \\
\hline \multicolumn{7}{|c|}{$\begin{array}{l}1 \text { Transformed using }\left(k_{i} \wedge\left(1 / k_{i}\right)\right. \\
\text { Extraction Method: Principal Axis Factoring of covariance matrix. Promax rotation. a. } 2 \text { factors } \\
\text { extracted. } 16 \text { iterations required. Source: WORLD VALUES SURVEY 1981-2008 OFFICIAL } \\
\text { AGGREGATE v.20090901, 2009. (2009). }\end{array}$} \\
\hline
\end{tabular}

The unique loadings indicate a definite pattern in the trust forms of social capital. They show that for many of the respondents their responses for Trust, the Importance of Friends, and Membership in Organizations, move together. Other respondents are focused on the importance of their friends and families, but have unrelated movement in their responses to the trust variable and memberships.

Figure 3.5 shows the value of these social capital factors across European countries over the available years of the study. While the factor analysis identifies two related but distinct forms of social capital the variance explained is too low to 
be used as latent variables in the analytical models. I will use these factors to analyze the path of the relationship between relative political extraction, forms of social capital and intolerance. The maps below show that the Northern European countries have high levels of both bridging and bonding capital, that is people can find friends and family important, while also having a generalized sense of trust and participate in groups. The other countries exhibit a more zero-sum relationship between trust. memberships and the importance of family.

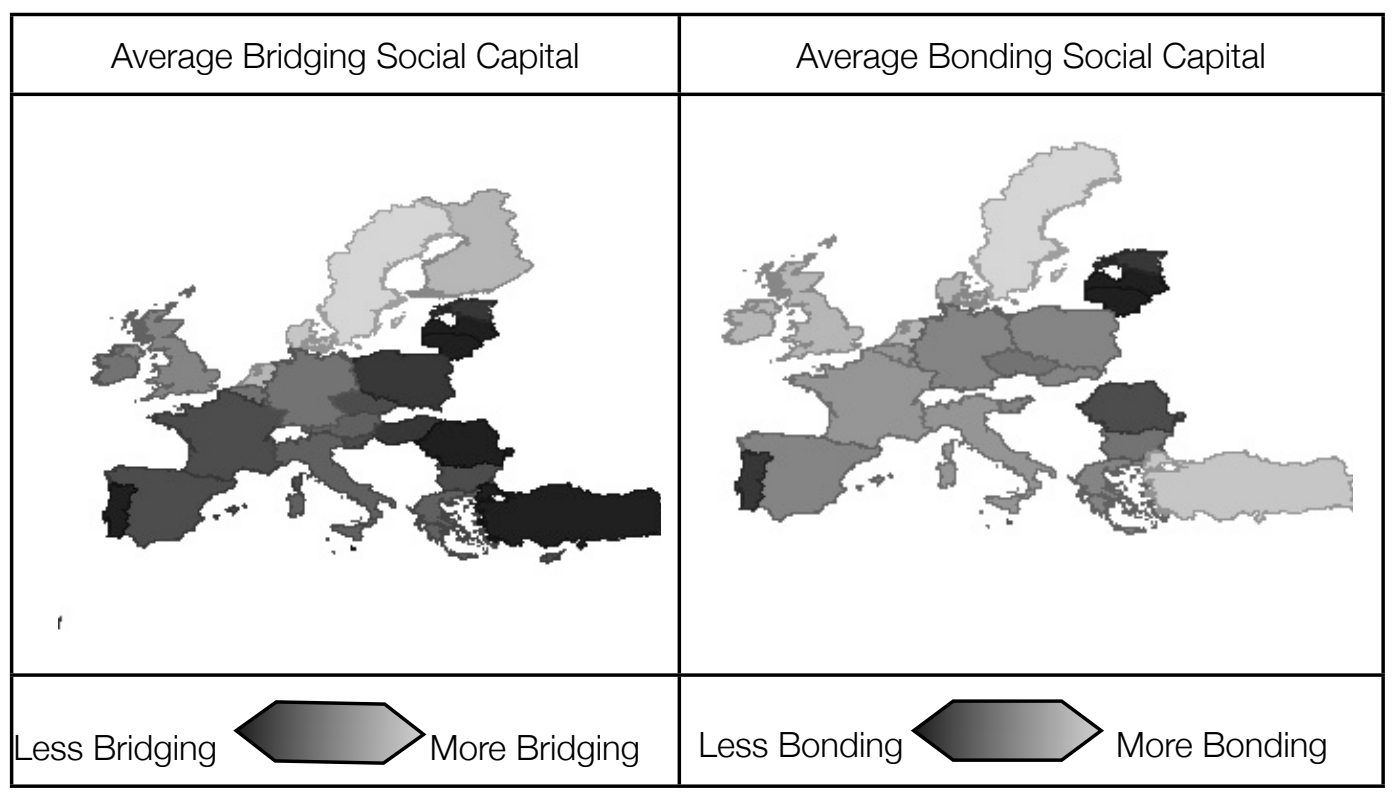

Figure 3.5: Social Capital Factor Maps (WVS-EVS)

The variance explained by the factors and the ability to quantify the different factors for a regression model using either OLS or ML estimators means that the full model can effectively include the factors for bridging and bonding social capital 
Noordijk

to help distinguish between these forms of trust and a relationship with Intolerance.

\subsection{Trust In Institutions}

In keeping with other analysis of social capital, a measure of trust in government using the scale of confidence variables included in both the World Values Survey and the European Values Survey. There are four salient questions asked across all the waves and all the countries included in this analysis. The questions seek the confidence level of respondents in a number of government institutions: the armed forces, police, parliament, and the civil service.

While a summed scale would be the most direct way of measuring confidence in government, there is a complex relationship between the confidence in the armed forces and the other confidence variables. It seems there are people with different kinds of confidence in government. As discussed in the literature, some with confidence in government have confidence in authority structures, while others may have confidence based on performance or perceived effectiveness.

Two confidence in government variables were extracted using Bartlett's method which retains the correlations between factors, but also weights the unique variances of the different dimensions (DiStefano, Zhu and Diana 2009). 
Details of the factor analysis are presented in Appendix C. The separation of official trust into its component factors provides potentially useful insight into the qualitative element of confidence in government and reveal some drivers of intolerance among individuals who otherwise might score highly on elements of social capital. Table 3.2 offers a comparison of different measures of official confidence correlated with the summed measure of intolerance.

Table 3.2: Public Institutions Confidence Correlations

\begin{tabular}{|c|c|c|c|c|}
\hline & $\begin{array}{l}\text { Civil Service/ } \\
\text { Parliament } \\
\text { Confidence } \\
\text { Factor }\end{array}$ & $\begin{array}{l}\text { Police/Armed } \\
\text { Forces } \\
\text { Confidence } \\
\text { Factor }\end{array}$ & $\begin{array}{l}\text { Summed } \\
\text { Official } \\
\text { Confidence }\end{array}$ & $\begin{array}{l}\text { Intolerance } \\
\text { Scale }\end{array}$ \\
\hline $\begin{array}{l}\text { Civil Service Parliament } \\
\text { Confidence Factor }{ }^{1}\end{array}$ & 1 & 77713 & 77713 & 68115 \\
\hline $\begin{array}{l}\text { Police and Armed Forces } \\
\text { Confidence }^{2}\end{array}$ & $.415^{\star *}$ & 1 & 77713 & 68115 \\
\hline Summed Official Confidence ${ }^{4}$ & $.942^{* *}$ & $.654^{* *}$ & 1 & 69427 \\
\hline Summed Intolerance Scale ${ }^{3}$ & $.011^{* \star}$ & $-.096^{\star \star}$ & -0.003 & 1 \\
\hline \multicolumn{5}{|c|}{$\begin{array}{l}\text { **. Correlation is significant at the } 0.01 \text { level (2-tailed). } \\
1,2,4 \text { : Lower scores indicate "Great Confidence", higher indicate "No Confidence" } \\
{ }^{4} \text { Summed scores from Confidence in Police, Civil Service and Parliament. } \\
{ }^{3} \text { Higher scores indicate increased intolerance of neighbors } \\
\text { N reported on off diagonal. } \\
\text { WORLD VALUES SURVEY 1981-2008 OFFICIAL AGGREGATE v.20090901, } 2009 . \\
\text { (2009). }\end{array}$} \\
\hline
\end{tabular}

As illustrated, the different dimensions of official confidence, although highly correlated, suppress the relationship between each other and intolerance. This observation is consistent with the literature on authoritarian personality and intolerance discussed in the literature review. The civil services confidence factor has a weak but direct relationship with intolerance indicating that confidence in the 
non-authority structures is aligned with improved tolerance. The armed forcescentered factor has a stronger and reversed correlation with intolerance than the civil services/ parliament factor. This reversed relationship with intolerance exists despite the two factors being correlated with one another at a level of .69. The official confidence measure that is simply the sum of the four confidence indicators shows a nearly completely suppressed relationship to intolerance. The differences in slopes between the summed confidence scale and the each of the other confidence factors is significant at $p<.05$. By separating the factors explanatory power and some understanding of the different forms of social capital and official trust and the relationship to intolerance.

\subsection{Religiosity}

In order to include the unique effects that a social institution like religion might have on the personal attitudes of individuals, as well as their being embedded in community networks centered around the church, I include an indicator of religiosity.

There are several variables that prompt responses about religion that span all waves and most countries in the World Values and European Values Surveys. Table 3.3 shows the mean scores for the range of religiosity questions asked most consistently across the waves.

Table 3.3: Descriptive Statistics for Religion Measures. 


\begin{tabular}{|l|l|l|l|l|l|}
\hline \multirow{2}{*}{} & & & & \multicolumn{2}{|l|}{ Standardized Variables } \\
\cline { 2 - 6 } & $N$ & Mean & Std. Deviation & Min & Max \\
\hline $\begin{array}{l}\text { Important in life: Religion 1-4, } \\
\text { 1=Very, 4=Not at all. }\end{array}$ & 74822 & 2.43 & 1.073 & -1.33322 & 1.46383 \\
$\begin{array}{l}\text { Confidence: Churches(1-4; } \\
\text { 1=Great Deal, 4=None) }\end{array}$ & 82621 & 2.43 & 0.982 & -1.45612 & 1.59793 \\
$\begin{array}{l}\text { How often do you attend religious } \\
\text { services (1-8; 1=more than } \\
\text { weekly, 8=never) }\end{array}$ & 84328 & 5.09 & 2.500 & -1.63555 & 1.16454 \\
$\begin{array}{l}\text { How important is God in your life } \\
\text { (1=Not at all, 9=extremely) }\end{array}$ & 82851 & 6.04 & 3.307 & -1.52458 & 1.19693 \\
\hline
\end{tabular}

The most straightforward method of capturing a measure of religiosity is to simply standardize the variables and sum them into a scale of religiosity. Detailed discussion of estimating religiosity is presented in Appendix D. Analysis of religiosity questions indicated strong inter-item correlations that would likely form a reliable single scale. The Cronbach's alpha for a scale based on these four item is .86. The resulting variable was adjusted to account for a multi-peaked distribution. The final calculated scale for religiosity retains the high Chronbach's alpha meaning that the information has been retained while reducing distortions caused by non-normality of the data.

The literature has shown that there are several dimensions to religiosity. I used factor analysis to test four indicators of religiosity to examine for multidimensionality. The analysis of the available measures indicates loading primarily on only one latent concept. If more of the questions on religiosity were available through the different waves and across countries, a nuanced measure of religiosity 
Noordijk

that parses out personal versus institutional religiosity might be possible.

However, the eigenvalues for the potential factors indicate that only one factor accounts for a great deal of the variance in the latent factors, as reflected in the . 86 correlation between the two factors. Only one religion variable is justifiable with the indicators at hand.

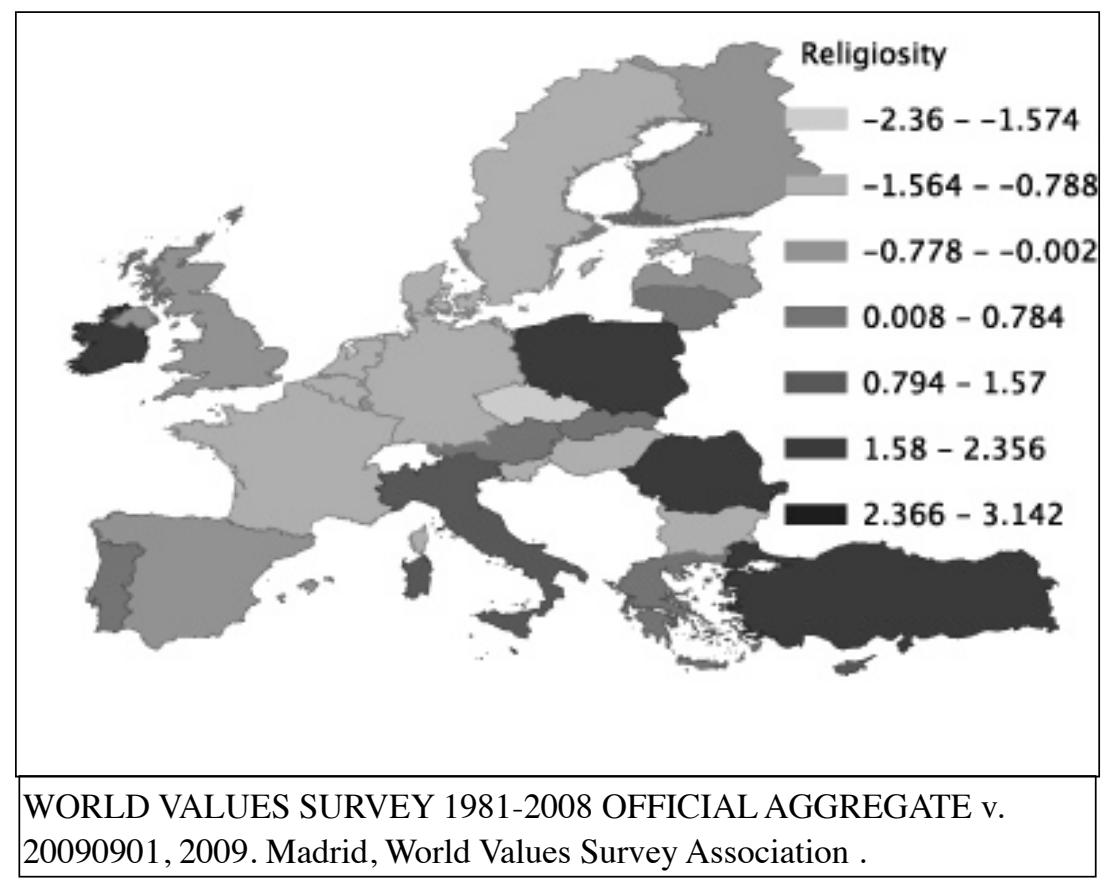

Figure 3.12: Average Level of Religiosity by Country (WVS-EVS)

The level of religiosity reflected in this variable does appear to be in harmony with other research on religiosity in Europe. The map below shows that religiosity is fairly low in Northern and Western Europe, while high in Ireland, Poland, and Turkey, with the other Roman Catholic States filling in the middle. 


\subsection{Minority Ethnic And Religious Group Status}

I calculated the modal ethnic and religious affiliations of the country from the dataset. For Northern European countries I only identify individuals outside the three main groups, non-affiliated, protestant and Roman Catholic, as minority respondents. I also created a second identifier if the respondent is muslim. However, the infrequency of the religious identifiers make this variable difficult to use in the full multi-level analysis. In single level analysis it provides an important control to explain why someone may be sympathetic towards minorities in defiance of expectations drawn from other characteristics.

\subsection{Education}

Education has been observed to correlate positively with tolerance in almost all studies. However, variation can occur within national systems as the goals of education can be either instrumental-technical or include socialization curricula as well. The Educational Attainment variable in the World Values Survey provides a cross-nationally comparable scale of 1-9 levels of attainment starting at $1=$ no formal education, to $9=$ completed education. Forms of socialization in past education systems will likely have a persistent effect on older citizens, so individual educational attainment and national average educational attainment. Therefore, mean national educational attainment may also tested as a context variable. The 
education question asked on the different waves of the survey varied from the first wave of the European Values Survey to the rest of the waves of the survey. In order to include the data for the countries that presented missing data in the years of the question change, I imputed the data using the waves for which data was presented using both questions. There is more detail in Appendix F on missing data techniques that were used to preserve this data for the analysis.

\subsection{Individual Political Position}

Political position on the right-left scale has been demonstrated to be strongly associated with intolerance; any model of intolerance attitudes must include some element of political self-identification. The World Values, and European Values Surveys ask each respondent to place themselves on a 1-10 scale of political alignment where $1=$ left wing and $10=$ right wing .

\subsection{Relative Political Extraction}

As described in the literature review, relative political extraction helps to measure the penetration of the state into society at a certain level of development. I calculated RPE for the sample of European countries for the years covered by the relevant waves of the World Values Survey. In keeping with the description of relative political extraction derived from the work led by Kugler and Arbetman, RPE 
was calculated using the total tax revenue, minus tariffs, of each country to create a variable of expected versus actual tax receipts for each country over the period.

Arbetman and Kugler (1997) updated in Kugler and Tammen (2012) the measurement of government capacity describe a linear relationship between the indicators and the dependent variables in their regression equations to estimate the expected tax ratio and the expected ratio economically active population over population. In developing equations to derive expected ratios for the smaller sample and range of years analyzed in this project there is improved fit with nonlinear relationships for important independent variables in the equations. Because the non-linear model deviates from the reference literature, and the model improvement is quite small (less than $2 \%$ of variance explained), retained the linear model.

The calculation of RPE uses the level of development and a vector of sectoral composition variables to predict the tax effort of countries. The model used for this analysis predicts .52\% $\left(R^{2}\right)$ of variance in tax effort. The residual unexplained variance is considered the Relative Political extraction. Detailed explanation of the model, including the regression results are presented in Appendix E.

The maps illustrate the relative political extraction of a range of the European countries over the period of this study. As might be expected, Sweden 
has the highest RPE overall and as one of the wealthiest countries, the highest level of absolute political capability. The figure also illustrates how the measure of relative capacity varies over time as governments are able to extract resources from their societies, or choose not to. ${ }^{2}$ Again the concept of RPE does not provide total available resources, but instead presents the tax effort in excess of that predicted for peer countries. In figure 3.13 Bulgaria appears to have higher capacity than the Netherlands some years. This indicates that Bulgaria's tax revenues were unexpectedly high for its level of development not that it has more total resources compared to the Netherlands or the United Kingdom.

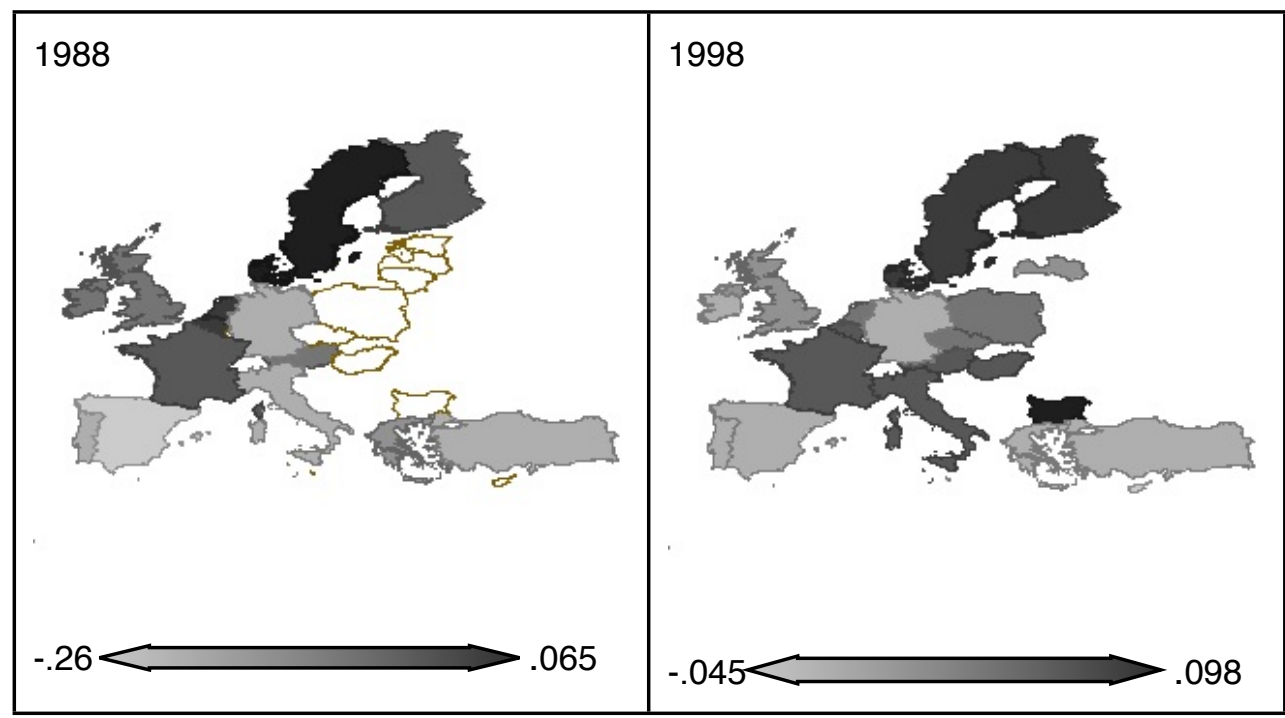

\footnotetext{
2 Cyprus data after 2004 is S. Cyprus officially reported data combined with data reported by the Turkish Republic of Northern Cyprus weighted $70 \%$ and $30 \%$ respectively. .
} 


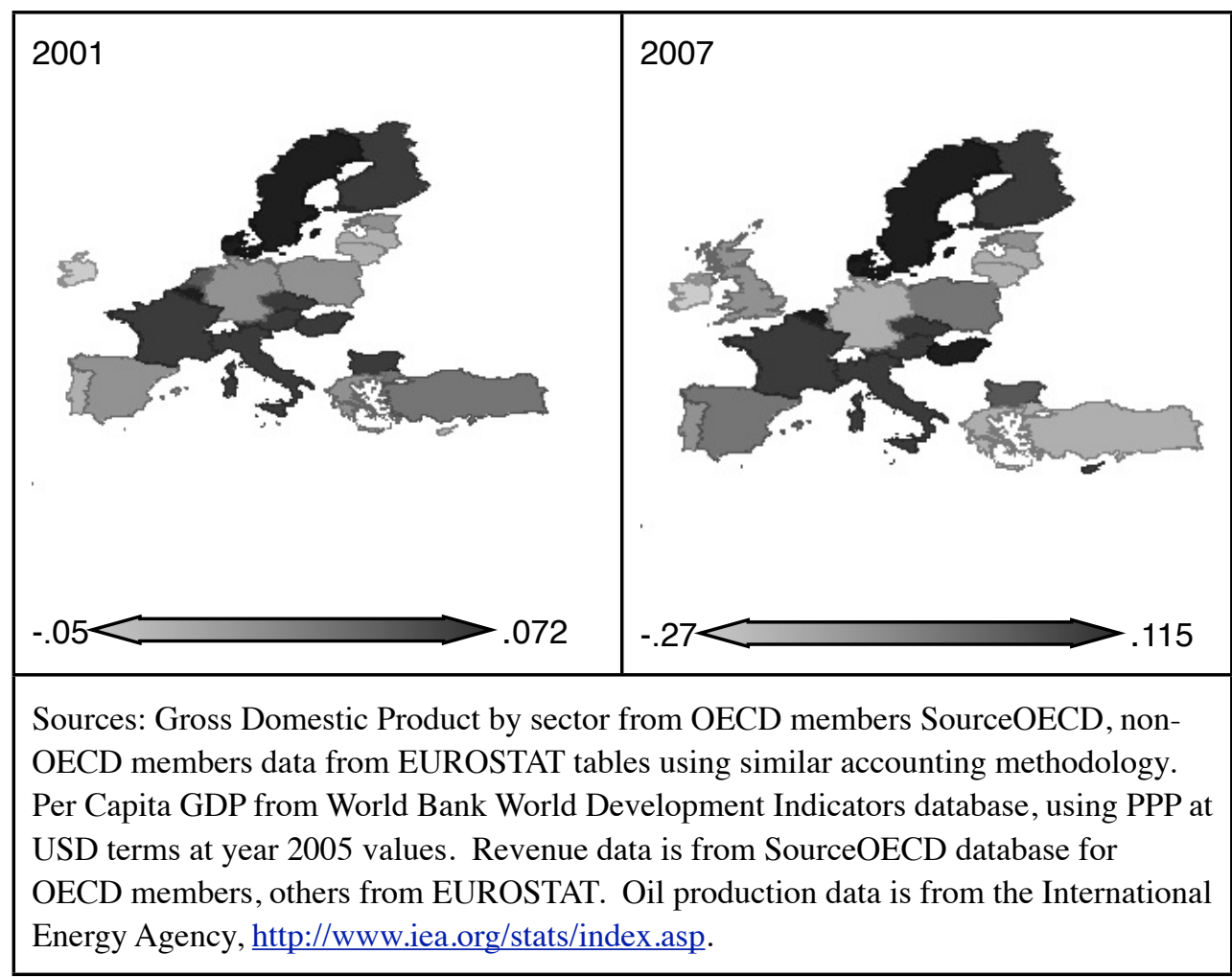

Figure 3.13: Relative Political Extraction of Selected Countries 1988-2007

\subsection{Moving Average of Participation of Right-wing Groups in Government.}

This context variable is in recognition of the fact that an effective government is unlikely to effectively execute policy with which it either disagrees, or which does not rise to the ruling coalitions' agendas. In an effort to estimate the institutional intentions of governing parties, I use the political party placement data and cabinet composition data from the Comparative Political Data Set 1960-2008, from the University of Bern (Armingeon, Engler, Potolidis, Gerber and Leimgruber 2010). I compiled a 5-year moving average of the right-wing composition of government scores to serve as a proxy for government intent. For 
Noordijk

post-communist states I use a moving average of the post-transition years, until a five year history was achieved, then the 5-year moving average was used. The Armingeon et al dataset did not include political party data for Turkey so values were calculated approximately comparable values for use in the analysis. ${ }^{3}$

\subsection{Ratio of Local to National Discretionary Spending}

The models test the proximity of governance hypothesis that is implicit in

Evans' work about the interaction between the state and civil society (Evans 1995). The literature on social capital also seems to indicate that the closer to local civil society that government policy is executed, the more effective the policy, and more sustaining of social capital it is likely to be (Putnam, et al. 2003;

Akkerman, et al. 2004b). The data for budgetary allocation was collected from the OECD and Eurostat for non-OECD European states. The allocation variable uses percentage of non-social insurance spending by local and regional governments divided by total spending minus social insurance. For small countries with no subregions, the figure was set to one. Data for spending ratio in Turkey was acquired

\footnotetext{
${ }^{3}$ Weighted government political placement values were calculated using a simplified version of Armingeon et al's method of weighted cabinet participation. For cases without a designation of right-left political values for political parties, each of the parties were coded based on supporters' self-placement in the right-left spectrum on the 1990-2007 waves of the World Values Survey. The leftmost values were subtracted from the of the major parties and divided by the range to gain a scale comparable to that used by Armingeon et al. It is a Left=0, Right $=100$ scale. As in Armingeon et al, the period of Prime Ministry was then weighted by time in office for each year.
} 
Noordijk

from the EDDS database at the Central Bank of the Turkish Republic (TurkStat 1990-2011; CBRT 2010). 
Noordijk

Bridging Intolerance

111

CHAPTER 4: ANALYSIS

\subsection{Intolerance In Europe Over Time}

Figure 4.1 below shows the mean scores for intolerance in the European countries being studied between the different waves of the World Values Survey.

Because not all countries have participated in the surveys for each wave the data in the figures show a general comparison over time. The data in the left frame is from wave 2, the earliest available, while the lower right frame is from the latest available data in 2008. The figure 4.1 illustrates the intolerance scores for each of the country-waves for the European Union and accession states available through the surveys. The table shows a general trend toward improved tolerance, especially the return to a normal level for France in 2008-2009 after the 2005 wave reflected uncertainty due to nation-wide riots that had occurred weeks before the survey. However, the news is not all good, as a number of states, notably the Netherlands and the Czech Republic each had substantial increases in intolerance for the 2008-2009 wave of the European Values Survey over the levels reported in the prior wave of the World Values Survey. A detailed table of intolerance by wave and year is reported in Appendix B. 


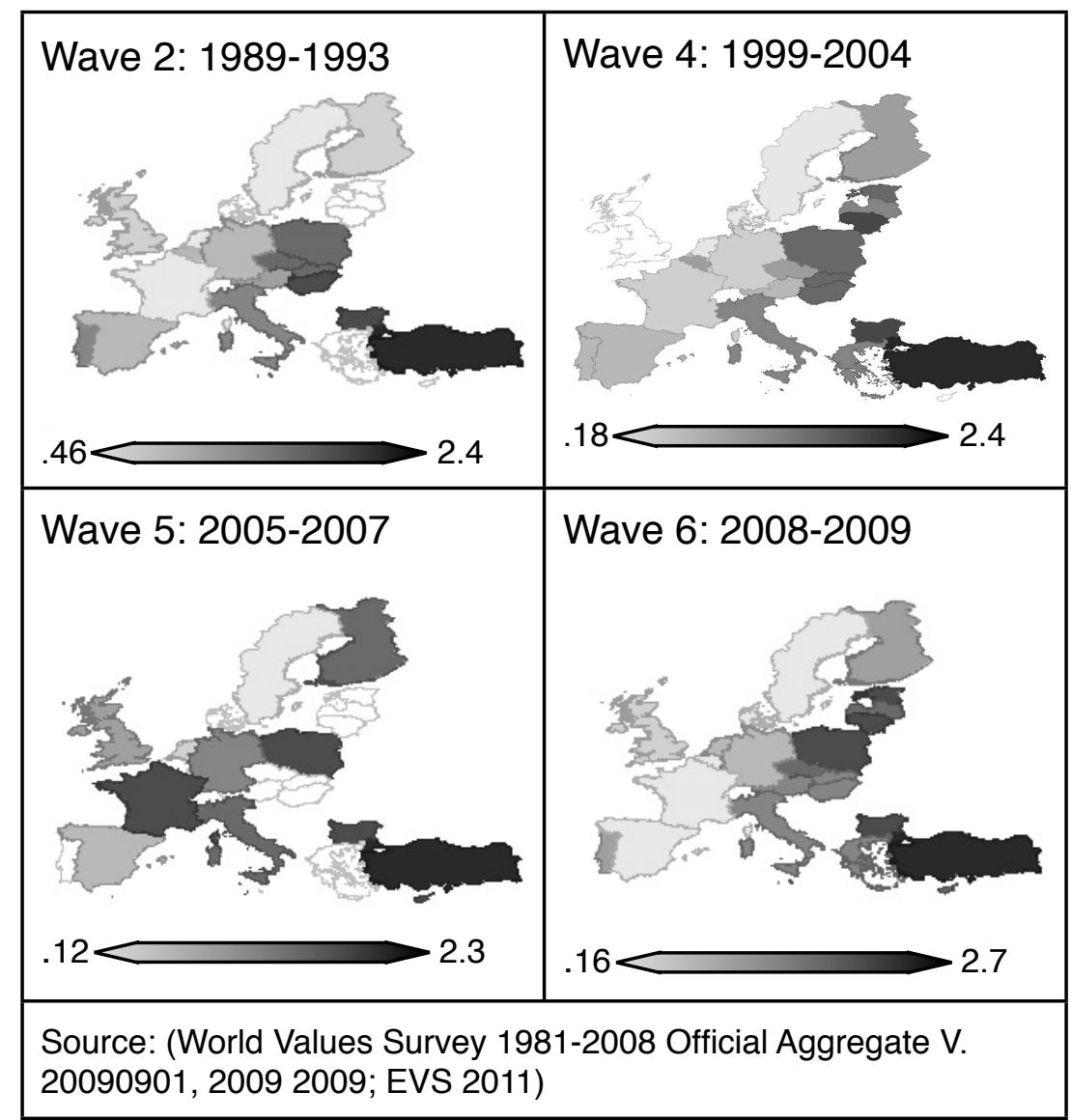

Figure 4.1: Summed 4-Item Intolerance in Europe 1989-2009

The data reflect the observation that overall in Europe, and in all of Western

Europe except France, there was improvement of social tolerance over the 15 years covered by these surveys until the $2008-2009$ wave. The France anomaly is explained by the fact that data collection began 30 days after major race riots spread throughout the French suburbs. The data from the 2008-2009 wave of the European Values Survey indicate that France has returned to levels lower than 
before the riots. Some countries in Eastern Europe such as Hungary and Slovak Republic have made tremendous improvement in tolerance over the period, while other countries, such as Slovenia, Latvia and Turkey have notched increases in intolerance along with their Northern European neighbors the Netherlands and Sweden.

\subsection{Demographic Correlates Of Intolerance}

Chapter three provided an explanation of different measures of intolerance that will be used to gauge EU progress towards tolerance goals, and explore correlates of intolerance and that can provide insight to guide policy.

Table 4.1: Correlates of Intolerance: Demographics, National Characteristics

\begin{tabular}{|c|c|c|}
\hline & $\begin{array}{l}\text { Summed 4-item } \\
\text { Intolerance scale }\end{array}$ & $\begin{array}{l}\text { Behavior and race } \\
\text { dimension }\end{array}$ \\
\hline Religiosity (-1 Irreligious, 1 Religious) & $.178^{* *}$ & $-.026^{\star \star}$ \\
\hline $\begin{array}{l}\text { Bridging social capital (friends diffuse trust, } \\
\text { memberships) }\end{array}$ & $-.216^{\star \star}$ & $-.014^{* *}$ \\
\hline Self Position in Political Scale (1=Left, 9=Right) & $.113^{\star *}$ & $-.016^{\star *}$ \\
\hline Gender $(0=$ Female, $1=$ Male $)$ & $-.028^{* *}$ & $-.037^{\star \star}$ \\
\hline Age & $.108^{* \star}$ & -0.004 \\
\hline Educational Attainment & $-.190^{* *}$ & $-.049^{* *}$ \\
\hline Scale of Incomes & $-.165^{* *}$ & $-.030^{* *}$ \\
\hline Is respondent of a minority religion & $-.040^{* *}$ & $-.038^{* \star}$ \\
\hline Size of town & $-.119^{* *}$ & $-.050^{* *}$ \\
\hline \multicolumn{3}{|l|}{ Country-Wave Level Correlations } \\
\hline GDP per Capita (2005 PPP USD) & $-0.77^{\star \star}$ & $0.24^{\star}$ \\
\hline Growth Rate of Migration & $-0.2^{\star \star}$ & $0.29^{\star \star}$ \\
\hline Relative Political Extraction & $-0.127^{\star \star}$ & $-0.303^{\star \star}$ \\
\hline Right-wing Governments (lagged moving average) & $0.383^{\star \star}$ & $-0.282^{\star \star}$ \\
\hline
\end{tabular}


${ }^{*} p<.05,{ }^{* *} p<.01$. Country-Wave level correlations are correlations between aggregated intolerance levels and the country-level indicators.

(World Values Survey 1981-2008 Official Aggregate V.20090901, 2009 2009)

Table 4.1 shows strong correlations in the expected directions between Intolerance and bridging social capital (-.216), religiosity (.178) and educational attainment (-.19) on the individual level. GDP (-.77), RPE (-.127), and Right-wing governments (.383) are all significant for the aggregated country-wave level data. The correlational relationship between RPE and intolerance is significant and in the hypothesized direction.

For the dimensional factor of race versus behavior the connection with RPE is even stronger than with the combined scale for intolerance. Correlation coefficients indicate that countries with higher RPE experience intolerance toward behavior more than racial attributes. Those states with recent experience with inmigration correlate with a significant uptick of intolerance against other races and foreign workers more than against drug users or alcoholics (.29). Keep in mind that in those states in-migration is correlated with decreased overall intolerance against immigrants or homosexuals (-.24). Finally, there is a direct relationship between per capita GDP and intolerance focused on foreign workers or minority races (.24), indicating that the specific form of intolerance targeting only immigrants is specific to the wealthier states. A sort of post-materialist intolerance. 


\subsection{Examining the hypotheses}

The series of hypotheses lead to the development of a path model that permits analysis of the relationship between relative political capacity and intolerance. It is taken as an assumption that European Union member states are not totalitarian states and accede to the goal of social tolerance.

The hypothesized mechanism is that relative political capacity will reduce intolerance through two primary paths. First, the presence and effectiveness of the state in society will foster the development of between-group focused bridging forms of social capital; second that there is a direct effect of relative political capacity in terms of the resources, both repressive and services that the state can deliver to individuals that reduce inter-group competition. The main hypothesis are examined in this section using several techniques, including a path model of the proposed mechanisms and hierarchical models that examine the proposed relationships. The path analysis is developed using ordinary least squares regression because it is robust to violations of normality in the dependent variable, but the nested nature of the data requires special techniques to address intraclass correlation ${ }^{4}$. Then, because of the clustered nature of the societies surveyed, a series of hierarchical linear models are used to examine the full model with the express inclusion of group-level considerations. 
The several sub-hypothesis are also tested and several of the relationships between intolerance, social capital, governance, and state-level characteristics are explored.

\subsection{Path Model Examining Relationships Between RPE, Social Capital And Intolerance}

The hypothesis that there is a positive relationship between the bridging forms of social capital and state capacity is tested with a single-level regression model controlling for other correlates of social capital. In addition, if the notion of state capacity controlling the forms of social capital that will emerge is correct, RPE should be inversely related, or unrelated to bonding capital. This test also provides the bridging social capital path to construct an overall path model using ordinary least squares regression to illustrate the relationships between relative political extraction, social capital and intolerance.

Modeling the path of relationships between RPE and the forms of social capital examines the mechanism proposed in hypothesis two; that stronger government capacity will constrain the formation of bonding social capital and foster bridging capacity. The regression of bridging social capital on relative political extraction, controlling for Education, Per Capita GDP and Religiosity, results in relationships that confirm the hypothesis. Table 4.4 presents the mean standardized parameters and R-squared for the 5 imputed datasets. 
Table 4.2: Relative Political Extraction on Bridging Social Capital for Path Model

\begin{tabular}{|c|c|}
\hline Model OLS & RPE on Bridging Social Capital \\
\hline & $\beta(t)$ \\
\hline Intercept & 0.21 \\
\hline Study (1=EVS,2=WVS) & $0.11(.9)$ \\
\hline Education & $0.24^{\star}(6.8)$ \\
\hline Religiosity & $.08^{*}(2.9)$ \\
\hline $\begin{array}{l}\text { Is Minority Religion } \\
\text { ( } 0=\text { majority, } 1=\text { Minority) }\end{array}$ & $0.056(1.65)$ \\
\hline RPE & $0.181^{*}(4.8)$ \\
\hline LN GDP per cap & $0.375^{\star}(8.8)$ \\
\hline $\mathrm{R}^{2}$ & 0.178 \\
\hline \multicolumn{2}{|c|}{$\begin{array}{l}\mathrm{N}=79735 \text {. Design Effect }=112.5 \text {, Adjusted } \mathrm{N}=708 \\
\text { Bridging Social Capital is on a scale of } 1=\text { intense }<->-1=\text { weak. } \\
\text { t-scores for group-level variables estimated using } \mathrm{N} \text { for degrees of freedom at each } \\
\text { level. } \\
\text { *significant at } p<.05 \\
\text { Source: (World Values Survey 1981-2008 Official Aggregate V.20090901, } 2009 \text { 2009; } \\
\text { European Values Study 1981-2008, Longitudinal Data File 2011) }\end{array}$} \\
\hline
\end{tabular}

The table illustrates strong support for the hypothesis that there is a strengthening relationship between RPE and bridging social capital. The standardized parameters show that for each standard deviation increase in RPE there is a .181 intensification of bridging social capital. Education and per capita GDP also have strong associations with bridging social capital. Religiosity, also has an intensifying effect on bridging capital. This observation is likely because one of the components of the bridging capital factor is membership in a religious 
organization and religious individuals are also engaged in other service oriented organizations as discussed in the literature review.

A second regression model, in table 4.8 below, to test the path between RPE and the bonding form of social capital does not confirm the expectation of hypothesis 2.3; the relationship between RPE and bonding capital is in the same direction as with bridging capital. However, the relationship is very weak, .075 standardized coefficient. The model accounts for roughly $3 \%$ of the variance in bonding capital. The bonding social capital model has a conditional intraclass correlation of only .04 , indicating that it the characteristics of bonding social capital are driven by individual level characteristics that are not included in this path. The item that correlates most with bonding capital is religiosity. The relationship indicates that more religious people, other factors being equal, tend have a more in-group orientation. It is also worthwhile to remember that although bonding and bridging capital are factors drawn from the same measured indicators, they are, largely independent of each other so there are states, like Sweden, that score intensely on both bridging and bonding capital.

The models that were tested in this section indicate that the expected relationship between bridging forms of social capital and RPE exists which indicates a confirmation of hypothesis 2.2. The expected negative relationship between bonding, or inward focused forms of social capital, and relative political 
extraction was not present however rejecting the relationship expected in hypothesis 2.3 .

In order to examine the direct effect of bridging social capital on intolerance the path analysis model is populated with other indicator variables. This model also specifies the paths between Intolerance and bridging social capital and the relationships between and among RPE, GDP, education, political self-position plus the institutional trust and religiosity forms of social capital as well.

Path analysis requires that the entire web of effects be examined on order to identify the paths of relationships among the variables in the model. To examine the path of bridging social capital in the single-level model it must be populated with all the relevant relationships, otherwise there may be unidentified suppression or moderation effects that will confound interpretation.

The table illustrates the first part of the path which passes through education and has a -.09 correlation with Intolerance in the final model. The path model illustrates that only a very small part of the relationship between RPE and Intolerance stems from the relationship of RPE and GDP per capita through education. The path diagram shows the relationships as modeled by the path analysis, and manifest in the single-level regression model of the relationships between intolerance and the individual level variables, and the national-wave level variables of GDP and RPE. 
Table 4.2: Intolerance Single-level Regression for the Path Analysis

\begin{tabular}{|l|l|l|}
\hline & Ordinary Least Squares & Random Intercepts Regression \\
\cline { 2 - 3 } & $\beta(t)$ & $B(t)$ \\
\hline Intercept & -0.05 & -0.07 \\
\hline Study (EVS,WVS) & $0.004(1.6)$ & $.086(1.3)$ \\
\hline Political Self-Placement & $0.08(3.1)$ & $.08(19.6)$ \\
\hline Age & $0.063(2.21)$ & $.0133(27.8)$ \\
\hline Religiosity & $.084(2.9)$ & $.03(9.8)$ \\
\hline Educational Attainment & $-0.10(-3.4)$ & $-.10(-26.2)$ \\
\hline Bridging Capital & $-.11(-3.8)$ & $-.308(-21.5)$ \\
\hline Bonding Capital & $-0.012(-.6)$ & $.005(.5)$ \\
\hline Ln (per Cap GDP) & $-0.315(-2.8)$ & $-1.14(-8)$ \\
\hline RPE & $.006(.07)$ & $.096(.06)$ \\
\hline R 2 & 0.205 & \\
\hline $\begin{array}{l}\text { Dependent Variable= Intolerance summed with sqrt transformation. } \\
\text { N=79128, Design effect= 66, Adjusted N=1192, } \\
\text { All Standardized Regression Coefficients } \\
\text { *significant at } p<.05 . \\
\text { Source: World Values Survey 1980-2005 combined dataset. }\end{array}$ \\
\hline
\end{tabular}

The table provides the path model of the single-level OLS regression next to a random intercept hierarchical model. The singe-level regression has an Rsquared of .20. What both models provide is confirmation of that bridging social capital is associated with improved tolerance; the single-level regression with a single fixed intercept at the mean income and political capacity level, shows a -.11 standardized correlation between bridging social capital and Intolerance, the 
Noordijk

hierarchical linear model indicates that even if the intercept for the individual-level model is allowed to vary by country-year, the relationship holds.

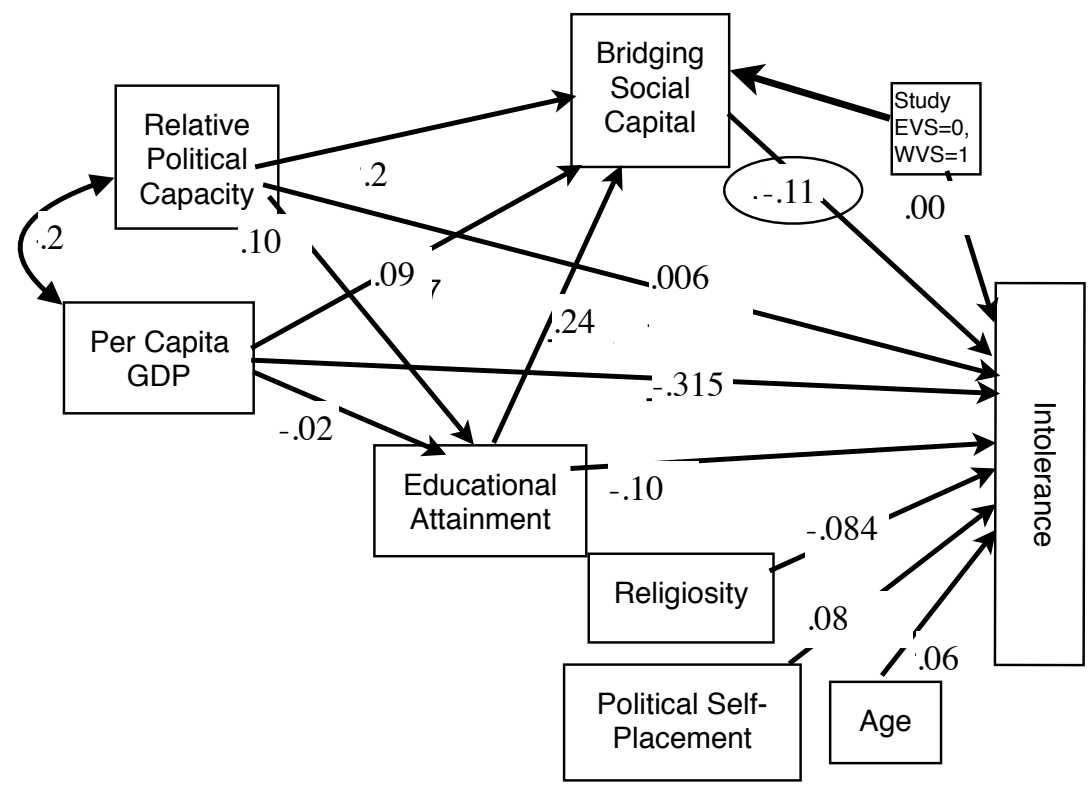

Path model estimated using OLS regression for the total model (direct paths) and for the two indirect paths estimated.

Source: World Values Survey 1980-2005 combined dataset. World Values Association.

Figure 4.2: Path Analysis of RPE to Intolerance, Single-level Regression

\subsubsection{Path model test of hypothesis 1: Political capacity will have a direct effect on intolerance.}

Figure 4.2 illustrates that the direct path between relative political extraction and transformed intolerance in the model is a very weak and not significant .006. This is the opposite direction of the hypothesis and means the null hypothesis of no effect cannot be rejected by this model. However, the discussion of the 
relationship of RPE and intolerance illustrated by the path model, indicates that the effect of RPE on intolerance is mediated both through education and social capital. As a note the random intercept multi-level models in section 4.6 also show a non-significant relationship of RPE and intolerance in the opposite of the hypothesized direction.

\subsubsection{Path model tests of hypotheses 2, 2.1, 2.2: Political capacity of the government will reduce intolerance through bridging social capital.}

These hypotheses are confirmed in the path model. The unexpected direct relationship of RPE and intolerance in the direct path is moderated by the indirect paths through educational attainment, bridging social capital, and GDP. The path analysis in figure 4.2 illustrates the relationship of RPE to intolerance through bridging capital and education.

Hypothesis 2.1, that bridging social capital (Trust-based) is associated with reduced Intolerance, is supported in the path model. The path between bridging social capital and intolerance is statistically significant with a coefficient of $-.11(p<$. 05). Remember that the bridging social capital variable is constructed so that negative numbers indicate denser networks and greater social trust. The -.11 correlation indicates that as individuals participate in fewer organizations and have less trust, they are more likely to exhibit intolerance.

Hypothesis 2.2, that increased government capacity will improve the level of bridging social capital, is also supported by the OLS regression used to 
populate the path model. The RPE to bridging social capital path, has a -.18 correlation, consistent with the hypothesis. The path between bridging social capital and the intolerance variable has a correlation of -.11. Therefore, eighteen percent of the path that is between bridging social capital and the intolerance variable is a product of relative political extraction.

Additionally, RPE is associated with ten percent of educational attainment scores, which have a .24 coefficient associated with bridging capital. The product of the path, .10 by .24 , is the .02 that is contributed indirectly to bridging capital by RPE through educational attainment. The net indirect contribution of RPE to Intolerance through bridging social capital is .02 plus .01 through education for a total indirect path of .03. The relationship between Intolerance and RPE is still a very weak effect, requiring an examination using the more powerful tool of a multilevel linear regression.

\subsection{2: Path model test of hypothesis 2.3, Intense bonding social capital is associated with summed intolerance}

Hypothesis 2.3 is not supported by the results of the path model presented in table 4.1. The standardized regression coefficient of -.012 is not close to significant. Even the parallel random intercept multi-level model with improved sensitivity, presented alongside the OLS path model in table 4.1 does not support the hypothesis that bonding capital is directly related to intolerance. Table 4.1 and the discussion of its results indicate that there was no significant relationship 
between RPE and bonding forms of social capital. This rejects the hypothesized mechanism of constrained bonding social capital. Indeed, the maps of social capital in Europe (figure 3.9) show that some high bridging capital states like Sweden, Denmark, and the Netherlands, also have high levels of bonding social capital.

The path model is useful for illustrating the mechanisms of the relationship between government capacity and intolerance. Relative political capacity is associated with improved educational results, and a strengthened relationship of GDP per capita and intolerance. Without the path model, the simple correlation between RPE and intolerance would lead to a conclusion that increased capacity suppresses intolerance, however the mechanism is more complicated, and has implications for focusing limited public resources.

The OLS model does not permit varying intercepts and really dealing with the context-dependent nature of the surveys and the environment of the relationships between intolerance and its correlates requires the use of multi-level techniques which permit varying intercepts.

\section{6: Testing Hypotheses With Multi-level Models.}

The statistical power of multi-level models is determined by the number of groups, more than the number of individual cases (Hox 2002). The constraints 
caused by the small number of group-level (country wave) indicators, the multilevel model is limited in the number of country-level variables or cross-level interactions that can be tested in the multi-level model without losing power. Following the direction of a number of texts reviewed in the literature discussion, the focus will be on the interaction of social capital and relative political extraction with few context-level variables such as RPE and GDP per cap in each analysis.

The subsequent models examine the role of RPE and bridging social capital in multi-level models that include the contextual effects of GDP/Capita and RPE, as well as the cross-level interaction of RPE and bridging capital. The interaction term allows the slope of bridging capital to vary by country. The observation of the single model, that the impact of RPE on bridging social capital, and on Intolerance is affected by the right-left nature of the government, indicates that the slope of social capital varies by country-wave.

Several models are presented in the table in Appendix $\mathrm{J}$ that lead to the specification of the model in table 4.3. The first is the null model containing random intercepts to provide a baseline for comparison and derivation of the psuedo- $R^{2}$.

The relationships of interest for this study are the relationships of intolerance, RPE and bridging social capital with each other and interacted on intolerance. The model below allows the inspection of the relationships of the 
country-level variables on the individual-level intercepts, and the relationship between bridging social capital and RPE as nested in the context of each country in each wave of the survey. In multi-level regression models the observations of the single-level models carry forward to the multi-level model in the slopes of the individual-level and group level variables. The fixed effect coefficients of the group-level variables act on the intercept for individual's regression equations.

\subsection{1: Analysis}

The results of the hierarchical model for the 1986-2007 data looks similar to the final OLS regression for the path model. The relationships of education, as well as political self-assignment, age, income and gender all retain significant individual-level slopes with intolerance in the expected direction.

The addition of GDP per capita reduces the between country error term (random intercept) by more than half, and doubling the explained variance between the null model from the appendix and populated model below. While none of the other context variables had statistically significant fixed effects.

The unstandardized slope of bridging social capital on intolerance is between -.28 to -.33 in all the models and still significant at the .00 . This result provides consistent support to hypothesis 2.1 , that intensified bridging social capital is associated with lower intolerance.

Table 4.3: Hierarchical Model 1986-2007 Data 


\begin{tabular}{|c|c|}
\hline Fixed Effects & Coefficients \\
\hline Intercept y00 & -0.21 \\
\hline Religiosity (centered) & $.04^{\star \star}$ \\
\hline Gender (male) & $.27^{\star *}$ \\
\hline Education (centered) & $-.09^{\star \star}$ \\
\hline Right-Left Political (centered) & $.08^{\star \star}$ \\
\hline Income (centered) & $-.017^{\star \star}$ \\
\hline Bridging Social Capital (centered) & $-.33^{\star \star}$ \\
\hline Age (centered) & $.013^{\star \star}$ \\
\hline Town Size & $-.04^{\star \star}$ \\
\hline Relative Political Extraction & 1.90 \\
\hline In GDP/Capita (centered) & $-1.03^{* \star}$ \\
\hline Migration. rate & -2.24 \\
\hline Soc. Security Spending/GDP & -2.9 \\
\hline Local expenditure /total expenditure & -0.036 \\
\hline RPE x Bridging Capital & $-1.39^{*}$ \\
\hline Ln GDP x Bridging & $-.15^{\star \star}$ \\
\hline Local Exp x Bridging & 0.12 \\
\hline \multicolumn{2}{|l|}{ Random Effects } \\
\hline Residual & 3.13 \\
\hline Random Intercept & $.22^{*}$ \\
\hline Random Slope Bridging & $.025^{\star \star}$ \\
\hline Slopes by Intercepts Bridging & 0.006 \\
\hline \multicolumn{2}{|l|}{ Model Fit (smaller is better) } \\
\hline $\mathrm{AIC}$ & 226570.00 \\
\hline $\mathrm{BIC}$ & 226606.00 \\
\hline Pseudo $R^{2}$ & 0.19 \\
\hline \multicolumn{2}{|c|}{$\begin{array}{l}\text { Individual } N=77,015 \text {, Group-level } N=72 \text {. Mixed Regression, Unstructured Random } \\
\text { Effects (variance components). Right-wing parties in percentage of total cabinet posts, } \\
\text { weighted by days. Source: own calculations for Turkey based on Schmidt and Beyer } \\
\text { (1992); } 1991 \text { onwards: Political Data Yearbook(s), EJPR. } \\
\text { Source: World Values Survey 1980-2005 combined dataset. World Values Association. }\end{array}$} \\
\hline
\end{tabular}

While the direct path between RPE and intolerance does not have a 
statistically significant coefficient, it is positive which is the opposite direction proposed for hypothesis one (1.9). However, the cross-level interaction term RPE x bridging also highlights the relationship between RPE and bridging social capital in the model. The coefficient of the cross-level interaction term is -1.39 and is significant even though the coefficient for RPE alone is not. The -1.39 coefficient of the interaction term indicates that at higher levels of RPE, the relationship between bridging social capital and intolerance is slightly, but significantly intensified. Review of the hierarchical models in Appendix $\mathrm{J}$ provide more support for the idea that some change in RPE accounts for an element of the random slope of bridging social capital. This is because there a reduction of the random slope for the bridging social capital (from .04 to .03), meaning that some of the random variation in slope for bridging social capital, is accounted for by RPE.

The error term for the random slope of bridging social capital (.025) indicates that there is slight, but statistically significant variation in the slope between intolerance and bridging social capital at the country-wave level. The slope by intercept error term of ,006 for bridging social capital means that the variation in slopes is not a product of the intolerance.

The variation is accounted for without further explaining the model fit, which still has a psuedo-r-squared of .18 to .19 for both models. The existence of an inconsistent relationship in the interaction effect explains why there is no 
increase in the slope of bridging capital for an increase in relative political extraction.

This observation is also confirmed by the relative lack of slope variance for bridging social capital. If the slope of bridging capital on Intolerance is almost always the same, the slope of the interaction of RPE and bridging social capital cannot have a consistent effect on Intolerance because RPE changes from group to group. While the slope RPE $x$ bridging capital is significant, indicating that the variance of slope from context to context accounts for a non-trivial amount of the error in the model, however there is a large standard error of the estimate and small degrees of freedom ( 31) means the relationship has little power.

The hierarchical model also includes the interaction of country-wave level per capita GDP with bridging social capital. The coefficient of -.15 is significant. For higher levels of GDP the slope of the relationship between bridging capital and intolerance will also change slightly. Illustrating that the relationship between per capita GDP and intolerance is also partially mediated by bridging social capital.

First the level of recent influx of immigrants has a reversed relationship with intolerance, that is intolerance is inversely related with the immigration rate. Second, the level of unemployment in the country has a significant relationship with intolerance but the weak relationship indicated is the reverse of common assumptions (model 3 in Appendix J). This is in contrast with results of some 
other studies, however other authors have observed that unemployment at the individual level does have a direct relationship with intolerance (Coenders and Scheepers 2003). Possible explanations might be that migrants seek strong economies and countries with capable governments as destination countries.

Contact theories of intolerance also are supported by the strong reversed relationship of town size and intolerance as most migrants and their heirs settle in urban settings.

Finally, a separate term for social security spending over GDP is included to explore the idea that a strong social safety net reduces the dependence on tightly bonded organizations for social welfare support and reduces the costs of defections by potential partners in organizations or enterprises that lie on the edge of an individual's network of social controls. Social security spending is not significant in the fully specified model in table 4.3.

The model rejects a direct effect of RPE on social intolerance. Hypothesis one is rejected. However, hypothesis two; that RPE will foster bridging social capital is supported. As is hypothesis 2.1 , the expectation that intensified bridging social capital is associated with lower intolerance.

\subsection{2: Testing the relationships of relative political extraction, local expenditure and bridging social capital}

Hypothesis three postulates that, a smaller locus of public spending control will contribute to greater social capital and reduced intolerance, controlling for 
other factors. This is following arguments in the literature that local organizations will be engaged if they have input into spending decisions, and that local civilsociety groups will be supported local expenditures. In these results, the locus of expenditure has no significant direct relationship with intolerance (-.04), nor one that is mediated through bridging social capital illustrated by the interaction term between bridging social capital and ratio of local control (.12). Hypothesis three cannot be sustained based on these results. The policy or environmental conditions for tolerance and policy decisions on how to address issues of intolerance are not linked simply to local expenditure. How the resources are used appears to matter more than what level of government reports spending.

Hypothesis four is tested in the model where neither local expenditure, or the interaction of local expenditure with social capital are significant in the setting of the 72 country-years included in the sample.

\subsection{3: Multi-level models With 2008 and 2009 cases testing interaction with right-wing government and the $E U$ effect}

Table 4.4 presents several models (seven through ten) largely testing the same issues discussed above but with additional country-year cases drawn from the 2008-2009 wave of the World Values and European Values Surveys. The most important additions to the models are the interaction of right-wing government participation and the inclusion of Time EU; a measure of years the country has been in the EU since the SIngle European Act of 1986. The models 
also differ from prior models because all variables have been grand-mean centered and standardized on their standard deviation. Because the data from the new wave of the surveys has only recently been released and is not entirely recoded to match the prior waves, the models below omit a number of the interesting variables covered in the previous sections such as individual income and town size. However, the overall outcome of the new models is that the relationships evident between intolerance, bridging social capital and relative political extraction persist even with a larger range of countries and cases.

\subsection{4: Testing hypothesis four; Right-wing participation in government will mediate the relationship between political extraction and Intolerance.}

Model A, in table 4.4, includes both an independent variable of the trailing moving average for right-wing party participation in government and an interaction effect with relative political extraction. This model includes these variable to test the hypothesized relationship between right-wing governments and political extraction. Hypothesis four from the introduction postulated that right-wing governments will be less likely than other governments to use political capacity in an effort to directly constrain intolerance. The expectation is that there would be a direct relationship between right-wing government participation and intolerance. The model also tests for the interaction between RPE and right-wing participation in government to examine mediation effect. The fixed effect coefficient for rightwing government is .04 with a t-value of 1.74 , below the significance threshold of 
1.96. The interaction effect in model A fails to reject the null hypothesis that rightwing participation in governments has no effect on the relationship between relative political capacity and intolerance. The coefficient of the interaction term is -.02 with a t-value of .97 .

The coefficient for the direct relationship between intolerance and rightwing party composition of government in the models with the newer cases confirms the result of the multi-level models with the smaller dataset. There is a weak relationship between right-wing government participation and intolerance (. 04 in models A and B, and even weaker .03 in model C) indicating that as governments have greater participation of right-wing parties, the reported intolerance level increases slightly. This is in addition to the relationship of individuals' right-left political disposition and intolerance (.05 and $p<.01)$. The interaction term for right-wing party participation in governments with RPE is also below significance, with a t-score of -.72 the interaction effect does not approach significance at p.05. The coefficient is -.02 indicating that as RPE increases the marginal effect of right-wing participation declines.

Hypothesis four asserts that the participation of right-wing parties in the Parliament will effect how political capacity is applied by governments. The weak relationship indicated by the coefficient for the interaction term does not support 
the hypothesis. There appears to be a direct effect, but it is only very weakly

related to RPE.

Table 4.4: Models with 2008-2009 Cases Added, Models A through C

\begin{tabular}{|c|c|c|c|c|c|c|}
\hline Fixed Effects of Standardized & $\begin{array}{l}\text { Mod } \\
\text { el } A\end{array}$ & $t$ & $\begin{array}{l}\text { Model } \\
B\end{array}$ & $t$ & $\begin{array}{l}\text { Model } \\
\text { C }\end{array}$ & $t$ \\
\hline Intercept & 0.61 & 26.47 & 0.61 & 26.55 & 0.68 & 31.31 \\
\hline Male & 0.08 & 20.15 & 0.08 & 20.16 & 0.08 & 20.17 \\
\hline Bridging Social Capital & -0.07 & -11.8 & -0.07 & -11.52 & -0.07 & -12.45 \\
\hline Religiosity & 0.03 & 15.3 & 0.03 & 15.30 & 0.03 & 15.44 \\
\hline Political Self-Placement & 0.05 & 26.8 & 0.05 & 26.90 & 0.05 & 26.86 \\
\hline Age & 0.07 & $35.4 \varnothing$ & 0.07 & 35.48 & 0.07 & 35.50 \\
\hline Education & -0.08 & -38.2 & -0.08 & -38.23 & -0.08 & -38.17 \\
\hline Ln GDP/cap & -0.23 & -10.2 & -0.24 & -10.38 & -0.09 & -2.96 \\
\hline RPE & -0.01 & -0.57 & -0.02 & -0.81 & -0.06 & -2.97 \\
\hline Bridging * GDP & -0.01 & -2.36 & -0.01 & -2.52 & -0.01 & -2.24 \\
\hline Gov-right 5 year MA & 0.04 & 1.74 & 0.04 & 1.86 & 0.03 & 1.50 \\
\hline Bridging * RPE & -0.01 & -0.97 & & & & \\
\hline RPE by Gov right & -0.02 & -0.72 & & & & \\
\hline Bridging Group & & & 0.04 & 1.14 & & \\
\hline Bridging Group * Bridging Ind. & & & -0.01 & -1.57 & & \\
\hline Time EU & & & & & -0.22 & -6.51 \\
\hline Random Effects & Est. & Wald & Est. & Wald Z & Est. & Wald Z \\
\hline Residual & 0.376 & 231.4 & 0.376 & 231.428 & 0.376 & 231.400 \\
\hline Random Intercept & 0.042 & 6.19 & 0.042 & 6.237 & 0.028 & 6.157 \\
\hline Bridging by Intercept & 0.001 & 0.944 & 0.002 & 1.241 & 0.001 & 1.358 \\
\hline Bridging Random Slope & 0.002 & 4.518 & 0.002 & 4.517 & 0.002 & 4.570 \\
\hline \multicolumn{7}{|l|}{ Model Fit } \\
\hline Psuedo R2 & 0.19 & & 0.19 & & 0.20 & \\
\hline AlC Fit & $2002 \varepsilon$ & & 200293 & & 200251 & \\
\hline
\end{tabular}


Dependent variable $=$ Transformed and centered intolerance

Individual N=98279, Group-level N = 85.

Mixed Regression, unstructured random effects.

Right-wing parties in percentage of total cabinet posts, weighted by days.

Source: own calculations for Turkey based on Schmidt and Beyer (1992); 1991

onwards: Political Data Yearbook(s), EJPR.

(World Values Survey 1981-2008 Official Aggregate V.20090901, 2009 2009;

European Values Study 1981-2008, Longitudinal Data File 2011)

\subsection{5: Effect of the duration of European Union membership on intolerance and RPE}

Model $\mathrm{C}$ includes a new term in the independent variables, duration of membership in the European Union since 1986. This variable is calculated simply by subtracting the year of survey from the year the country joined the European Union, or since the ratification of the Single European Act in 1986.

With the term for duration in the European Union included, several shifts of values in the model are revealed. The coefficient of the direct effect on intolerance is substantial and significant $-.22(p<.01)$, indicating that longer term membership is associated with improved social tolerance. Additionally, duration in the EU has suppression effect on GDP/capita, accounting for more than half the relationship between national wealth and intolerance. The direct term for RPE shifts from the very weak positive relationship in models one through five, to a significant and negative relationship in model ten. The coefficient -.06 is significant at $p<.01$. Although still not a strong effect compared to bridging social capital or education. 
It is significant and in the direction expected in hypothesis one. In the presence of whatever factors are captured in the indicator Time EU, RPE behaves as expected in the hypotheses from chapter one. The more recent accession and candidate countries have much higher intolerance levels than the older EU members.

\subsubsection{Effect of group-level bridging social capital on individual bridging social capital and intolerance.}

Model B, illustrated in table 4.4, indicates that the group-level reservoir of social capital does not have as strong a relationship with intolerance as does an individual's level of social capital. This result was indicated by other models that illustrated relative indifference in the slope of bridging social capital to the levels of intolerance, however, model B specifically tests for this relationship. A group-level variable was created by taking the country-wave average social capital for each country in the sample. The variable was centered on the grand mean and standardized. The direct effect of the group-level variable for bridging social capital indicates that the .04 shift in the intercept of intolerance is the opposite of the direct effect. That is, the greater the average intensity of bridging social capital, the intercept of intolerance for that country-wave actually increases, although the relationship is weak and not significant as an indicator in a random sample of countries. However, the interaction term does indicate that with higher levels of social capital the impact of an individual's level of bridging social capital is slightly intensified-- again, the relationship is weak, and not significant. The 
random slope for bridging social capital in model nine is also unaffected by the inclusion of the group-level and interaction terms, indicating that there are other sources for the slight differences in slope of bridging social capital from countrywave to country-wave.

\section{7: Multi-level Examination Of Bridging Social Capital}

The path model in section 4.5 presented a ordinary least squares model that investigated the causal paths between GDP, political extraction, education and social capital on intolerance. As bridging social capital is a lynchpin of the link between of political extraction and intolerance, it warrants more investigation. Also, table 4.4 from the path model to bridging social capital indicate that while religiosity is associated with increased intolerance, it is also associated with more intense bridging social capital. This section uses hierarchical techniques to revisit the relationship of bridging social capital the other independent variables. All the variables are standardized by the standard deviation and centered on the grand means.

The use of a single-level regression model to measure the paths of relationships between the hypothesized variables allows for an understanding of effects in the aggregate, but is not as sensitive to changes of group-level variables. Comparing the multi-level model below to the path regression on bridging social 
capital and new model allows for including the impact of group-level variables on the individual-level intercepts and inspection of the relationship between religiosity and bridging social capital. The model below differs from the single-level regression above in two important ways. First, the intercepts are allowed to vary by country-year, secondly it includes indicators for how the group-level variables effect the intercepts in each country. That means that relationships observed moving in one direction in the aggregated ordinary least squares regression may flip for the individual level as the impact of different intercepts and the changes on intercepts caused by context variables is accounted inside the model.

Table 4.5: Hierarchical Random-Intercept Regression on Bridging Social Capital

\begin{tabular}{|c|c|c|c|c|}
\hline Model Bridging 1,2 & \multicolumn{2}{|c|}{ Random Intercept } & \multicolumn{2}{|c|}{ Random Slope Religiosity } \\
\hline Fixed Effects- Standardized Z-scores & Coefficients & Sig. & Coefficients & Sig. \\
\hline Intercept & 0.02 & 0.72 & 0.02 & 0.70 \\
\hline Study (WVS=1,EVS=0) & 0.00 & -0.03 & -0.004 & 0.890 \\
\hline Gender ( $1=$ Female, $0=$ Male) & 0.04 & 0.00 & 0.04 & 0.00 \\
\hline Religiosity & 0.11 & 0.00 & 0.114 & 0.000 \\
\hline Minority ( $0=$ minority, $1=$ =majority) & 0.08 & 0.00 & 0.07 & 0.00 \\
\hline Education & 0.20 & 0.00 & 0.20 & 0.00 \\
\hline Income & 0.09 & 0.00 & 0.09 & 0.00 \\
\hline Political Self-position & 0.04 & 0.00 & 0.04 & 0.00 \\
\hline Age & 0.010 & 0.04 & 0.010 & 0.04 \\
\hline GDP per Cap & 0.30 & 0.00 & 0.31 & 0.00 \\
\hline Relative Political Extraction & 0.18 & 0.00 & 0.21 & 0.00 \\
\hline Government Right Participation & 0.08 & 0.08 & 0.04 & 0.38 \\
\hline Local expenditure ratio & 0.21 & 0.00 & 0.15 & 0.00 \\
\hline Random Effects & $\begin{array}{l}\text { Residual } \\
\text { Variance }\end{array}$ & Sig. & $\begin{array}{l}\text { Residual } \\
\text { Variance }\end{array}$ & Sig. \\
\hline Residual (within group variance) & 0.74 & 0.00 & 0.74 & 0.00 \\
\hline $\begin{array}{l}\text { Random Intercept (variance between } \\
\text { groups) }\end{array}$ & 0.08 & 0.00 & 0.08 & 0.00 \\
\hline Religiosity Random Slope & & & 0.002 & 0.001 \\
\hline
\end{tabular}




\begin{tabular}{|l|l|l|l|l|}
\hline Religiosity Slope by Intercept & & & 0.007 & 0.002 \\
\hline Model Fit & AIC 166865 & & AIC 166839 & \\
\hline Depend & & \\
\hline
\end{tabular}

Dependent is grand mean-centered bridging social capital. Source: World Values Survey 1980-2010 combined dataset. World Values Association. Mixed model using variance components structured random effects and random coefficients models.

Even with the improved sensitivity and possibility that relationships will shift with the introduction of the random or group-level intercepts, the results are consistent with the path model. Table 4.5 illustrates that the relationships noted in the single-level path model still hold even with the reduced degrees of freedom while random slopes by context are allowed.

\subsubsection{Revisiting hypothesis 3; Local expenditure ratio and bridging social capital.}

There are several results of interest in these models. One is that an increased ratio of local expenditure will improve bridging social capital is borne out in this model, that is in conflict with the result of the interaction term of bridging social capital and local expenditure from the hierarchical model. The result supports the mechanism of improved tolerance proposed in hypothesis three. A standard deviation increase in the local expenditure ratio is associated with a .21 intensification of bridging social capital (the scale of bridging social capital is reversed). This effect can be compared to the other effects in the model as they are all standardized. The .21 coefficient reduces to a .15 effect when a random error for religiosity is included, indicating some interaction effect between personal 
religiosity and local expenditure. Both the .21 and .15 coefficients are among the strongest correlates of bridging social capital in the model.

\subsubsection{Religiosity and bridging social capital: a closer look.}

Religiosity and bridging social capital are investigated in the hierarchical regression that includes random slopes and intercepts for religiosity, shown in table 4.5. The results indicate that religiosity intensifies memberships and social trust-- bridging social capital. The coefficient is $-.11(p<.01)$, indicating that it is one of the more powerfully correlated independent variables included in the model (remember these are standardized coefficients). The effect of religiosity on bridging social capital weakens only slightly at higher levels of social capital with a random coefficient for slopes by intercepts of .007. There is some statistically significant variability in the slope of religiosity on the formation of bridging social capital as indicated by the $.002(p<.01)$ coefficient for random slopes.

The model indicates that while the effect of religiosity on bridging social capital is strong and increased religiosity intensifies the stock of an individual's social capital, the relationship is variable and weakens at higher levels of social capital.

\subsubsection{Minority status and bridging social capital}

According to the models in figure 4.5 , minority religion status is associated with a .07 standard deviation decline in the intensity of their bridging social capital 
reserves. This is a clear indication that social capital efforts should target minority communities, of course for social capital to be bridging it must bridge outside identity communities meaning spreading to majority communities as well. Until the last ten years, little of the policy effort in the Netherlands case studies included the majority population, these results seem to indicate that is not a rational policy choice. There has been a recent shift in the past several years among some Dutch cities with a neighborhood focus that includes majority participation. As the majority population is also more likely to express intolerance, efforts to address intolerance should be focused on majority population as well as increasing minority social capital.

\subsection{Summary and Conclusion of Analysis}

The path model and hierarchical models were used to test the hypothesized relationships between and among social intolerance, relative political extraction and social capital.

Hypothesis 1: Increased relative political capacity will be associated with lower levels of Intolerance in the European Union and accession states. The hypothesized direct path between relative political extraction and intolerance was not supported in any of the models, save model ten. In fact, in most of the models, including the OLS path model the direct relationship between RPE and 
intolerance was not significant and was positively correlated with intolerance. In model ten, the independent variable for time in the European Union was added as a measure of government intent. When that variable was included in the model, the suppression effect on RPE potentially caused by per capita GDP was reduced and the direct path was both statistically significant and negative.

Hypothesis 2: Relative political capacity will reduce intolerance by encouraging bridging forms of social capital. Relative political capacity will reduce intolerance by constraining bonding forms of social capital. The path model, the several multi-level hierarchical models and especially the final hierarchical model in table 4.5, which analyzed the contributing factors to bridging social capital, all support the thesis that relative political capacity fosters the formation of bridging social capital. However, the second part of this hypothesis, that relative political capacity will constrain the emergence of bonding capital is not supported in the path model.

Hypothesis 2.1: Bridging social capital (Trust-based) is associated with reduced intolerance. This hypothesis is supported in every investigation. All the models show a very strong relationship between bridging social capital and intolerance, often, with education, the independent variable with the highest correlation with improved tolerance. 
Hypothesis 3: Local allocation of state resources will foster stronger bridging social capital. The models provided slightly contradictory outcomes. In the hierarchical model testing effects on intolerance, the interaction term between bridging social capital and local ratio of spending was not statistically significant. The lack of significance for the interaction indicates that the relationship between bridging social capital and intolerance did not differ with levels of local spending. However, further inspection of the relationship with a model regressed on bridging capital in section 4.7 indicates support for the hypothesis with a strongly significant $(p<.05)$ standardized coefficient of .21 . The direct analysis of the relationship is a better gauge of the relationship than the interaction effect, so the hypothesis should be accepted.

Hypothesis 4: Government intention (measured by right-wing participation) interacted with relative political capacity should have a stronger effect on intolerance than relative political capacity measured alone. This hypothesis was directly tested in the hierarchical models. The results showed a very weak and not significant relationship for the direct effect of right-wing participation in government. 


\section{CHAPTER 5: TWO DUTCH CASES.}

Investigating the efforts of public officials to tackle the challenges of intolerance in a single national context. The examples illustrate that the tasks of integrating different cultural groups falls largely to local governments, and that those governments use their resources to actively promote programs to foster bridging social capital, both for the community and individuals. Furthermore, the case of these cities in the Netherlands shows the usefulness of policy diffusion through public administration networks. The local implementation of policy and the use of networks echoes both the subsidiarity structure of the European Union and the open method of coordination for non-coercive pursuit of policy goals that remain under the national-level competency.

Governance of integration and immigrant policy in the European Union falls under national competency since the Maastricht Treaty. This means that there is no "European" policy on integration of minorities into society. The policy environment is one of parallel governance in which treaty goals have been articulated, but policy is established and implemented in a manner idiosyncratic to national political conditions (Zielonka 2007). Under the principle of subsidiarity, the national governments retain control of policy implementation. In the case of the Netherlands, policy implementation is further devolved to municipal authorites, who are connected to each other through policy networks, and to other European cities through the Committee of the Regions. 
The international treaty obligations of the Netherlands have informed the development of policy among technocrats since the first major review in 1979, the international obligations are mentioned in at least three major reports over the years (Pennix 1979; WRR 1990; WRR 2001a). However, while policy in the Netherlands has been informed by international obligations, the national and local context of policy and implementation is paramount. Also, the Netherlands has rarely been in danger of violating the vague strictures of EU and Council of Europe treaties covering intolerance and migration.

As one of the major migration destination countries and founding European Union members, the Netherlands has led the way in developing immigration and integration policy for ethnic minorities (Borket, Bosswick, Heckmann and LükenKlaßen 2007, 10-22; Scholten and Timmermans 2010, 532-535). The Netherlands has had some form of articulated minorities policy since the late 1970s after a national report noted the need to formally accept the permanence of immigrant groups (Pennix 1979; WRR 1990). In addition to the Minorities Policy, the Dutch legal environment has enfranchised minorities by extending the right to vote in local elections in 1988; Dutch officials engaged with consultative bodies composed of local minority leaders; and the Netherlands emphasized protection against discrimination as embodied in the 1994 Equal Treatment Act which intensified tracking of discrimination by governments and employers (Borket, et al. 
2007, 21-22). However, despite not ever articulating policies that extended political franchise to immigrants as "multiculturalism," the majority Dutch culture hosted a political backlash against accommodation in the new millennium.

The policy structure of the Netherlands is similar to that of the European Union in the larger context. Local governments in cities and towns have chief administrative responsibility for managing policy set at the national level for achieving integration and combatting intolerance (WRR 1990, 86-88). However, that administrative responsibility is directed by national-level policy directions and framed in the policy conversations of the day. Local administrators rely on national directives, funding and data collection to manage their efforts. However, they also participate in policy networks that are at least partly supported by the central government. The local administrators access national research and data networks managed by the central government, as well as policy networks composed of other Dutch city administrators, non-governmental organizations and academics (Entzinger 2006, 127).

The national policy conversation throughout the 1970s to the assimilationist trend of the 2000s has been focused primarily on the responsibility of ethnic minorities to engage in broader society, with much less conversation about ethnic Dutch society engaging with and incorporating minorities into social activities. Interestingly, apart from a few programs promoting intercultural, and 
intergenerational dialogue, the emphasis in the Netherlands, including Utrecht and Rotterdam has largely been focused on the participation of minority and immigrant residents in organizations outside of the home with recognition of majority responsibility for inclusion mentioned but not emphasized.

Integration policy was given added impetus by a 1979 analysis of the situation of ethnic minorities and existing policy conducted by the Netherlands government's research institute, the WRR. The 1979 analysis examined the situation of several minority groups then extant in the Netherlands including Moluccan, Surinamese, Caribbean, and Mediterranean immigrants. The report found that there was little coherence in Dutch nationality policy because, prior to the 1970s, the government policy behaved as though immigrants were transitory (Pennix 1979, 160). This conclusion was surprising because in 1973 half a million immigrants were former colonial subjects; they were officially citizens but still treated as temporary communities. The other major community of immigrants was the Mediterranean labor recruitment group composed largely of Greek, Spanish, and Turkish labor migrants. More recently, a combination of economic and political refugees from Arab states and Africa have also settled in the Netherlands (WRR 2001a, 46).

Highlighting the immediacy of acknowledging a multi-ethnic society, Amsterdam has a population of immigrants and non-ethnic Dutch exceeding fifty 
percent, while Rotterdam and some mid-sized cities like Utrecht have non-ethnic Dutch (allochtonen) populations exceeding twenty percent (Entzinger 2006, 123; Scholten and Holzhacker 2009, 81-82). Even more starkly, the youth populations of ethnic minorities currently exceeds the ethnic Dutch (autochtonen) youth population in Utrecht (Manders 2011). Dutch policy on immigration and integration since 1979 has been marked by comparatively intensive research and evaluation, but shifts in methodology, political environment, and unit of implementation have caused apparent shifts of focus in policy but not necessarily changes in implementation at the street-level (Entzinger 2000; Scholten and Holzhacker 2009).

Scholten (2008) writes that the local implementation of integration policy continues to reflect the community identity models of multiculturalism and integration of the 1980s and 1990s. However, in my conversations with bureaucrats in both Utrecht and Rotterdam (two major allochtonen population centers), they stressed the focus on people as individuals and not as part of communities. The newer term for policy directed at integration or assimilation is the struggle against social exclusion (Manders 2011; Jagmohansingh 2012).

\subsection{Three periods of Dutch policy related to social capital and multicultural society: the national context.}

Most of the period of integration policy since the 1970s, when social capital is mentioned at all, it is almost exclusively focused on the importance of 
immigrants being engaged in economic activity and organizations. It is not until more recently that greater emphasis has been put on community cohesion and bridging capital activities of the majority community. Programs like "Welcome to Rotterdam", neighborhood interventions in Rotterdam and Amsterdam and community projects in Utrecht, have an intentional element of drawing ethnic Dutch into shared activities (WRR 2001b; Engbersen, Snel and Weltfvede 2005; Lub 2005, 32-35; Scholten 2009).

The first of these periods of Dutch policies (1979-1990) emphasized pillarization and bonding within groups connection to officials through formal public consultation organizations. The initial national policy report in 1979 contained several policy recommendations, foremost among them were coordinating national efforts at meeting the basic needs of immigrants and fostering their participation in society. Activity was focused within pillars of organizations and outreach. The effect of policies meant to assist minority communities to manage their own affairs was bonding minorities to one another and then linking them municipal governments. However, this policy experienced difficulty because the representation organizations occasionally did not reflect the community they were assigned to represent, for example having Sunni (Grey Wolves) immigrants on a board to organize a Turkish immigrant population consisting of Alevi Kurds and ethnic Turks (WRR 1990, 89) (Entzinger 2006, 
125-126). In the first period of policy local officials allowed for some public instruction in the language of their home country and extended the electoral franchise for local elections.

During the second period of minorities policy (1991-2001) there was more of a focus on integration; with a shift towards the engagement of individuals in formal labor and an increased focus on social participation especially in the labor force (Scholten and Holzhacker 2009). There was a strong emphasis directed at improved education and language skills as the gateway to accessing employment and social integration. The focus of policy was also less "group" based and more focused on improving individual human capital, although social capital in the form of participation by groups and in organizations within the communities was still referenced in the reports structuring this period of national policy (WRR 1990, 50-52). Improved Dutch language and culture skills were emphasized in this period and were considered the responsibility of the state.

The inburgering (citizen creation) process established as national policy in this period focused on mandatory Dutch language classes (free at the time) with 600 hours of language lessons and training for participation in the labor markets as a means of empowering individuals to access labor and social networks outside the home. The 1989-90 report on integration policy that provided this policy outline also reflected that there was fairly little public instruction happening 
in the native tongue of immigrants, despite the public outcry against this "policy" that emerged at the end of the decade (WRR 1990, 77-83). Indeed, the report noted that the lack of education and discrimination by natives were equally causes of the high unemployment and social isolation experienced by ethnic minorities. Nonetheless, national policy direction was shifted away from addressing integration through communal identity group memberships and addressing issues through community-based multicultural organizations or consultation committees. Despite the shift in focus from identity community-based participation, there was an increasingly strong focus on developing human and social capital for individuals, including participation in ethnic group-based organizations but also in participation in the broader economic society (WRR 2001b, 50-52).

The third period in Dutch integration policy, beginning roughly with the rise of Pim Fortuyn's Liveable Rotterdam party and his subsequent murder in 2002, has been described as "the assimilationist turn," reflecting the political backlash against what had been described as the multiculturalist model pushed by scholars and the major political parties in the Netherlands (Scholten 2009; Scholten 2011a, 189). According to Scholten, the assimilationist backlash already had roots in the publications of the Social Cultural Research office, and political movements that redefined tolerance as limited to tolerating only those who shared majority cultural practices. Ironically, among the complaints of Fortuyn's supporters was that 
immigrants and asylum seekers did not share the Dutch value of social tolerance of different lifestyles (Scholten 2011b, 197). As a note, the 2008 World Values Survey wave from the Netherlands shows that the few respondents with a parent born abroad ( $n=133$ ) have significantly lower intolerance rates towards homosexuals or different race neighbors than the native population $(p<.05, p<.05)$ (World Values Survey 1981-2008 Official Aggregate V.20090901, 2009 2009). The data also show intolerance rates for "Homosexual" or "Different Race" neighbors among immigrants that are much lower than in presumptive home countries such as Turkey (.04 in the Netherlands vs .9 in Turkey and .045 vs .43).

The assumption of the politicians pushing back against the multiculturalist policies of the prior two periods was that the immigrants were not adopting Dutch values and that the policies were abject failures. This assumption persisted even against the conclusions of a special parliamentary report that was commissioned by the anti-immigrant Socialist Party in 2004 (Scholten 2011b, 192-194). The Temporary Committee on Integration (TCOI) found that many of the measures of policy had been more successful than expected, particularly in the areas of educational attainment and housing, while goals of employment and social participation were still below targets (Blok 2004, 534, 540-541). Furthermore, the report noted that allochtonen success was greater where there were consistent programs that targeted populations for language training, work programs, and 
education. The results of the report were challenged by the anti-immigrant parliamentarians who had commissioned the report, and the political coalitions of the new millennium pushed assimilation as the policy goal while pushing the burden of assimilation onto immigrants and asylum seekers.

A series of assimilationist laws were promoted by the new minister of Immigration and Integration, Rita Verdonk (Scholten 2011b, 188). Further examples of the new laws included the two Wet Inburgering laws in 2005 and 2006. The 2005 laws, "Wet inburgering in het buitenland" (the Integration Abroad Act), requires that individuals seeking immigration to the Netherlands, including for family reunification, must pass a language and citizenship test administered in their home country before they can apply from immigration (The Netherlands:

Discrimination in the Name of Integration Migrants' Rights under the Integration Abroad Act 2008). The exams and language training are at the expense of individuals. The 2006 law applies similar requirements on individuals already in the Netherlands who seek to remain in the country or to gain naturalization. In addition, the laws passed in this period tightened restrictions on dual citizenship (van Oers, de Hart and Groenendijk 2010, 19-23).

The language of assimilation and individual-level focus was echoed in several of the conversations with local level bureaucrats and researchers from Rotterdam and Utrecht (Brouwer 2011; Manders 2011; Jagmohansingh 2012). 
This echoes the observation of researchers, that direction of the national turn in integration and immigration policy turned away from multicultural integration and towards individualistic assimilation. However, in practice the local level policy has pursued pragmatic efforts at improving civic capacity through building social capital and utilizing a number of public, business and civil society partners, including groups organized by ethnic identity (Poppelaars 2007, 250-251; Jagmohansingh 2012).

\subsection{Social Capital and Civic Capacity Efforts at the Local Level}

The analysis of the dataset in the analysis section demonstrates that the level of revenues directed locally had a significant effect on the development of both bridging social capital and reducing intolerance. The conversation in the introduction of the Dutch case may give an indicator of both why the level of allocation may matter and why the national level right-left political orientation may matter less than other factors in success with social tolerance goals. When comparing the Netherlands ratio of local expenditure to some of its European peers the Netherlands is in the middle of the pack. However, the political structure dictates that most of the efforts at integration and social cohesion are devolved to the local level.

Below, examples from two Dutch cities are included to examine how they targeted social capital issues as a mechanism for achieving greater social 
tolerance. These cities are part of both Dutch policy networks and increasingly linked to Europe-wide policy networks and epistemic communities.

\subsubsection{The Participatie-Ladder: monitoring success in developing social capital of individuals at risk of social exclusion.}

One recommendation consistent across the government research institute reports through all three periods of policy, as well as the Parliamentary Commission on Integration in 2004, was the need for better measurement of program effectiveness (Pennix 1979; WRR 1990; WRR 2001a). Local versions of the inburgering process and efforts at combatting social exclusion that include emphasis on bridging social capital required a means of evaluating the base rate of participation in order to gauge the success of efforts. One instrument gaining widespread usage in the Netherlands is the Participatie Ladder. The Participatie Ladder is a program that embodies a number of the different conceptual strands discussed in this section. One, it is a tracking tool for cities to asses their efforts at improving individuals' social and human capital. Two, it was developed with the think tank RegioPlan, a consortium of twelve Dutch municipalities, and The Association of Netherlands Cities (Verenigde Nederlandse Gemeente) that work together to share the costs of developing new social science tools and reinforcing an existing policy network (Participatie Ladder 2012). Finally, it is an example of public policy network coordination that could easily extend beyond national borders. 
The Participatie Ladder is essentially a panel survey instrument that provides an indicator of individual social participation. Although the tool could provide a baseline for the general population's social engagement, it was developed primarily to asses the resources of unemployed individuals. Participants (recipients of state assistance, regardless of ethnicity) are assessed for their position on the "Participatie Ladder" that includes the frequency of contacts outside their families. Part of the program then makes assistance contingent on engaging in language courses (if required) before assigning placement in either paid or voluntary employment to increase the recipient's social network and skill set (Rezai and Barendrecht 2010, 34-35; Jagmohansingh 2012). Rotterdam and Utrecht have used the Participatie Ladder instrument since 2008 (Participatie Ladder 2012).

The Participatie Ladder is currently used to track the social capital reserves of social assistance recipients by 100 of the 430 Dutch cities. The ladder is a survey that evaluates respondents on six levels of social participation. The levels of participation rank from social isolation at one, to paid employment at six. The emphasis is on paid work, so it is not a perfect measure of social capital, however levels two through five emphasize the importance of engaging friends, joining organizations, and performing voluntary work respectively (Participatieladderhelpt Gemeenten Bij Het Maken Van De Juiste Keuzen 2011). The survey instrument 
contains 21 questions about the participant's social activities such as shopping or volunteering outside the home. The tool is meant to be used as a panel survey interviewing the same participants over time to track the effectiveness of policy efforts. Unfortunately the survey has not been conducted among the general population of any Dutch cities, so no base rate has been properly established against which at risk populations could be compared (Brouwer 2011). The closest similar metrics may be unemployment rates and rates of volunteerism found in surveys by the Dutch Centraal Bureau voor Statistiek or the European Values Surveys. The absence of a base case also highlights the emphasis of social capital development efforts and integration policy in general on minority populations, with less concern for employers. The City of Utrecht was a pilot member of the intercity consortium in the Participatie Ladder's development and has used the tool to assess the success of individuals and programmatic efforts to decrease social exclusion and improve social capital (Brouwer 2011).

Both Utrecht and Rotterdam use the Participatie Ladder as a tool for encouraging or requiring participation in activities outside the home. In Rotterdam, receipt of social assistance, is contingent on performing twenty hours of volunteer or paid work as a way of ensuring that individuals are learning new skills and creating a network that can lead to employment in some cases. 


\subsection{Rotterdam: Mensen Maken de Stad}

Rotterdam is an immigration city. According to recent data held by the city there is a majority allochtonen population among minors, like Utrecht. Rotterdam itself has only a 57 percent native Dutch population, a number that includes second and third generation ethnic minorities (Rotterdam Facts and Figures 2009, 12). In keeping with recent political changes in the Netherlands, where multiculturalism has been described as the cause of, not the solution to intolerance, Rotterdam has shifted its official policy focus away from identitygroup-based efforts and towards addressing individuals' needs (Jagmohansingh 2012). However, in practice, the policies remain engaged in reaching out to minorities, building social capital in mixed ethnicity communities and even subsidizing art and sports programs for poor and minority youth (Deelgemeente Begroting 2012 Charlois 2012; Jagmohansingh 2012).

The policy effort in Rotterdam and Utrecht is to incorporate citizens, nonprofit organizations and local employers in co-production of policies to improve both the human and social capital of individuals on social assistance (Engbersen, et al. 2005). In Rotterdam, conversations with social policy makers indicated that there remains a focus on social tolerance, with developing social capital seen as instrumental to achieving tolerance in a very diverse setting. The policy experience of Rotterdam also reflects the different phases of national policy, with the present 
political-policy environment emphasizing the experiences and needs of individuals over group identity (Scholten and Poppelaars 2008; Jagmohansingh 2012). However, in practice, civil society groups that are connected to different ethnic communities remain important partners. (Bijlage 2.: Stand Van Zaken Mensen Maken De Stad 2007 2012; Jagmohansingh 2012).

Rotterdam has an ongoing initiative to improve social cohesion and reduce intolerance between migrant and minority communities and older ethnic dutch residents of Rotterdam's neighborhoods. The Mensen Maken de Stad (MMS), or People Make the City, is an initiative to increase active citizenship and social capital and foster a co-production model of public policy with roots extending back to a citizen-led efforts at connecting new and old Rotterdammers in a city that has experienced very high in-migration over the past 30 years. The MMS is a merger of two different programs a civil society initiative called Opzoomeren and an official pilot program called StadsEtiquette. The two programs each work to foster bridging social capital by coordinating local efforts and intensive support from public sector, civil society and business actors at the neighborhood scale.

The civil society effort was led by organizations in several Rotterdam neighborhoods in the early 1990s and called Opzoomeren after the first street that enacted the effort (Lub 2005, 13-14). The Opzoomeren initiative was an effort to increase interactions among neighbors, engage community members in local 
leadership, and reduce mistrust and intolerance in a street by street, neighborhood-by-neighborhood model. The initiative was triggered deterioration of conditions in Rotterdam's neighborhoods, where residents did not feel safe on the streets and the physical character of the neighborhoods were substantially deteriorated. The Opzoomeren project worked by activating neighbors into participating an open discussion about the conditions of the neighborhood, and inviting participation in planning activities in response. Official help for the first initiatives came in the form of small grants for resources such as brooms, cleaning supplies, and occasionally funds for youth activities like sports leagues (Lub 2005, 13; Bijlage 2.: Stand Van Zaken Mensen Maken De Stad 2007 2012, 3). The Opzoomeren project grew to cover many streets and refined its methodology in the decade between the initial efforts and institutionalization as Mensen Maken de Stad in 2004. The methodology includes training for volunteers in identifying neighborhood leaders, assessing needs, and attaining the early participation of business and government stakeholders in the process of changing quality of life in the neighborhood (Lub 2005; Hengeveld and Janssens 2010). The program is supported financially and administratively by the city, with social services, police and even city maintenance workers coordinating their efforts in each focus neighborhood (Hengeveld and Janssens 2010). The program expressly supports the establishment of bridging social capital through place-focused efforts to get 
neighbors to work together solving problems, and view one another as part of a single community (Mensen Maken De Stad: 'Het Vervolg' 2006, 5). In addition to local financial support, programs are funded with pass-through money from the national government and grants to non-profit sector partners (Deelgemeente Begroting 2012 Charlois 2012, 123)

The Mensen Maken de Stad effort as supported by the City of Rotterdam also contains elements of a separate effort meant to train new residents in Dutch urban etiquette in response to rising public perception of a safety threat caused by immigrants (Lub 2005). The pilot effort of the Urban Etiquette program launched in Rotterdam from 2000 to 2001 was a city-directed effort to bring residents of some neighborhoods together to assess the problems in their neighborhood, and to teach, especially to the young, the expectations of public behavior in Dutch society. In addition to teaching behavior, the StadsEtiquette program helped neighbors conduct an assessment of problems including the capabilities and level of engagement of the community members. Like the Opzoomeren project, the StadsEtiquette program was focused on creating social capital, but with a somewhat tighter focus on livability issues and resolving conflict with immigrants (Rotterdam 2002, 13-16).

The StadsEtiquette project was successfully piloted in 2001-2002 just before the election of the Livable Rotterdam coalition led by the anti-immigrant 
politician Pim Fortuyn in 2002 (Hengeveld and Janssens 2010, 10-11). In spite of the fall of the Labor Party in Rotterdam and the election of an expressly antimulticuturalism, anti-muslim coalition to city government, Mensen Maken de Stad was launched as the StadsEtiquette program was combined with the successful civic capacity and tolerance model developed by Opzoomeren in the prior decade. The policy emphasis of the new coalition was less focused on the expansion of inter-communal trust, than cultural assimilation by immigrants to a notional standard of "Dutch" behavior, but the Mensen Maken de Stad program initiated in 2002 is precisely focused on social capital and increasing tolerance and trust in the community (Mensen Maken De Stad: 'Het Vervolg' 2006, 7-8). The emergence of a distinctly social capital centered, social tolerance model with support of public resources, indicates that street-level bureaucrats and active members of the public already understand the importance and effectiveness of social capital as a means to achieving improved tolerance and understanding. This experience underscores the observation of Scholten and Poppelaars on the divergence between national-level and local politicians and practical application of knowledge by bureaucrats and the civil society actors (Scholten and Poppelaars 2008).

Rotterdam funds sports and arts activities for that are organized different ethnic identifying civil society groups. In the new political climate, the model of 
pillarization by ethnic groups is rejected and replaced with a formal focus on individuals, the reality is that civil society organizations often emerge along ethnic or cultural lines. It is the role of the state to manage linking those organizations and using the existing groups to promote broader networks among their members. As has been illustrated in the case of Rotterdam's implementation of the Mensen Maken de Stad program, despite having a city council actively hostile to the idea of multiculturalism and integration, if not immigrants outright, the City of Rotterdam's professional staff implemented programs expressly meant to nurture bridging social capital with the intent of improving civic capacity and reducing intolerance. Also significant in this effort is the importance of public financial and professional support to grow this effort to over 2000 neighborhood streets. Only the government has the resources to coordinate and support these efforts, and the example of Mensen Maken de Stad and other social capital support programs provides a concrete illustration of how government resource can actively enhance tolerance through supporting the development of bridging social capital and improved civic capacity.

\subsection{Utrecht: Enhancing Social Capital Through Interventions, and Fostering National and European Policy Networks to Apply Research}

As mentioned before, the City of Utrecht is a multicultural city. It is a research and transportation hub with several universities, major think-tanks and government research institutes in the community. Some thirty percent of its 
population is non-white Dutch and there is a majority ethnic minority population among the young generation (Manders 2011). Like Rotterdam, Utrecht has focused efforts on supporting local organizations that work on improving social capital and intergroup understanding. The city provides funding for sports groups, arts, groups and cultural events in public spaces. Additionally, the city government has also faced the challenges of improving and replacing the housing stock with a target of reducing neighborhood homogeneity, and it has used the need for redevelopment as an opportunity to create civic capacity in order to improve participation in the process of redevelopment. Finally, the City of Utrecht, is a member of DIVOSA (the association of municipal managers, a public policy incubator) and pilot case for developing the ParticipatieLadder with other members of the association of Dutch municipalities (Verenigede Nederalandse Gemeenten). Utrecht is also a pioneering member of the European Union Fundamental Rights Agency and the Committee of the Region's efforts to establish a network of best practices in the Joined-up Governance project to disseminate best practices across the European Union (Sakkers 2012).

Examples of continued efforts to enhance public engagement and coproduction of policy in Utrecht can be found in the reports of activities from Overvecht, an area of the city that has been a focus for lower-income in-migration and perceived social cohesion problems for the city (Doe Mee in Overvecht: 
Wijkactieprogramma 2012-2013 2012) (van Kempen 2008). The reports show a continued focus on programs such as "street coaches" who work with social workers to direct at-risk youth to community programs and volunteer activities. The Overvecht neighborhood is also interesting because the Utrecht government has focused on redevelopment to change the housing mix to decrease rental unit concentration and avoid ethnic homogeneity (van Kempen 2008). Part of the effort of relocating and restructuring the neighborhood has been to incorporate minority voices in planning the neighborhood, an effort made difficult by the absence of civic participation among minority population in the district (Koster 2012). In response to the need to invest in the community and increase participation so community voices could be heard, as well as to increase civic capacity, the Doe Mee in Overvecht (Do It Together in Overvecht) initiative was created in 2008 (Doe Mee Overvecht). The initiative contains many programs directed at increasing social capital and civic capacity in this changing and challenged community. Including street mentors, a participation guideline on the website, and directions for coordinating efforts between city planners, city maintenance, social workers, and citizens. It is similar in many ways to the efforts of Mensen Maken de Stad.

Despite the national imperative to attack intolerance with identity-free policies, park activities and programs and promoted by the City of Utrecht do 
precisely focus on minority youth with sports, arts, and education programs (Peters 2011). The programs that target particular areas or needs such as education for Roma girls, or parenting coaches for Moroccan-Dutch parents (Manders 2011; Doe Mee in Overvecht: Wijkactieprogramma 2012-2013 2012). A recent analysis by Karin Peters (2012), of the role public parks play in promoting integration and inter-ethnic understanding found that two different types of parks in Utrecht contributed differently to the experiences that ethnic Dutch and ethnic minority families had vis-a-vis one another. The researcher found that while individuals from different groups rarely interacted directly, in general, sharing the same public space reduced threat perception of "Others." She also reviewed city grant-funded cultural activities at the a community center and found that the efforts to directly produce conversations between groups were effective in reducing potential conflict. Interestingly, her qualitative research revealed a fairly stark divided between active younger people, and older ethnic dutch residents with the older residents (generally) harboring greater suspicions of immigrants and ethnic minorities because of social isolation (Peters 2012). She also finds that local level interactions of individuals influences social cohesion and forms of social capital (trust, organization participation) in contrast to a national political narrative that highlights differences and the imperative of assimilation placed on immigrants. 
Finally, the Utrecht case is important as an illustration of how a medium sized municipality can leverage its resources through the sharing of its experiences in fostering social capital and confronting intolerance within a policy network.

\subsection{Bridging Capital for Cities: National and European Policy Networks to Increase Municipal Civic Capacity}

The Dutch cities studied are part of several interacting networks to share policy, research and expectations. The networks are both nested in the national context and the European contexts. Participation of the cities with the European UNion Agency for Fundamental Rights and the Committee of the Regions also indicates that the municipal managers are also aware of European Union objectives.

Utrecht was a founding member of the consortium (DIVOSA) that developed the ParticipatieLadder measurement tool. They continue to share best practices in how to apply that tool to improve individuals' levels of social and human capital as part of DIVOSA. Utrecht is an active part of the Verenigde Gemeenter der Nederlanden, the network of associated Dutch cities. That association pools resources to exchange information and research policy issues that are common challenges facing Dutch cities. The city government also works with the Central Statistics Agency to collect data for monitoring and evaluation of public policy. 
The city of Utrecht is also one of several pilot cities working with the Fundamental Rights Agency and the Committee of the Regions in the European Union to develop tools that share best-practices in combatting social intolerance and fostering inclusion (Joined-up Governance: Connecting Fundamental Rights 2012). The Joined-Up Governance efforts seeks to amplify the diffusion of best practices element of the Open Method of Coordination, in lieu of relying on the naming and shaming function of the monitoring performance and publishing results. Leveraging their own human rights experiences with those of other cities facing similar challenges is a major goal of Utrecht's efforts to be considered a "human rights" city (Sakkers 2012). In addition to being a pilot member of the FRA's network, Utrecht is active with other policy networks, such as, the Eurocities initiative, a partnership of 140 major European cities founded by in 1986 by six major cities; Barcelona, Birmingham, Frankfurt, Lyon, Milan and Rotterdam .

The active policy networks both within the Netherlands and in the wider European area have been developed precisely to enhance epistemic communities of policy makers and diffuse policy innovation. In the absence of the European Union shifting social tolerance policy into the Union's area of competence or joint competence where there could be some element of coercion to laggards, the best that can be hoped for under the Open Method of Coordination is that bureaucrats are able to share best practices. Institutionalizing expectations and practices is 
precisely what the Dutch cities have done domestically and are extending to the European Union-wide networks of regional and local administrators. The effective practice of promoting social tolerance through increasing bridging social capital can be disseminated and practiced by regional and municipal leaders, even in the face of political opposition at the national level in their countries.

\subsection{Conclusion of Netherlands Policy Cases}

The investigation of policy practice in the two Dutch cities illustrate several of the mechanisms behind relationships that emerged from the path and hierarchical linear models. Education and social capital were primary drivers of successful efforts to reduce intolerance. The role of political capacity as an indicator of improved social capital is illustrated by the resources Dutch cities poured specifically into improving bridging forms of social capital. Finally the Dutch cases illustrated that Dutch municipal policy-makers are aware of, and participate in, European Union institutions that pursue European Union policy objectives.

The apparent success of policy networks and shared resources for in the Dutch cities has strong implications for the potential of Europe-wide or even transcontinental policy networks. Also, at least one mystery from the models, the irrelevance of right-wing participation in government, was explained by the fairly consistent practices of street-level bureaucrats faced with pragmatic choices 
about how to address social policy issues in the face of shifting national-level politics. 


\section{CHAPTER 6: DISCUSSION AND CONCLUSION}

By analyzing the interaction of government capacity and the emergence of intensified bridging forms of social capital, this study contributes to our understanding of the mechanisms by which bridging social capital emerges. Combining techniques of comparative political economy and public administration to investigate the relationships and mechanisms of government capacity helps explain why and when government presence improves bridging social capital. It also helps fill the gap in knowledge left by Putnam's (2007) more recent observation that diversity undermines social capital. This study offers an important improvement by incorporating the role of existing government capacity in facilitating the rise of bridging forms of social capital, even in diverse settings.

Over the past three years the European Union has been rocked by the global financial crisis. The challenge of combatting intolerance has gotten even more daunting in the face of continued economic and politically motivated migration and persistent high unemployment in European Union states. Additionally, under the leadership of Germany and the United Kingdom, austerity has been the prescription for all ails. The policy environment facing public administrators is one of increased stressors on the public and a more competition for policy resources on the government side. Assessments of effectiveness are even more critical for policy now than the period for which the bulk of the data for this project was collected. 
The tests in the analysis show a consistent relationship between relative political extraction and bridging forms of social capital. The direct relationship between relative extraction and intolerance was much weaker and inconsistent. More intense bridging social capital is associated with reduced intolerance, relative political extraction is associated with improved bridging social capital, and the multi-level test of the interaction between bridging social capital and relative political extraction confirmed that the relationship of political capacity with Intolerance is mediated by its relationship to bridging social capital and education. The relationship confirms the main hypothesis offered that relative political capacity shapes the forms of social capital emerging in societies and that the rise of bridging social capital will be associated with improved social tolerance.

Although a direct relationship was proposed for relative political capacity on intolerance by constraining the impact of bonding forms of social capital, the data indicate that the role of the bonding form of social capital, as measured in this model, has little relationship with intolerance once other variables are included in the model. The fact that the Netherlands, Sweden and Norway among others, had more intense social capital, both bridging and bonding, than most other countries presents some clues as to why the relationship is not clear across all countries. The important observation is not that relative political extraction constrains the nasty effects of bonding social capital; it is that bridging social 
capital is the more important of the two for addressing social intolerance. The country-level maps of social capital in figure 3.9 show that individuals can simultaneously have elements of bonding capital like strong family ties and have active links to broader relationships. Those people strong in both are not dependent on their in-group identity for their support networks and not as subject to social control. Bridging capital appears to be key as it is associated with more diversity of contacts.

Two other powerful drivers of intolerance in these models were educational attainment and age. There is an interaction and context effect present in these items, as older cohorts are often not as well educated as younger individuals who are in a cohort that is more educated. As important as educational attainment is, the younger cohorts of the new accession states have also experienced some recent qualitative changes in the type of education. While the education systems of the EU 15 have long included some normative content promoting social tolerance and inclusion, this is a relatively recent phenomenon for many of the new EU member states and Turkey (Coenders and Scheepers 2003). A policy implication is that an emphasis needs to be made on school curriculum and outreach to maximize the qualitative impact of education especially for states at lower levels of economic development. 
The exploration of the Dutch case studies provided insight into the reality of the interaction between government resources, social capital and tolerance policy at the level of implementation in the European Union context of subsidiarity. The cases showed the emphasis of local policy implementors had on supporting bridging social capital and several policies meant to foster social capital resources in minority communities. The cases contributed insight explaining why the national right-left political context may not have mattered in the determining policy effectiveness as local leaders pursued pragmatic policies, that were coordinated between cities and with E.U. institutional actors.

National government policy documents emphasized the importance of social capital for immigrant integration in economic and civic life. The policy documents of the 1980 s and 1990 s encouraged the creation of better metrics for social capital and minority integration. The national and municipal contexts even called for the enhancement of minority civic capacity, both as groups and individuals. The national documents also acknowledged the European policy imperative for protecting human rights, including non-discrimination, although European Union pressure was never central to the policies proposed. By the 2000s the national policy context had shifted towards more focus on assimilation for minorities and less on integration with differences tolerated. 
The investigation of the municipal level activities was also quite instructive. Both to illustrate the types of policies that might be used to enhance government capacity (policy networks) and in the kinds of policies created to enhance personal and community social capital stocks. Some of the unexpected results from the quantitative analyses were also addressed. One phenomenon was the insensitivity of intolerance to changes in right-left distribution of government power at the national level. This was because the hard work of social tolerance programs is executed at the street-level, and municipal bureaucrats and social workers are more pragmatic than ideological. Also, the cases illustrated that local government focus is on improving bridging forms of social capital, and may also render bonding capital less necessary but did not actively suppress the persistence of identity-based trust networks.

Also, in the municipal cases reviewed, local governments worked together to develop methods to asses either personal social capital stocks (Participation Ladder) or community-wide bridging social capital (Mensen maken de Stad). Both projects have the intention of reducing social intolerance and social isolation as stated goals, and in the case of the Participation Ladder, as the phenomenon it is meant to measure. 


\section{1: Implications of Results for Policy}

The results of the analysis in this document also support the emphasis on the role of bridging social capital in improving governance. The obverse is more directly supported in this analysis however, as governance seems to be linked to more intense bridging forms of social capital. If bridging social capital leads to better governance, and relative political extraction is associated with improved bridging social capital, the expectation should be that there is a feedback process between governance and civil society that improves civic capacity. An improved ability to identify and find effective remedies to community is not surprising. Associated with the ability to identify and address problems is the locus of policy creation and implementation. The analysis and cases indicate support for the hypothesis that more local control of expenditures results in greater bridging social capital. Local groups and actors may find their activities more relevant if they expect to be able to participate in the creation and execution of policy.

The relationship between bridging social capital and intolerance is fairly insensitive to changes in per capita GDP, meaning that the policies directly focused on fostering social capital are relevant to all European Union member states, not simply the rich ones.

There are two broader implications for policy in the EU at large. The current focus of the Fundamental Rights Agency (FRA) in enhancing cooperation 
and networks in civil society seems to be an effective strategy for improving both oversight and social capital. The European Union is already expending effort focused on fostering networks between non-governmental organizations and officials between countries to exchange best practices and experiences. In many of the European Union member countries, the efforts at facilitating integration and managing multiculturalism falls to local officials. Facilitating the spread of best practices should fall heavily to the supporting network of relevant urban officials. However, the effort should also be directed at linking individuals and organizations within each of the member states and encouraging national governments to put resources into community organizations that are focused on tasks or activities as opposed to identity. It appears that general efforts focused on improving memberships in social, business, sport, or activism can have positive effects on achieving social tolerance goals in conjunction with other efforts.

The second element is related to harnessing the effects of political capacity more directly. The current arrangement for improving social tolerance in the European Union is modeled on the Open Method of Coordination. However, the FRA does not have the means to compel reporting that Eurostat and other agencies have to harmonize measurement. The EU also needs stronger "naming and shaming" procedures to stimulate efforts in dawdling countries or other 
Noordijk

means of putting social tolerance on the agenda of states with indifferent governments.

Additionally, the efforts at improving social tolerance in new accession states should certainly involve facilitated policy-diffusion by sharing best practices among functional agencies of street-level bureaucrats like social workers and law enforcement. This is an argument for supporting efforts like the "Joined-up" governance network created by the Committee of the Regions and the Fundamental Rights Agency of the European Union (Joined-up Governance: Connecting Fundamental Rights 2012). Finally, encouraging links between well established civil society organizations may help bridge the gap to older Europeans who are outside the education system but still connected to labor or social groups.

\section{2: Next Steps for Research and Practice}

Further avenues for research and model improvement, fall into four groups; Measurement improvement, model specification, improved estimation of policy effectiveness to help target resources effectively, extension of the model beyond Europe.

First, improving the measure of intolerance could certainly help track progress and policy effectiveness. As noted in the literature review, intolerance is 
difficult to accurately measure. It would be fruitful if more comprehensive questions for assessing intolerant attitudes were included in social surveys.

Questions that are structured on a Likert scale would improve analysis and permit for more accurate modeling of effects.

Secondly, relative political capacity, as it is conceptualized in this paper includes taxes paid to social insurance in the comparisons between societies because of the poor fit in calculating relative political extraction with a term for social insurance omitted. Even in Europe there is non-uniformity in what services are paid for by other taxes, taxes at different levels of government or through regulatory requirements that do not show up on the government balance sheet. If this model were extended beyond the European Union setting to countries with even wider divergence in whether revenue was paying for social insurance or other expenses. The model should adopt a more complete conception of government performance.

Improved estimates of treatment effectiveness to establish a sort of costbenefit model for social capital improving policies like those explored in the next section. There has been yet another wave of data collected for the years 2010-2011, this new data will permit the use of a growth model. Growth models add some complexity, but better control for within country variations. With improved model fit from better specification and a growth curve model, it might be 
Noordijk

possible to locate inflection points in the relationship between social capital and intolerance to determine countries or municipalities that might gain the most from dedicated social capital programs.

Finally, although the European Union has a very specific policy goal in reducing intolerance, it is certainly not unique in recognizing intolerance as a public bad. The models can be extended beyond Europe. As can the recommendations for policy. For example, in the process of researching this project it became apparent that there is no reason that the networks of public agencies and the promulgation of best practices in the Open Method of Coordination in tackling intolerance need stop at the borders of Europe. 


\section{Sources Cited}

Adler, Paul S., and Seok-Woo Kwon. (2002) Social Capital: Prospects for a New Concept. The Academy of Management Review 27:17.

Akkerman, Tjitske , Maarten M. A.I Hajer, and John J. Grin. (2004a) The Interactive State: Democratisation from Above? 52:82-95.

Akkerman, Tjitske, Maarten Hajer, and John Grin. (2004b) The Interactive State: Democratization from Above? Political Studies 52:82-95.

Albano, Roberto, and Filippo Barbera. (2010) Social Capital, Welfare State, and Political Legitimacy. American Behavioral Scientist 53:677-690.

Almond, Gabriel A., R. Scott Appleby, and Emmanuel Sivan. (2003) Strong Religion : The Rise of Fundamentalisms around the World. Chicago: University of Chicago Press.

Altemeyer, Bob. (1996) The Authoritarian Specter. Cambridge, Mass.: Harvard University Press.

Arbetman, Marina Kugler Jacek. (1997) Political Capacity and Economic Behavior. The Political Economy of Global Interdependence;. Boulder, Colo.: Westview Press.

Arbetman, Marina, and Jacek Kugler. (1997) Political Capacity and Economic Behavior. The Political Economy of Global Interdependence. Boulder, Colo.: Westview Press.

Armingeon, laus, Sarah Engler, Panajotis Potolidis, Marlène Gerber, and Philipp Leimgruber. (2010) Comparative Political Data Set 1960-2008,. Institute of Political Science, University of Berne 2010.

Bermeo, Nancy Gina. (2003) Ordinary People in Extraordinary Times : The Citizenry and the Breakdown of Democracy. Princeton, N.J.: Princeton University Press.

Bickel, Robert. (2007) Multilevel Analysis for Applied Research : It's Just Regression! Methodology in the Social Sciences. New York: Guilford Press.

Bijlage 2.: Stand Van Zaken Mensen Maken De Stad 2007. (2012), p. 4. City of Rotterdam: City of Rotterdam.

Blok, Stefan. (2004) Bruggen Bouwen (Building Bridges). p. 657. The Hague: Tijdelijk Commissie Onderzoek Integratiebeleid.

Borket, Maren, Wolfgang Bosswick, Friedrich Heckmann, and Doris LükenKlaßen. (2007) Local Integration Policies for Migrants in Europe. p. 69.

Dublin: Cities for Local Intergration Policy.

Brouwer, Peter. 5 November 20112011.

Burt, Ronald $\neg \nmid S$. (2004) Structural Holes and Good Ideas. American Journal of Sociology 110:349-399. 
CBRT. (2010) Central Bank of the Republic of Turkey Electronic Data Delivery System. Ankara: Central Bank of Turkey.

Charter of Fundamental Rights of the European Union. (2009). Brussels:

European Union.

Cheibub, Jose Antonio. (1998) Political Regimes and the Extractive Capapcity of Governments: Taxation in Democracies and Dictatorships. World Politics 50:28.

, European Union Monitoring Center on Racism and Xenophobia. 2005a. Majorities' Attitudes Towards Minorities in (Former) Candidate Countries of the European Union: Results from the Eurobarometer in Candidate Countries 2003. Report 3. European Union Monitoring Center on Racism and Xenophobia

, European Union Monitoring Center on Racism and Xenophobia. 2005b. Majorities' Attitudes Towards Minorities in European Union Member States: Results from the Standard Eurobarometer 1997-2000-2003.

Report 2. European Union Monitoring Center on Racism and Xenophobia

, European Union Monitoring Center on Racism and Xenophobia. 2005c. Majorities' Attitudes Towards Minorities in Western and Eastern European Societies: Results from the European Social Survey 2002-2003. Report 4. European Union Monitoring Center on Racism and Xenophobia

Coenders, Marcel, Marcel Lubbers, and Peer Scheepers. (2005d) Majorities' Attitudes Towards Minorities: Key Findings from the Eurobarometer and the European Social Survey, Summary. Brussels, Belgium: European Monitoring Centre on Racism and Xenophobia.

- - - . (2004) Majority Populations' Attitudes Towards Migrant and Minorities.

Nijmegen, Netherlands: University Institute for Social and Cultural Research.

, European Union Monitoring Center on Racism and Xenophobia. 2005e.

Majority Populations' Attitudes Towards Migrants and Minorities. Report

1. European Union Monitoring Center on Racism and Xenophobia

- - - (2008a) Support for Repatriation Policies of Migrants: Comparisons across and Explanations for European Countries. International Journal of Comparative Sociology \%R 10.1177/0020715208088911 49:175-194.

Coenders, Marcel, Marcel Lubbers, Peer Scheepers, and Maykel Verkuyten. (2008b) More Than Two Decades of Changing Ethnic Attitudes in the Netherlands. Journal of Social Issues 64:269-285.

Coenders, Marcel, and Peer Scheepers. (2003) The Effect of Education on Nationalism and Ethnic Exclusionism: An International Comparison. Political Psychology 24:313-343 
Coleman, James. (1988) Social Capital in the Creation of Human Capital. American Journal of Sociology 94:S95-S120.

Commission, European. (2009) Policy Areas: Justice, Freedom and Security. Brussels: European Union.

Convention for the Protection of Human Rights and Fundamental Freedoms as Amended by Protocol No. 11. (2009): Council of Europe.

Dahl, Robert Alan. (1971) Polyarchy; Participation and Opposition. New Haven,: Yale University Press.

de Ruiter, Rik. (2008) Developing Multilateral Surveillance Tools in the Eu. West European Politics 31:896-914.

, Revenue. 2012. Deelgemeente Begroting 2012 Charlois.

Diamond, Larry Jay, Juan J. Linz, and Seymour Martin Lipset. (1990) Politics in Developing Countries : Comparing Experiences with Democracy. Boulder, Colo.: L. Rienner Publishers.

Dijkstra, Steven, Karin Geuijen, and Arie de Ruijter. (2001) Multiculturalism and Social Integration in Europe. International Political Science Review / Revue internationale de science politique 22:55.

DiStefano, Christine, Min Zhu, and Mindrila. Diana. (2009) Understanding and Using Factor Scores: Considerations for the Applied Researcher. Practical Assessment, Research and Evaluation 14:11.

Doe Mee in Overvecht: Wijkactieprogramma 2012-2013. (2012), p. 22. Utrecht: Wijkactieprogram Gemeente Utrecht.

Doe Mee Overvecht.

Durlauf, Steven, and Marcel Fafchamps. (2004) Social Capital. p. 91: National Bureau of Economic Research.

The E.U.M.C., the Predecessor of the F.R.A. (2007). Vienna, Austria: European Union Agency for Fundamental Rights.

Eisinga, Rob, and Jaak Billiet. (1999) Christian Religion and Ethnic Prejudice in Cross-National Perspective. International Journal of Comparative Sociology (Brill) 40:375.

Eisinga, Rob, Albert Felling, and Jan Peters. (1990) Religious Belief, Church Involvement, and Ethnocentrism in the Netherlands. Journal for the Scientific Study of Religion 29:54.

Engbersen, Godfried, Erik Snel, and Afke Weltfvede. (2005) Social Herovering in Amsterdam En Rotterdam Amsterdam: Amsterdam U P.

Entzinger, Han. (2006) Changing the Rules While the Game Is On: From Multiculturalism to Assimilation in the Netherlands. In Migration, Citizenship, Ethnos: Incorporation Regimes in Germany, Western Europe and North America, edited by Michal Bodemann and Gökçe Yurdakul, pp. 121-144. New York: Palgrave.

- - - (2000) Dynamics of Integration Policies: A Multidimensional Model. In Challenging Immigration and Ethnic Relations Politics : Comparative 
European Perspectives, edited by Ruud Koopmans and Paul Statham, pp. 97-118. Oxford ; New York: Oxford University Press.

The Eumc, the Predecessor of the Fra. (2007). Vienna, Austria: European Union Agency for Fundamental Rights.

, European Union Agency for Fundemental Rights. 2008. European Union Agency for Fundemental Rights Annual Report.

. 2009. European Union Minorities and Discrimination Survey: Main Results Report. European Union Agency for Fundamental Human Rights.

Fundemental Rights Agency, European Union Agency for Fundamental Human

Rights. 2009. European Union Minorities and Discrimination Survey.

Data in Focus Report: Muslims. European Union Agency for

Fundamental Human Rights

European Values Study 1981-2008, Longitudinal Data File. (2011). Cologne GESIS Data Archive.

Evans, Peter. (1989) Pedatory, Developmental and Apparatuses: A Comparative Political Economy Perspective on the Third World State. Sociological Forum 4:561-587.

Evans, Peter B. (1995) Embedded Autonomy. Princeton: Princeton Unversity Press.

EVS. (2011) European Values Survey 1981-2010 Cologne, Germany: GESIS Data Archive.

Fennema, Meindert. (2000) Legal Repression of Extreme-Right Parties and Racial Discrimination. In Challenging Immigration and Ethnic Relations

Politics : Comparative European Perspectives, edited by Ruud Koopmans and Paul Statham, pp. 97-118. Oxford ; New York: Oxford University Press.

Fight against Racism and Xenophobia. (2010). Brussels: European Union. FRA, European Union Agency for Fundemental Rights. 2007a. Report on

Racism and Xenophobia in the Member States of the E.U. European

Union Agency for Fundemental Rights

, European Union Agency for Fundamental Rights. 2007b. Trends and

Developments 1997-2005- Combating Ethnic and Racial Discriminiation

and Promoting Equality in the European Union.

Fukuyama, Francis. (1995a) Social Capital and the Global Foreign Affairs

74:89-103.

- - - (1995b) Social Capital and the Global Economy. Foreign Affairs 74:89-103.

- - - (2001) Social Capital, Civil Society and Development. Third World Quarterly 22:7.

Garson, David G. (2010) Statnotes.

Gesthuizen, Maurice, Peer Scheepers, and Tom van der Meer. (2008) Ethnic Diversity and Social Capital in Europe: Tests of Putnam's Thesis in European Countries. Scandinavian Political Studies Forthcoming. 
Granovetter, Mark. (1985) Economic Action and Social Structure: The Problem of Embeddedness. American Journal of Sociology 91:481-510.

- - - (1983) The Strength of Weak Ties: A Network Theory Revisited. Sociological Theory 1:201-233.

Grimheden, Jonas. 9/1/2007 2007.

Hello, Evelyn, Peer Scheepers, and MÈrove Gijsberts. (2002) Education and Ethnic Prejudice in Europe: Explanations for Cross-National Variances in the Educational Effect on Ethnic Prejudice. Scandinavian Journal of Educational Research 46:5.

Hengeveld, Frans, and Johan Janssens. (2010) Mensen Maken De Stad: Beschrijving Van Goed Practice. p. 32. Utrecht: MOVISIE.

Honaker, James, Gary King, and Matthew Blackwell. (2009) Amelia li: A Program for Missing Data.

Hooghe, Marc, Tim Reeskens, Dietland Stolle, and Ann Trappers. (2006) Ethnic Diversity, Trust, and Ethnocentrism in Europe: And Multilevel Analysis of 21 European Countries. In 102nd Annual Meeting of the American Political Science Association, p. 30. Philadelphia, PA: American Political Science Association.

Hooghe, Marc, Tim Reeskens, Ann Trappers, and Bart Meuleman. (2008) Migration to European Countries: A Structural Explaination of Patterns, 1980-2004. International Migration Review 42:476-504.

Hox, J. J. (2002) Multilevel Analysis : Techniques and Applications. Quantitative Methodology Series. Mahwah, N.J.: Lawrence Erlbaum Associates.

Hutchinson, Judy, Avis C. Vidal, Robert Putnam, Ivan Light, Xavier de Souza Briggs, William M. Rohe, Jennifer Gress, and Michael Woolcock. (2004) Using Social Capital to Help Integrate Planning Theory, Research, and Practice. 70:142.

Iglic, Hajdeja. (2010) Voluntary Association and Tolerance: An Ambiguous Relationship. American Behavioral Scientist 53:717-736.

Ignatieff, Micheal. (1993) Blood and Belonging. New York: Noonday Press. Inglehart, Ronald. (1997) Modernization and Postmodernization : Cultural, Economic, and Political Change in 43 Societies. Princeton University Press.

Ireland, Patrick. (2000) Reaping What They Sow: Institutions and Immigrant Political Participation in Western Europe. In Challenging Immigration and Ethnic Relations Politics : Comparative European Perspectives, edited by Ruud Koopmans and Paul Statham, pp. 234-282. Oxford ; New York: Oxford University Press.

Jagmohansingh, Shanti. 31, January 20122012.

Joined-up Governance: Connecting Fundamental Rights. (2012), pp. Webpage introducing joined-ip governance model. Vienna, : European Union Agency for Fundamental Rights. 
Karpov, Vyacheslav. (1999) Political Intolerance in Poland and the United States. Social Forces 77:1525-1549.

Kemmis, Daniel. (1990) Community and the Politics of Place. Norman: University of Oklahoma Press.

King, G., J. Honaker, A. Joseph, and K. Scheve. (2001) Analyzing Incomplete Political Science Data: An Alternative Algorithm for Multiple Imputation. American Political Science Review 95:49-69.

Kitschelt, Herbert. (2000) Linkages between Citizens and Politicians in Democratic Polities. Comparative Political Studies 33:845.

- - - . (1986) Political Opportunity Structures and Political Protest: AntiNuclear Movements in Four Democracies. British Journal of Political Science 16:57-85.

, Fundemental Rights Agency. 2009. Letter to European Parliament Regarding State Sacntioned Homophobia in Lithuania FRA-Directorate

Kline, Rex B. (2005) Principles and Practice of Structural Equation Modeling. Methodology in the Social Sciences. 2nd ed. New York: Guilford Press.

Knack, Stephen. (2002) Social Capital and the Quality of Government: Evidence from the States. American Journal of Political Science 46:772-785.

Knoke, David. (1999) Organizational Networks and Corporate Social Capital. In Corporate Social Capital and Liability, edited by Roger Th A. J. Leenders and Shaul M. Gabbay, pp. 17-43. Boston: Kluwer Academic.

Koenig, Matthias. (2007) Europeanising the Governance of Religious Diversity: An Institutionalist Account of Muslim Struggles for Public Recognition. Journal of Ethnic \& Migration Studies 33:911.

Konig, Ruben, Rob Eisinga, and Peer Scheepers. (2000) Explaining the Relationship between Christian Religion and Anti-Semitism in the Netherlands. Review of Religious Research 41:373.

Koopmans, Ruud. (1999) Political. Opportunity. Structure. Some Splitting to Balance the Lumping. Sociological Forum 14:93-105.

Koopmans, Ruud, and Paul Statham. (2000) Migration and Ethnic Relations as a Field of Political Contention: An Opportunity Structure Approach. In Challenging Immigration and Ethnic Relations Politics : Comparative European Perspectives, edited by Ruud Koopmans and Paul Statham, pp. 13-56. Oxford ; New York: Oxford University Press.

Koster, Martijn. 7/13/2012 2012.

Kugler, Jacek, and Ronald L. Tammen. (2012) Performance of Governments. Boulder, CO: Rowman-Littlefield.

Linz, Juan J., and Alfred C. Stepan. (1996a) Toward Consolidated Democracies. Journal of Democracy 7:14.

Linz, Juan, and Alfred Stepan. (1996b) Problems of Democratic Transitions and Consolidation. Baltimore: Johns Hopkins University Press. 
Lipset, Seymour Martin. (1959) Some Social Requisites of Democracy: Economic Development and Political Legitimacy

. American Political Science Review 53:69-105.

Lub, Vasco. (2005) Mensen Maken De Stad (People Make the City). In Sociology, p. 90. Rotterdam, NL: Erasmus Universiteit Rotterdam.

Maloney, William A., Jan W. van Deth, and Sigrid Rossdeutscher. (2008) Civic Orientations: Does Associational Type Matter? Political Studies 56:261-287.

Manders, Marja. email, November 1, 20112011.

McKnight, Patrick, Katherine McKnight, Souraya Sidani, and Aurelio Figueredo. (2007) Missing Data: A Gentle Introduction. New York: Guilford Press.

, Onderwijs en Samenleving Dienst Jeugd. 2006. Mensen Maken De Stad: 'Het Vervolg'. City of Rotterdam

Mielants, Eric. (2006) The Long-Term Historical Development of Racist Tendencies within the Political and Social Context of Belgium. International Journal of Comparative Sociology 47:313-334.

Migdal, Joel S. (1988) Strong Societies and Weak States : State-Society Relations and State Capabilities in the Third World. Princeton, N.J.: Princeton University Press.

Mudde, Cas. (2005) Racist Extremism in Central and Eastern Europe. East European Politics \& Societies 19:161.

Nedergaard, Peter. (2007) Maximizing Policy Learning in International Committees: An Analysis of the European Open Method of Coordination (Omc) Committees. Scandinavian Political Studies 30:521-546.

The Netherlands: Discrimination in the Name of Integration Migrants' Rights under the Integration Abroad Act. (2008), p. 43: Human Rights Watch.

Newton, Kenneth. (2001) Trust, Social Capital, Civil Society, and Democracy. International Political Science Review / Revue internationale de science politique 22:201.

Norris, Pippa. (1999) Critical Citizens : Global Support for Democratic Government. Oxford England: New York.

- - - (2002) Democratic Phoenix. Cambridge: Cambridge University Press.

- - - (2005) Radical Right : Voters and Parties in the Electoral Market. Cambridge University Press.

Organski, A.F. K. (1997) Theoretical Link of Political Capacity to Development. In Political Capacity and Economic Behavior, edited by Marina Arbetman and Jacek Kugler, pp. 47-66. Boulder, Colo.: Westview Press.

Participatie Ladder. (2012). Utrecht: DIVOSA.

Participatieladderhelpt Gemeenten Bij Het Maken Van De Juiste Keuzen. (2011), p. Paticipation ladder Utrecht: TNO.

Paxton, Pamela. (2007) Association Memberships and Generalized Trust: A Multilevel Model across 31 Countries. Social Forces 86:47. 
- - - . (1999) Is Social Capital Declining in the United States? A Multiple Indicator Assessment. American Journal of Sociology 105:88-127.

- - - . (2002) Social Capital and Democracy: An Interdependent Relationship. American Sociological Review 67:254-277.

Pennix, Rinus. (1979) Etnische Minderheden. A: Rapport Aan De Regering; B: Naar Een Algemeen Etnisch Minderhedenbeleid? , p. 174. Den Haag: Wetenschappelijk Raadvoor voor het Regeringbeleid.

Peters, Karin. (2011) Living Together in Multi-Ethnic Neighborhoods: The Meaning of Public Spaces for Issues of Social Integration. Wageningen, NL: Wageningen Universtity Press.

- - - (2012) Living Together in Multi-Ethnic Neighborhoods: The Meaning of Public Spaces for Issues of Social Integration. Wageningen, NL: Wageningen Universtity Press.

Poppelaars, Caelesta. (2007) Resource Exchange in Urban Governance: On the Means That Matter. Urabn Affairs Review 43:3-27.

Portes, Alejandro. (1998) Social Capital: It's Origins and Applications in Modern Sociology. Annual Review of Sociology 24:1-24.

- - - . (2000) The Two Meanings of Social Capital. Sociological Forum 15:1.

Przeworski, Adam, and Fernando Papaterra Limongi Neto. (1997) Modernization: Theories and Facts. World Politics 49:155.

Przeworski, Adam, Susan Carol Stokes, and Bernard Manin. (1999) Democracy, Accountability, and Representation. Cambridge, U.K. ;; New York: Cambridge University Press.

Putnam, Robert. (2007) E Pluribus Unum: Diversity and Community on the Twenty-First Century Scandinavian Political Studies 30:137-173.

Putnam, Robert D. (2000) Bowling Alone: The Collapse and Revivial of American Community. New York: Simon and Schuster.

- - - . (1994) What Makes Democracy Work? Why Democratic Governments Succeed in Some Places and Fail in Others. In IPA review, p. 31.

Putnam, Robert D., and Arnaldo Bagnasco. (1996) Making Democracy Work. International journal of urban and regional research 20:359 (7 pages).

Putnam, Robert D., and Marvin B. Becker. (1995) Making Democracy Work: Civic Traditions in Modern Italy. The journal of interdisciplinary history 26:306 (2 pages).

Putnam, Robert D., Lewis M. Feldstein, and Don Cohen. (2003) Better Together: Restoring the American Community. New York: Simon \& Schuster.

Putnam, Robert D., Robert Leonardi, and Raffaella Nanetti. (1993) Making Democracy Work : Civic Traditions in Modern Italy. Princeton, N.J.: Princeton University Press.

Quintelier, Ellen, and Yves Dejaeghere. (2008) Does European Citizenship Increase Tolerance in Young People? European Union Politics \% $R$ 10.1177/1465116508093488 9:339-362. 
Radulova, Elissaveta. (2007) The Omc: An Opaque Method of Consideration or Deliberative Governance in Action. European Integration 29:363-380.

Ram, Melanie H. (2003) Democratization through European Integration: The Case of Minority Rights in the Czech Republic and Romania. Studies in Comparative International Development 38:28-56.

Rechel, Bernd. (2008) What Has Limited the Eu's Impact on Minority Rights in Accession Countries? East European Politics and Societies \%R 10.1177/0888325407311796 22:171-191.

Rex, John. (2000) Multiculturalism and Political Integration in Europe. In Challenging Immigration and Ethnic Relations Politics : Comparative European Perspectives, edited by Ruud Koopmans and Paul Statham, pp. 57-73. Oxford ; New York: Oxford University Press.

Rezai, Sara, and Sander Barendrecht. (2010) De Tweede Generatie in

Rotterdam: Enkele Cijfers En Achtergronden. p. 151. Rotterdam:

Erasmus Universiteit Rotterdam: RISBO

City of Rotterdam

Rice, Tom W., and Jan L. Feldman. (1997) Civic Culture and Democracy from

Europe to America. Journal of Politics 59:1143-1172.

Rotterdam, City of. (2002) Uitgave: Project Stadsetiquette, Gemeente

Rotterdam. p. 57. Rotterdam: City of Rotterdam.

Rotterdam Facts and Figures (2009), p. 33. Rotterdam: Chief Marketing Office Rotterdam.

Sakkers, Hans. 2012.

Scheepers, Peer. 9/17/2007 2007.

Scheepers, Peer, MÈrove Gijsberts, and Evelyn Hello. (2002) Religiosity and

Prejudice against Ethnic Minorities in Europe: Cross-National Tests on a

Controversial Relationship. Review of Religious Research 43:242.

Scheepers, Peer, Manfred Te Grotenhuis, and Frans Van Der Slik. (2002)

Education, Religiosity and Moral Attitudes: Explaining Cross-National

Effect Differences. Sociology of Religion 63:157.

Scholten, Peter. (2011a) Constructing Dutch Immigrant Policy. British Journal of Polits and International Relations 13:92.

- - - . (2009) The Coproduction of Immigrant Integration Policy and Research in the Netherlands: The Case of the Scientific Council for Government Policy. Science \& Public Policy (SPP) 36:561-573.

- - - (2011b) Framing Immigrant Integration. Amsterdam: Amsterdam University Press.

Scholten, Peter, and Ronald Holzhacker. (2009) Bonding, Bridging and Ethnic Minorities in the Netherlands: Changing Discourses in a Changing Nation. Nations and Nationalism 15:19.

Scholten, Peter, and Caelesta Poppelaars. (2008) Two Worlds Apart: The Divergence of National and Local Immigrant Integration Policies in the Netherlands. Administration \& Society 40:22. 
Scholten, Peter, and Arco Timmermans. (2010) Setting the Immigrant Policy Agenda: Expertise and Politics in the Netherlands, France and the United Kingdom. Journal of Comparative Policy Analysis: Research and Practice 12:17.

Semyonov, Moshe, Rebeca Raijman, and Anastasia Gorodzeisky. (2008) Foreigners' limpact on European Societies: Public Views and Perceptions in a Cross-National Comparative Perspective. International Journal of Comparative Sociology 49:5-29.

Snijders, T. A. B., and R. J. Bosker. (1999) Multilevel Analysis : An Introduction to Basic and Advanced Multilevel Modeling. London ; Thousand Oaks, Calif.: Sage Publications.

Sobel, Joel. (2002) Can We Trust Social Capital? Journal of Economic Literature 40:139.

Stepan, Alfred C. (2000) Religion, Democracy, and The "Twin Tolerations". Journal of Democracy 11:37.

Tarrow, Sidney. (1996) Making Social Science Work across Space and Time: A Critical Reflection on Robert Putnam's Making Democracy Work. The American Political Science Review 90:389-397.

- - - . (1998) Power in Movement: Social Movements and Contentious Politics. Cambridge: University of Cambridge Press.

Tarrow, Sidney G. (2005) The New Transnational Activism. Cambridge Studies in Contentious Politics. New York: Cambridge University Press.

Thranhardt, Dietrich. (2000) Conflict, Consensus, and Policy Outcomes: Immigration and Integration in Germany and the Netherlands. In Challenging Immigration and Ethnic Relations Politics : Comparative European Perspectives, edited by Ruud Koopmans and Paul Statham, pp. 162-186. Oxford ; New York: Oxford University Press.

Tilly, Charles. (2005) Trust and Rule. New York: Cambridge University Press.

Togeby, Lise. (2004) It Depends...How Organizational Participation Affects Political Participation and Social Trust among Second Generation Immigrants in Denmark. Journal of Ethnic and Migration Studies 30:509-528.

, European Union Agency for Fundemental Rights. 2007. Trends and Developments 1997-2005- Combating Ethnic and Racial Discrimination and Promoting Equality in the European Union.

TurkStat. (1990-2011) Turkey's Statistical Yearbook. edited by Data Dissemination Group. Ankara, Turkey: Turkish Statistical Institute. Uniform Crime Reports. (2010). Washington, D.C.: Federal Bureau of Investigation.

Van Deth, Jan W. (2003) Measuring Social Capital: Orthodoxies and Continuing Controversies. International Journal of Social Research Methodology 6:79-92. 
van Deth, Jan W., and Sonja Zmerli. (2010) Introduction: Civicness, Equality, and Democracy--A "Dark Side" Of Social Capital? American Behavioral Scientist 53:631-639.

van Kempen, Ronald. (2008) Social Cohesion, Social Mix, and Urban Policies in the Netherlands. In Housing Studies Conference, p. 20. York, England.

van Oers, Ricky, Betty de Hart, and Kees FGroenendijk. (2010) Country Report: The Netherlands. In EUDO Citizenship Observatory, p. 49. Badia Fiesolana, San Domenico di Fiesole , Italy: EUDO Citizenship Observatory, European University Institute.

van Oers, Ricky, Betty de Hart, and Kees Groenendijk. (2010) Country Report: The Netherlands. In EUDO Citizenship Observatory, p. 49. Badia Fiesolana, San Domenico di Fiesole, Italy: EUDO Citizenship Observatory, European University Institute.

Van Oudenaren, John. (2005) Uniting Europe : An Introduction to the European Union. Europe Today. 2nd ed. Lanham, MD: Rowman \& Littlefield.

Velluti, Samantha. (2007) What European Union Strategy for Integrating Migrants? The Role of Omc Soft Mechanisms in the Development of an Eu Immigration Policy. European Journal of Migration \& Law 9:53-82.

Visser, Jelle. (2006) Union Membership Statistics in 24 Countries. Monthly Labor Review:38-49.

Wallis, J., and B. Dollery. (2002) Social Capital and Local Government Capacity. Australian Journal of Public Administration 61:76.

Williams, Dilafruz, Craig Shinn, Masami Nishishiba, and Doug Morgan. (2002) Toward an Understanding of Civic Capacity: An Anatomy of Community Issues That Matter to Students. Journal of Public Affairs 6:241-264.

Wimberley, Ronald C., Donald A. Clelland, Thomas C. Hood, and C.M. Lipsey. (1976) The Civil Religious Dimension: Is It There? Social Forces 54:890-900.

Wood, David, and Birol Yeşilada. (2002) The Emergıng European Unıon. New York: Longman.

Woolcock, Michael. (1998) Social Capital and Economic Development: Toward a Theoretical Synthesis and Policy Framework. Theory and Society 27:151-208.

World Values Survey 1981-2008 Official Aggregate V.20090901, 2009. (2009). Madrid: World Values Survey Association . Aggregate File Producer:ASEP/JDS.

WRR. (1990) Immigrant Policy: Summary of the 36th Report. In Rapporten Aan de Regering, p. 107. The Hague: Wetenschappelijke Raad voor het Regeringsbeleid.

- - - . (2001a) Nederland Als Immigratiesamenleveing. In Rapporten Aan de Regering, p. 264. The Hague: Wetenschappelijke Raad voor het Regeringsbeleid. 
Noordijk

- - - (2001b) Netherlands as Immigrant Society: Summary. In Rapporten Aan de Regering, p. 78. The Hague: Wetenschappelijke Raad voor het Regeringsbeleid.

Zielonka, Jan. (2007) Plurilateral Governance in the European Union. Journal of Common Market Studies 45:187-209. 


\section{APPENDIX A: CalCULATING INTOLERANCE MeAsuRES}

In order to more clearly identify is Inspecting the polychoric correlations of the responses to the questions can identify the relationships between each of the above elements of the "neighbors" scale ${ }^{5}$. The table below shows the polychoric correlations between the different questions, with the standard error shown in the diagonal. The creation of a polychoric correlations table allows for the factor analysis of relationships between the binary variables by generating an estimate of correlations from presumed scalar variables. Using a polychoric correlations matrix allows the use of factor analysis in order to identify underlying latent variables that can contribute to a better understanding of the phenomenon being measured.

Table A.1: Intolerance Component Correlations

\begin{tabular}{|c|c|c|c|c|c|c|}
\hline & $\begin{array}{l}\text { Different } \\
\text { Race }\end{array}$ & $\begin{array}{l}\text { Heavy } \\
\text { Drinker }\end{array}$ & Immigrant & AIDS & $\begin{array}{l}\text { Drug } \\
\text { Addict }\end{array}$ & Homosexual \\
\hline Dif. Race & 1 & 0.01 & 0.00 & 0.00 & 0.01 & 0.01 \\
\hline Heavy Drink & 0.27 & 1 & 0.01 & 0.00 & 0.00 & 0.0 \\
\hline Immigrant & 0.77 & 0.31 & 1 & 0.00 & 0.01 & 0.0 \\
\hline AIDS & 0.57 & 0.46 & 0.55 & 1 & 0.00 & 0.00 \\
\hline Drug Addict & 0.23 & 0.63 & 0.28 & 0.62 & 1 & 0.00 \\
\hline Homosexual & 0.51 & 0.5 & 0.49 & 0.79 & 0.64 & 1 \\
\hline
\end{tabular}

\footnotetext{
${ }^{5}$ Polychoric correlation is a maximum-likelihood estimator of the correlations between ordinal or binary observed variables developed on the assumption that those variables represent a normally distributed latent scalar concept.
} 
The polychoric correlations illustrate the connections between two apparent groupings of the variables, one concentrated on the race or immigrant status of an individual, another on Homosexuality and AIDS status, and to a lesser extent on drug addiction. Analysis of the correlation table using the factor analysis function in SPSS provides an estimate of how the different elements of this scale relate to one another.

Because of its robustness in dealing with minor violations of bivariate normality, Principal Component Analysis was chosen to analyze the correlations matrix and extract two components of intolerance found in the "neighbors" scale (Kline 2005; Garson 2010). The promax rotation allows for the correlation of extracted factors - in keeping with a conception of intolerance that incorporates racial and status components. Table A.2, shows the variance loadings of the different variables on two components of the intolerance scale.

The matrix of pattern loadings is of particular interest as it is the unique variance contributed to the factors by each of the observed variables. The structure and pattern matrices are very close to one another for these two factors because they have a small correlation and the contributions to variance shown in the structure matrix are largely unique to each of the two factors.

Table A.2: Intolerance Loadings Matrices 


\begin{tabular}{|l|l|l|l|l|l|l|}
\cline { 2 - 7 } & \multicolumn{2}{|l|}{ Structure Matrix } & \multicolumn{2}{l|}{$\begin{array}{l}\text { Pattern Matrix (unique } \\
\text { variance) }\end{array}$} & \multicolumn{2}{l|}{ Component Score } \\
\cline { 2 - 7 } & $\begin{array}{l}\text { Behavior to } \\
\text { Race }\end{array}$ & General & $\begin{array}{l}\text { Behavior to } \\
\text { Race } \\
\text { Dimension }\end{array}$ & General & $\begin{array}{l}\text { Behavior to } \\
\text { Race } \\
\text { Dimension }\end{array}$ & General \\
\hline $\begin{array}{l}\text { Different } \\
\text { Race }\end{array}$ & 0.97 & -0.10 & 0.97 & 0.00 & 0.28 & -0.00 \\
\hline Immigrant & 0.96 & -0.18 & 0.95 & -0.09 & 0.27 & -0.04 \\
\hline Homosexuals & -0.22 & 0.92 & -0.13 & 0.91 & -0.04 & 0.47 \\
\hline AIDS Sufferer & 0.02 & 0.94 & 0.11 & 0.95 & -0.03 & 0.49 \\
\hline $\begin{array}{l}\text { Heavy } \\
\text { Drinker }\end{array}$ & -0.87 & -0.27 & -0.90 & -0.35 & -0.26 & -0.19 \\
\hline Drug Addicts & -0.90 & 0.36 & -0.88 & 0.27 & -0.25 & 0.14 \\
\hline Correlation between factors= -.098 & & & \\
\hline $\begin{array}{l}\text { Promax rotation with Kaiser Normalization using Principal Component Analysis } \\
\text { Data: World Values Survey Combined Dataset. 2009. }\end{array}$ & \\
\hline
\end{tabular}

I have named the two factors identified by the different loadings that contribute variance to the two factors "Behavior<>Race" and "General". As can be seen from the pattern matrix, the loadings for the "Behavior<>Race" factor load very strongly and positively with respondents who claimed an objection to neighbors of either a different race or immigrant status. The sexual orientation or AIDS status of individuals only contributes slightly or negatively to the factor. On the other hand, undesirable behaviors of drinking or drug addiction are inversely loaded on this factor. The combination of negative loadings on undesirable behavior with positive loadings for race and immigrants highlights one of the 
strengths of using factor analysis to understand the relationships in the data. This identifies a unique axis of intolerance for people who have specific objections to potential neighbors by race or immigrant status.

Those intolerant of behaviors like drug abuse or to a lesser extent homosexuality are on the left (negative) end of the axis, those who are intolerant of everyone, or no one, fall in the middle, and those with a special intolerance centered on race or immigrant status fall on the right. The loadings indicate the presence of respondents who, instead of having a generalized intolerance for all potential 'undesirables' have a special dislike for different races and immigrants versus the behaviors of people. Imagine how the loadings would work for a particular individual who mentions a problem with both a racial minority and an immigrant but not that of an addict or a heavy drinker; that person would score a maximum score on the Behavior $<>$ Race factor, more than an individual who had expressed uniform intolerance towards everyone.

In order to capture the different components of intolerance in a way that can be used in the models, the Bartlett-regression extraction method available in SPSS. That method turns the pattern matrix into regression coefficients (pattern matrix scores are standardized variance scores) for each factor. It is a less efficient way of conserving information than a structural equation model, but structural equation models are beyond the scope of this project and the loss of 
Noordijk

some explanatory power is compensated by the utility of identifying the underlying factors. 
APPENDIX B: MEMBERShIP QUESTIONS AND RECODING

\begin{tabular}{|c|c|c|}
\hline \multicolumn{3}{|c|}{ Examples of Different Wording for Memberships Questions between EVS and WVS. } \\
\hline Country Year Survey & Question & Question Translated \\
\hline $\begin{array}{l}\text { United Kingdom } 2006 \\
\text { WVS }\end{array}$ & $\begin{array}{l}\text { Now I am going to read off a list of voluntary } \\
\text { organizations. For each one, could you tell } \\
\text { me whether you are an active member, an } \\
\text { inactive member or not a member of that } \\
\text { type of organization? }\end{array}$ & \\
\hline $\begin{array}{l}\text { United Kingdom } 2000 \\
\text { EVS }\end{array}$ & $\begin{array}{l}\text { Please look carefully at the following list of } \\
\text { voluntary organizations and say... } \\
\text { a) to which if any you belong? } \\
\text { b) which, if any, you are currently doing } \\
\text { voluntary work for? }\end{array}$ & \\
\hline Netherlands 2006 WVS & $\begin{array}{l}\text { Nu lees ik een lijst voor van organisaties/ } \\
\text { verenigingen. Kunt u voor elke organisatie } \\
\text { aangeven of u een actief lid bent, een } \\
\text { inactief lid of geen lid van dat type } \\
\text { organisatie? }\end{array}$ & $\begin{array}{l}\text { Now I am reading a list of } \\
\text { organizations/associations. } \\
\text { For each one, could you tell } \\
\text { me whether you are an } \\
\text { active member, an inactive } \\
\text { member or not a member of } \\
\text { that type of organization? }\end{array}$ \\
\hline Netherlands 1999 EVS & $\begin{array}{l}\text { Op KAART } 5 \text { staat een lijst met organisaties } \\
\text { en activitien. } \\
\text { a) Wilt u voor elk daarvan aangeven of u er } \\
\text { lid bent of er aan mee doet? } \\
\text { b) Doet u voor een van deze organisaties of } \\
\text { activiteiten onbetaald vrijwilligerswerk? } \\
\text { Voor welke? }\end{array}$ & $\begin{array}{l}\text { On card } 5 \text { there is a list of } \\
\text { organizations and activities. } \\
\text { a) For each, will you } \\
\text { indicate whether you are } \\
\text { a member or engage in } \\
\text { the activity? } \\
\text { b) Do you do unpaid } \\
\text { voluntary work for any of } \\
\text { these organizations or } \\
\text { activities? For which? }\end{array}$ \\
\hline
\end{tabular}


Examples of Different Wording for Memberships Questions between EVS and WVS.

\begin{tabular}{|c|c|c|}
\hline Country Year Survey & Question & Question Translated \\
\hline Turkey 2001 EVS & $\begin{array}{l}\text { Siz dernek, vakıf, sendika siyasi parti veya } \\
\text { bunun gibi herhangi bir gönülü kuruluşa üye } \\
\text { misiniz? } \\
\text { If yes then... } \\
\text { Şimdi size çeşitli alanlarda bazı gönüllü } \\
\text { kuruluşlar sayacağım. } \\
\text { a. Bu alanlarda çalışan bir kuruluşlar, } \\
\text { derneğe vakfa vs. üye olup olmadığınızı } \\
\text { b. Eğer üye iseniz bu kuruluş için para } \\
\text { almadan, gönüllü olarak bazı faaliyetler, } \\
\text { çalışmalar yapıp yapmadığınızı söyleyinizi }\end{array}$ & $\begin{array}{l}\text { Are you a member of a club, } \\
\text { faith-based charity, labor } \\
\text { union, political party, or any } \\
\text { similar voluntary } \\
\text { organization? } \\
\text { Now I will say my list of } \\
\text { some voluntary } \\
\text { organizations of various } \\
\text { kinds to you. } \\
\text { a. For each of the various } \\
\text { activities, organizations } \\
\text { and foundations working } \\
\text { in this field of activities, } \\
\text { are you a member or not? } \\
\text { b. If a member, could you } \\
\text { say whether or not you } \\
\text { worked in this } \\
\text { organization without } \\
\text { receiving pay or did some } \\
\text { volunteer activities? }\end{array}$ \\
\hline Turkey 2000 WVS & $\begin{array}{l}\text { Şimdi size çeşitli gönüllü kuruluşlardan } \\
\text { oluşan bir liste okuyacağım. Bu listede } \\
\text { değişik türde gönüllü kuruluşlar (örneğin } \\
\text { dernek, vakıf ve benzeri) var. Okuduğum her } \\
\text { gönüllü kuruluş için, üye olup olmadığınızı } \\
\text { belirtiniz. Eğer bu tür bir gönüllü kuruluşa } \\
\text { üye iseniz, aktif yani faal bir üye misiniz, } \\
\text { yoksa pasif yani faaliyetlere pek katılmayan } \\
\text { bir üye mi? }\end{array}$ & $\begin{array}{l}\text { Now I am going to read a list } \\
\text { of a variety of voluntary } \\
\text { organizations to you. There } \\
\text { are a variety of different } \\
\text { organizations on the list } \\
\text { (groups like, associations, } \\
\text { foundations, religious } \\
\text { organizations for example). } \\
\text { For each voluntary } \\
\text { organization I read, tell me if } \\
\text { you are a member or not. If } \\
\text { you are a member of such } \\
\text { an organization, whether you } \\
\text { are an active member, or a } \\
\text { passive member who does } \\
\text { not participate in many } \\
\text { activities? }\end{array}$ \\
\hline
\end{tabular}


APPENDIX C: SOCIAL CAPITAL

Memberships Responses Compared.

The World Values Surveys and European Values Studies use slightly

different wording in the questions used to explore participation in social

organizations. This section explains how both studies were rectified to include data from all available countries and years.

A look at the dendrograms in figures 3.6 and 3.7 below, show the similarity of relationships between the groups for both survey instruments, with both reflecting the same clusters of organizations appearing among respondents. The political party memberships, environmental group membership, professional organization and human right organization memberships cluster together within five steps while the education and arts connect at 11 steps. The dendrograms indicate that membership in voluntary organizations tend cluster together, except for union membership and religious organization membership. The graph for waves using the EVS wording is first, and WVS wording is below it. 


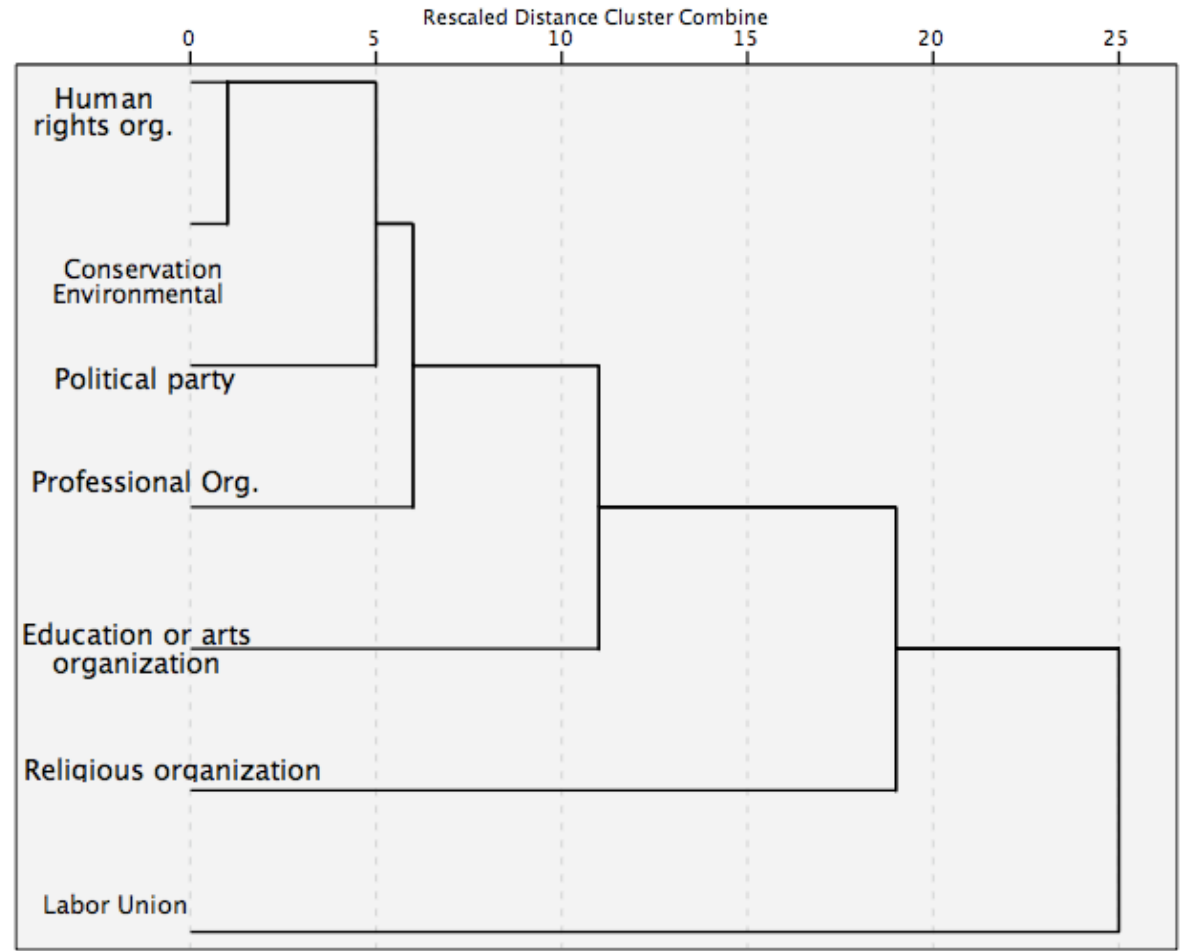

WORLD VALUES SURVEY 1981-2008 OFFICIAL AGGREGATE v.20090901, 2009. (2009).

Figure C.1 :Cluster Diagram for Membership Question from European Values Survey: Waves 2 and 4 


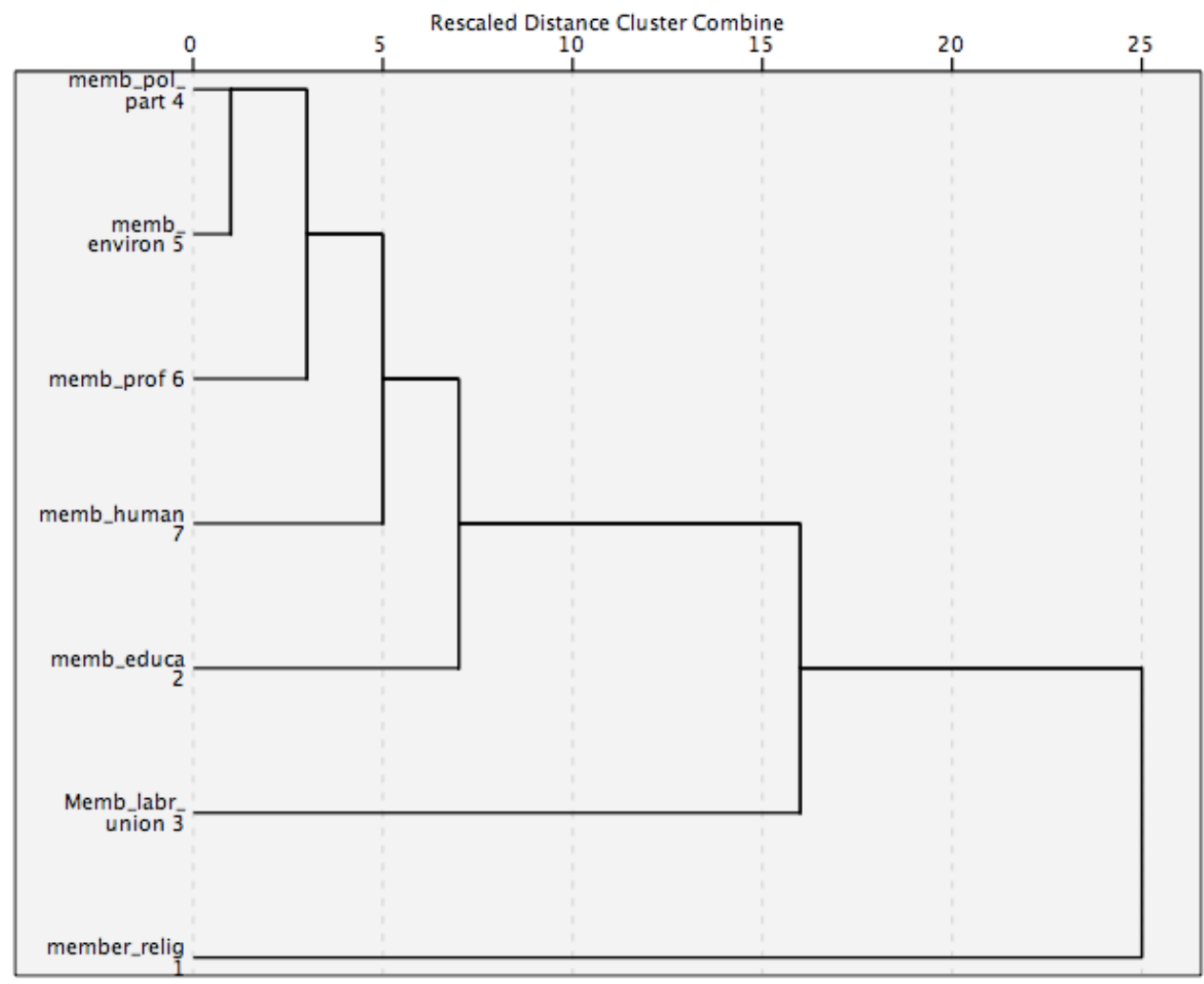

WORLD VALUES SURVEY 1981-2008 OFFICIAL AGGREGATE v.20090901, 2009. (2009).

Figure C.2: Cluster Diagram for Membership Question from World Values Survey: Waves 1,3 and 5

In order to make the responses from the different survey instruments available in the EVS and WVS comparable, the membership variables for the WVS were recoded to reflect the binary coding of the EVS questionnaires. The wording of the WVS instruments offers the respondents the choice of claiming "active" or "inactive" membership versus simply being asked to self-identify as a member, or not, is the EVS questionnaire. Given the choice of being an inactive member, the 
WVS instruments consistently return a much higher level of membership than the EVS, even in the few cases where a clear trend is visible in the EVS surveys. In order to bring the scales to a similar range and level, if a respondent was coded as an active or inactive member, the answer was recoded to member. This is closer to the wording of the questions about membership in the EVS survey instruments and it also creates a binary variable, instead of the 0-2 three point scale in the WVS questionnaires. With the two variables adjusted to the same scale and similar wording it is possible to compare the relationships between membership types and other elements of social capital within countries for individuals. as well as other parts of the proposed model for individuals within countries, and between countries for the two different waves, but not between countries for all the waves. Each analysis of the models includes a dummy for the wave of the survey instrument, the multi-level models returned non-significant effects of instrument

\section{Testing the External Validity of Membership Questions}

Because of the challenges associated with the slightly different wording of the two questionnaires used in the surveys, I tested both the external validity of the self-reporting membership variables, and compared the effects of the two different survey instruments. To do this, I ran a regression of the self-reporting of labor union membership contained in the WVS/EVS instruments against union 
membership data for seventeen European countries as reported in a 2006

Monthly Labor Review article (Visser 2006). Visser describes union density as the number of union members divided by all wage and salary earners collected from government administrative data or labor surveys (2006, 40-41).

Table B.1 : Analyzing Effect of Changes in Wording for Union Membership Questions

\begin{tabular}{|l|l|l|l|l|l|}
\hline Model & & $B$ & Std. Error & $\beta$ & Sig. \\
\hline \multirow{2}{*}{\begin{tabular}{l} 
Adj. $\mathrm{R}^{2}=65$ \\
\cline { 2 - 6 }
\end{tabular}} & (Constant) & 0.179 & 0.035 & & 0 \\
\cline { 2 - 6 } & $\begin{array}{l}\text { Combined WVS and } \\
\text { EVS Reported }\end{array}$ & 1.246 & 0.14 & 0.812 & 0 \\
\hline $\begin{array}{l}2 \\
\text { Adj. } \mathrm{R}^{2}=.73\end{array}$ & (Constant) & 0.2 & 0.032 & & 0 \\
\cline { 2 - 6 } & $\begin{array}{l}\text { Combined WVS and } \\
\text { EVS Reported }\end{array}$ & 1.39 & 0.129 & 0.906 & 0 \\
\cline { 2 - 6 } & Survey dummy WVS $=1$ & -0.166 & 0.046 & -0.304 & 0.001 \\
\hline
\end{tabular}

a. Dependent Variable:Reported Union Density

$\mathrm{N}=42$, Source: WORLD VALUES SURVEY 1981-2008 OFFICIAL AGGREGATE v.20090901, 2009. (2009).. Visser, J. (2006). Union Membership Statistics in 24 Countries. Monthly Labor Review, 38-49.

Table B.1 above contains the results of the analysis. The results illustrate how well each of the survey instruments match up to labor union statistics produced by European governments. The model adjusted $\mathrm{R}^{2}$ of .73 indicates that even for the low number of cases, the variation in combined WVS and EVS questions predicts seventy-three percent of the variance in recorded union density for each country each year that both data sets were available. The intercept of . 197 illustrates that the EVS data appears to slightly overestimate the union 
membership rates. The slope for the combined questionnaire is greater than one, indicating that the combined variable tends to overestimate membership.

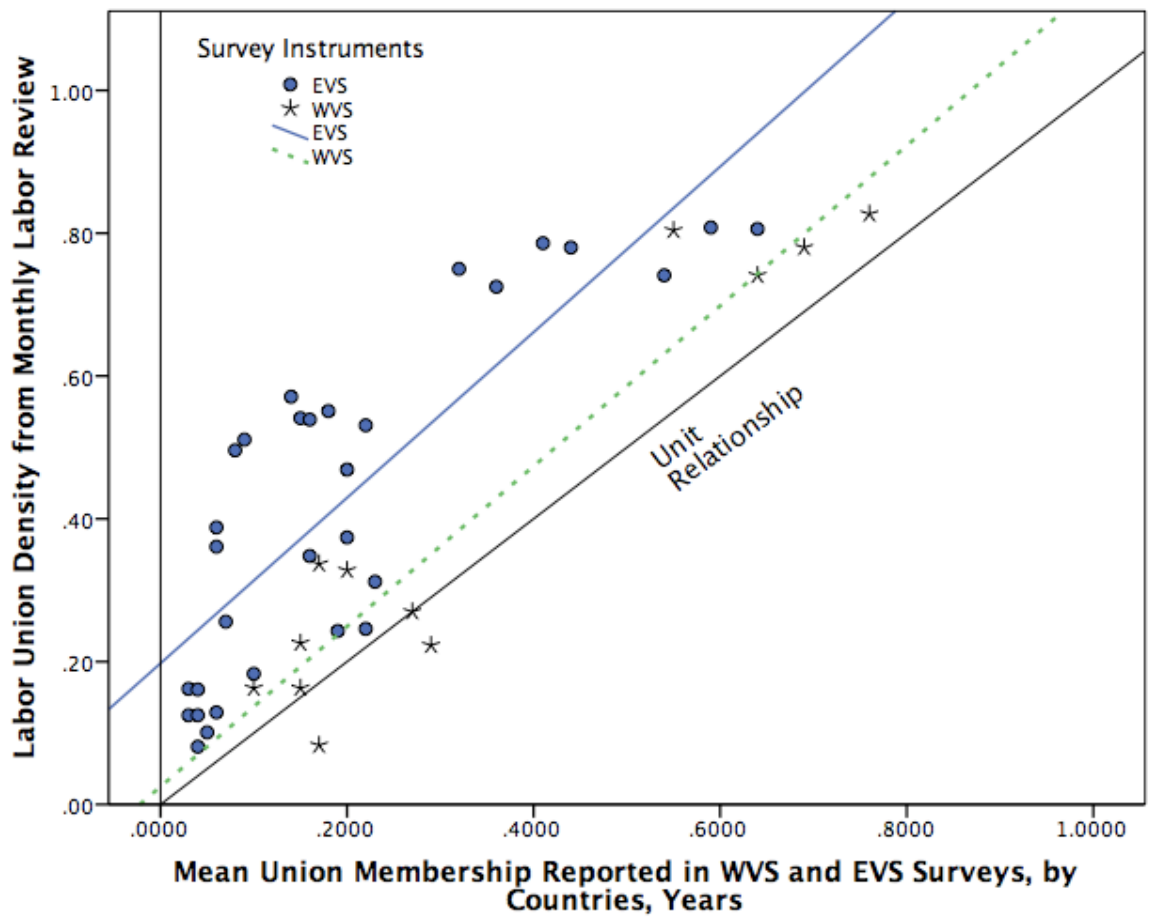

Figure C.1: Survey Measure of Union Membership Compared to Union Reported Membership

Figure C.1 contains the mean union membership reported for each country year sorted by survey instrument and charted against the union density for each country, each year, reported in Visser (2006). The top solid line is the mean slope for the European Values Survey questionnaire and the dotted line is the slope for the World Values Survey questions. Both are parallel to the unit relationship line, but at different levels. The WVS questions (including both active inactive member 
options) is closer to the recorded union membership density. Figure C.2 illustrates the unstandardized predictors from the model with unified membership coding and the inclusion of the dummy term for the survey instrument. The second model shifts the slope very close to a unit relationship. As illustrated, when adjusted for the survey type and the predicted slope line is almost exactly overlain on the unit relationship predictor line for union membership (unit slope).

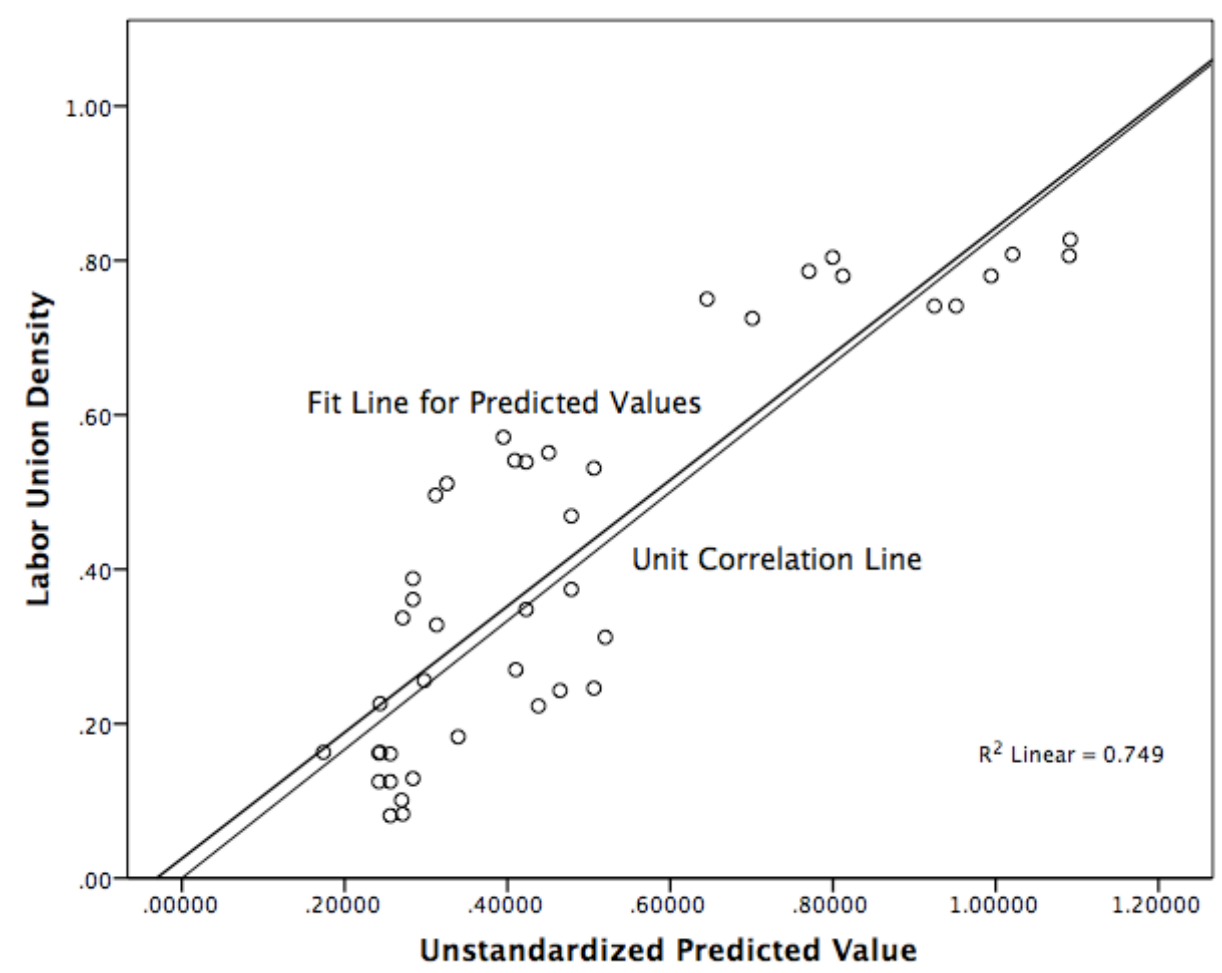

Flgure C.2: Fit Line of Union Membership Reported in WVS Survey 


\section{Importance Of Family And Friends}

The importance of family and friends questions, plus the generalized trust question comprise the indicators for forms of social participation and trust--

elements of social capital. All the indicators in table C.2, except the importance of family variable, exhibited normal distributions. The importance of family variable had heavy kurtosis (kurtosis score of 10). Eighty-five percent of respondents reported family as being very important, with another ten percent responding that family is somewhat important. An inverse power transformation using $(\mathrm{ki} \wedge(1 / \mathrm{ki})$, reduced the reported kurtosis to less than 3 (2.10), while preserving the distribution and standard error.

Table C.2: Importance of Family and Friends, and Trust

\begin{tabular}{|c|c|c|c|}
\hline & $\begin{array}{l}\text { Important in } \\
\text { life: Friends }\end{array}$ & $\begin{array}{l}\text { Most People } \\
\text { can be trusted }\end{array}$ & $\begin{array}{l}\text { Important in life: } \\
\text { Family (transformed) }\end{array}$ \\
\hline $\begin{array}{l}\text { Important in life: Friends } \\
(1=\text { Very, } 4=\text { Not at All) }\end{array}$ & 1 & $.121^{* *}$ & $.146^{* *}$ \\
\hline $\begin{array}{l}\text { Most People can be trusted } \\
(1=\text { Yes, } 2=\mathrm{No})\end{array}$ & $.119^{* \star}$ & 1 & $-.012^{* \star}$ \\
\hline $\begin{array}{l}\text { Important in life: Family } \\
\text { (transformed) }\end{array}$ & $.146^{* \star}$ & $-.010^{* *}$ & 1 \\
\hline \multicolumn{4}{|c|}{$\begin{array}{l}* * \text {. Correlation is significant at } p<.01 \text {. } \\
\text { Pearson correlation except Most People Can be Trusted (Spearman for non- } \\
\text { parametric correlation.) } \\
\mathrm{N}=71170<>83212 \\
\text { WORLD VALUES SURVEY 1981-2008 OFFICIAL AGGREGATE v.20090901, 2009. (2009). }\end{array}$} \\
\hline
\end{tabular}

The table reports the correlations of each indicator with one another and The correlations between the variables are fairly low and attempts to identify 
factors showed no clear pattern, indicating that each variable is measuring a unique phenomenon or that they are interacting in a way that prohibits easy interpretation. The slight and negative correlation between the Trust question and the Importance of Family variable is noteworthy as it illustrates the conceptual difference between within group trust and more diffuse forms of trust. The diffuse forms of trust are those more generally associated with benevolent forms of social capital.

\section{Confidence in Government}

The cluster analysis results are illustrated by the dendrogram below (figure C.4). The dendrogram reinforces the patterns evident in the correlations table.

Confidence in parliament and confidence in the civil services clustered together immediately. The police and armed forces clusters were merged much later.

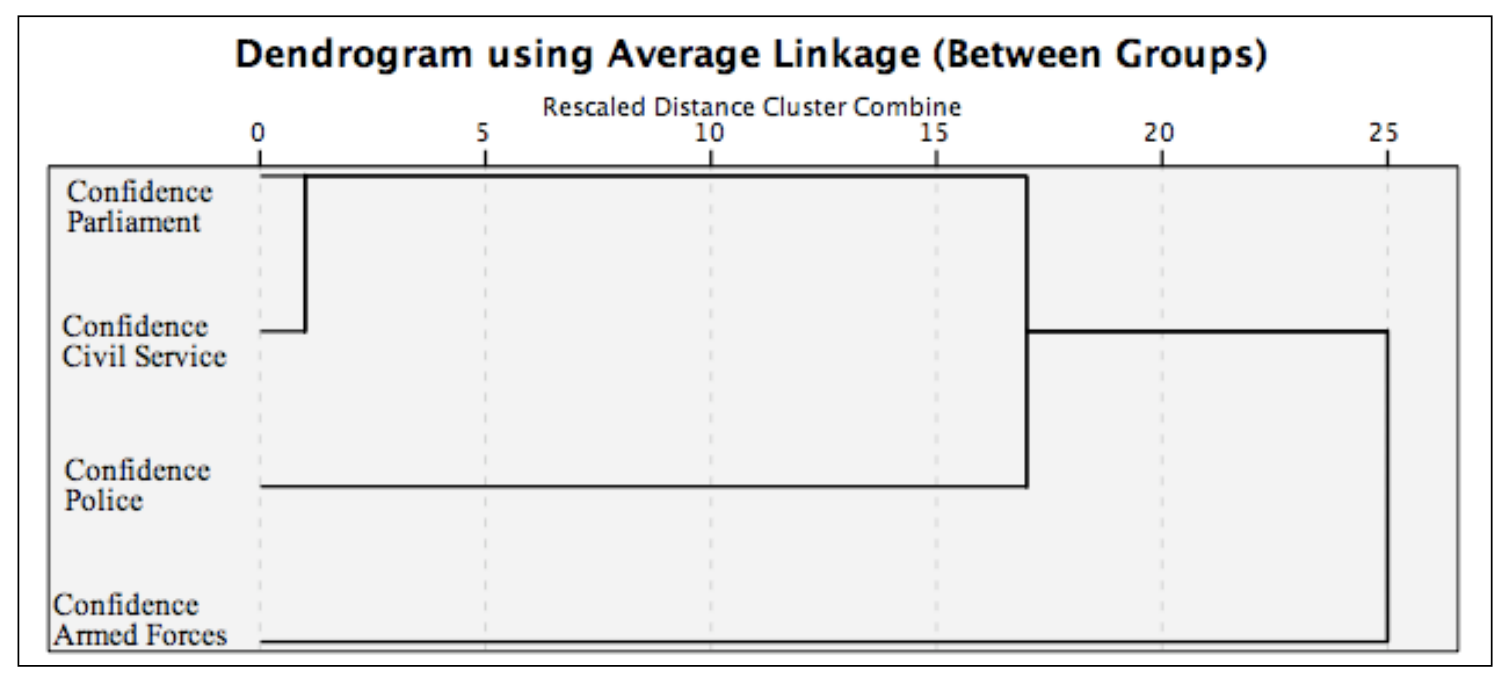

Figure C.4: Official Confidence Clusters 
Factor analysis following up on the initial reviews of the data revealed groupings of the variables similar to that of the cluster analysis. The table below provides the factor loadings in the structure matrix, unique variance accounted for by each of the factors is displayed by the pattern matrix, and finally the factor coefficients used to derive the two factor variables are in the last columns. For principal axis factoring using an oblique rotation (allowing correlation between factors), the pattern matrix provides the best information for identifying the underlaying latent structure. In the pattern matrix for the official trust scale of questions two clear patterns emerge. The first confidence factor explains much of the unique variance for confidence in the parliament and the civil service, with a slight reverse relationship with confidence in the armed forces. The second factor is slightly less well defined but still distinct. The loadings in the pattern matrix center on the confidence in the armed forces and confidence in the police and almost no cross-loading on the other two indicators. Correlation between the two factors is .69, which indicates that respondents with confidence in government institutions generally extend that confidence to the different branches. The table below contains the Pearson correlations between the different questions.

Table C.3: Public Institutions Confidence Correlations

\begin{tabular}{|l|r|r|r|r|}
\hline & Armed Forces & The Police & Parliament & Civil Services \\
\hline Armed Forces & 1 & $\mathrm{n}=81311$ & 79767 & 79251 \\
\hline The Police & $.383^{\star *}$ & 1 & 80950 & 80381 \\
\hline Parliament & $.260^{\star *}$ & $.430^{* *}$ & 1 & 79622 \\
\hline
\end{tabular}




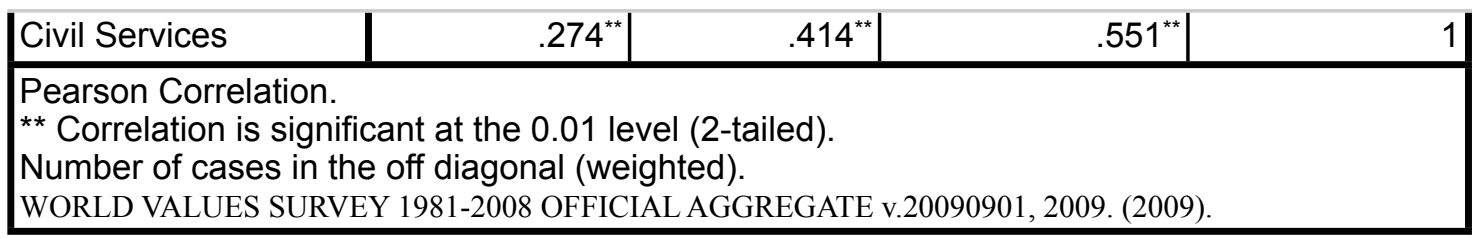

In order to tease out the different types of relationships among the confidence indicators I conducted two analyses; first, a hierarchical cluster analysis followed by factor analysis to further understand the relationships between the variables and derive factors that capture the different dimensions of confidence in government. The coefficients derived and used to calculate the two factors are provided in the table. They show that the first factor weights confidence in the parliament the most (.78), and gives lesser but positive weight to confidence in the civil service responses (.5) and the police respectively (.11). However, individuals' responses to confidence in the armed forces are reverse weighted and weak (-.08). This means that people with low confidence in parliament and the civil service but higher confidence in the armed forces will score higher in this factor than someone with equally low regard for all branches. Conversely, the second factor weights heavily on both the armed forces and police confidence variables, and reverse weights parliament confidence and all but ignores the civil service responses. The first factor is more of a general confidence factor, while the second highlights confidence in authority institutions than governance institutions. 
Table C.4: Official Confidence Factor Dimensions

\begin{tabular}{|c|c|c|c|c|c|c|}
\hline & \multicolumn{2}{|c|}{$\begin{array}{l}\text { Structure Matrix } \\
\text { (loadings) }\end{array}$} & \multicolumn{2}{|c|}{$\begin{array}{l}\text { Pattern Matrix } \\
\text { (unique variance) }\end{array}$} & \multicolumn{2}{|c|}{ Factor Coefficients } \\
\hline & Civil Parl & $\begin{array}{l}\text { Police } \\
\text { Army }\end{array}$ & Civil Parl & $\begin{array}{l}\text { Police } \\
\text { Army }\end{array}$ & Civil Parl & $\begin{array}{l}\text { Police } \\
\text { Army }\end{array}$ \\
\hline Confidence: Armed Forces & 0.353 & 0.572 & -0.074 & 0.623 & -0.070 & 0.815 \\
\hline Confidence: The Police & 0.562 & 0.672 & 0.190 & 0.542 & 0.109 & 0.885 \\
\hline Confidence: Parliament & 0.776 & 0.503 & 0.812 & -0.054 & 0.796 & -0.179 \\
\hline $\begin{array}{l}\text { Confidence: The Civil } \\
\text { Services }\end{array}$ & 0.698 & 0.508 & 0.660 & 0.055 & 0.496 & 0.057 \\
\hline Factor Correlation & & & & & & 0.415 \\
\hline \multicolumn{7}{|c|}{$\begin{array}{l}\text { Extraction Method: Principal Axis Factoring. Rotation Method: Promax with Kaiser Normalization. } \\
\text { Factor Scores Method: Bartlett. } \\
\text { Questions are coded: } 1=\text { Great Deal of Confidence,4=None } \\
\text { Source: WORLD VALUES SURVEY 1981-2008 OFFICIAL AGGREGATE v.20090901, 2009. (2009). }\end{array}$} \\
\hline
\end{tabular}




\section{APPENDIX D: EstimATING RELIGIOSITY}

Because the literature indicates that there are at least two dimensions of religiosity that may have bearing on intolerance, factor analysis was conducted to extract them. Those two dimensions, a personal religiosity and institutionaldoctrinal dimension did not emerge from the data as explaining a great deal of independent variation.

Table D.1: Unique Loadings for Factor Analysis of Religion Variables

\begin{tabular}{|c|c|c|}
\hline Pattern Matrix ${ }^{a}$ & Personal Religiosity & Institutional Religiosity \\
\hline $\begin{array}{l}\text { How often do you attend religious } \\
\text { services? }\end{array}$ & 0.219 & 0.548 \\
\hline Important in life: Religion & 0.703 & 0.167 \\
\hline Confidence: Churches & 0.222 & 0.544 \\
\hline $\begin{array}{l}\text { How important is God in your life } \\
\text { (reversed and rescaled.) }\end{array}$ & 0.696 & 0.178 \\
\hline Eigenvalues & 2.9 & 0.45 \\
\hline \multicolumn{3}{|c|}{$\begin{array}{l}\text { Responses coded with lower values indicating more intense religiosity. } \\
\text { Extraction Method: Principal Axis Factoring; Rotation Method: Promax with Kaiser Normalization; } \\
\text { Rotation converged in } 3 \text { iterations. World Values Survey 1981-2008 Official Aggregate v.20090901, } \\
\text { 2009. (2009). }\end{array}$} \\
\hline
\end{tabular}

A scale of the religiosity items was created using the four religiosity indicators and reversing them. Unfortunately, a straightforward sum of the religiosity variables is problematic as the "Importance of God" measure has a multi-peaked distribution at the ends and in the middle that makes it somewhat platykurtotic (-1.32). Those extreme values carried over into the summed scale and flattened the distribution. To calculate the measure of religiosity I created an 
additive scale using standardized indicators of top three items in table 3.13 above.

Then I multiplied the three item scale by the absolute value of the standardized "Importance of God in your life" indicator, effectively using the "Importance of God" measure to weight the intensity and reverse the scale of the other indicators. The resulting distribution is illustrated in figure D.1 below. It still retains some of the peakedness of the summed scale, but has a much more normal distribution with a skewness of -.33 , and kurtosis -.23 , well within the normal range for social science statistics.

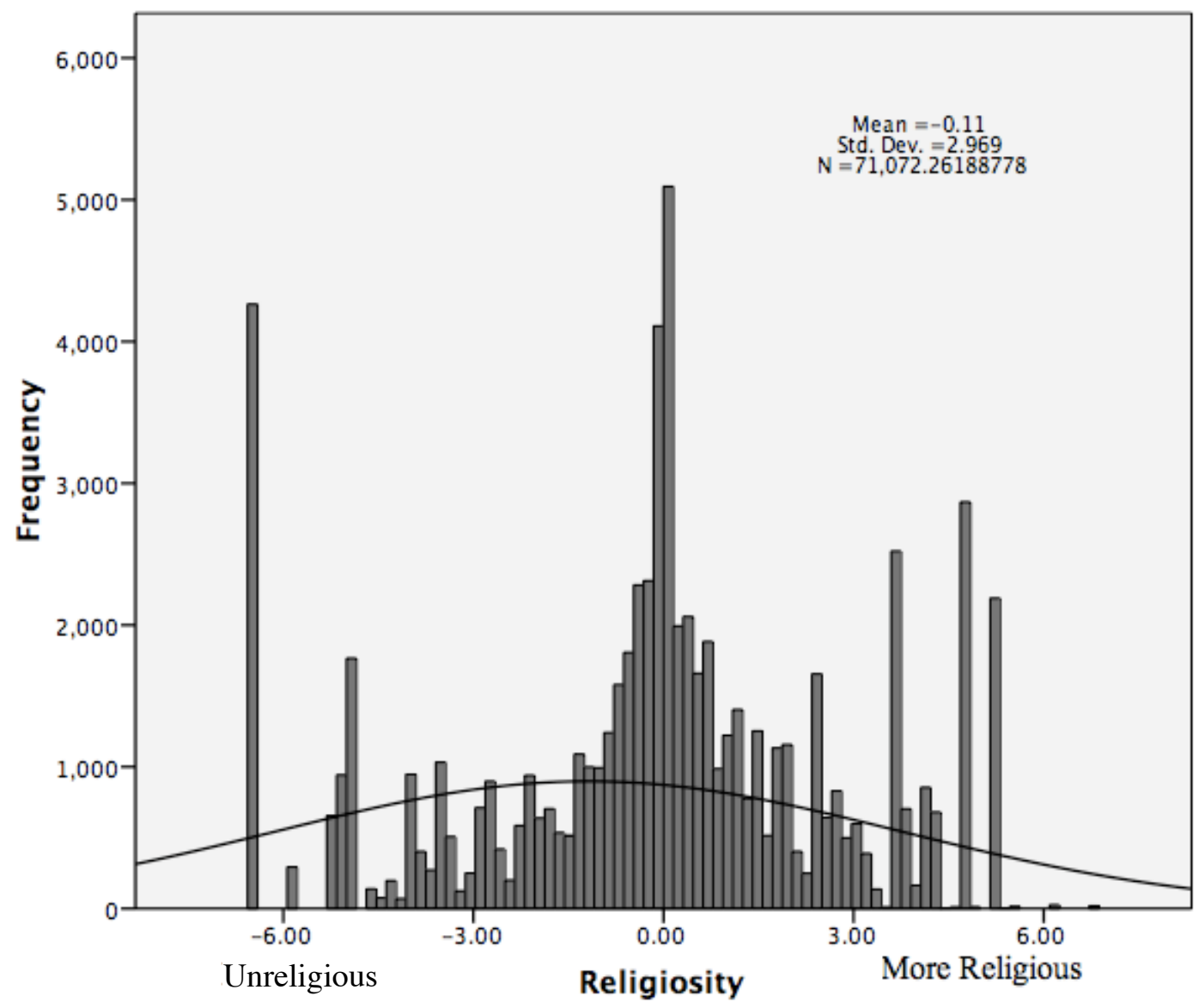


Figure D.1: Frequency Distribution of Religiosity Indicator 


\section{APPENDIX E: CALCULATING RPE}

The table below illustrates the results of the regression equations described in the literature review above for relative political extraction. The table shows the unstandardized coefficients for component of relative political extraction.

Table E.1: Regression Model of Relative Political Extraction

\begin{tabular}{|c|c|c|}
\hline \multicolumn{2}{|l|}{ RPE 1986-2008 } & \multirow{2}{*}{$\begin{array}{l}\text { RPE-soc security } \\
\text { Standardized } \beta\end{array}$} \\
\hline & Standardized $\beta$ & \\
\hline Intercept & 0.378 & \\
\hline Mining/GDP & 0.03 & -0.237 \\
\hline Export/GDP & -0.046 & 0.210 \\
\hline Oil Prod. 1000 bbl/d & -0.180 & 0.211 \\
\hline Agriculture/GDP & -0.574 & -0.366 \\
\hline GDP/Capita & 0.220 & -0.12 \\
\hline $\mathrm{N}=470$ & Adjusted $\mathrm{R}^{2}=.515$ & Adjusted $\mathrm{R}^{2}=.232$ \\
\hline \multicolumn{2}{|c|}{ Dependent Variable is Total Revenues - Tariffs. Total revenues-soc sec - tariffs. } & \\
\hline \multicolumn{3}{|c|}{$\begin{array}{l}\text { Sources: Gross Domestic Product by sector from OECD members SourceOECD, non-OECD members } \\
\text { data from EUROSTAT tables using similar accounting methodology. Per Capita GDP from World } \\
\text { Bank World Development Indicators database, using PPP at USD terms at year } 2005 \text { values. Revenue } \\
\text { data is from SourceOECD database for OECD members, others from EUROSTAT. Oil production } \\
\text { data is from the International Energy Agency, http://www.iea.org/stats/index.asp. }\end{array}$} \\
\hline
\end{tabular}

In table E.2 below the mean political extraction for each of the countries

over the available years of the studies is reported. Again the values are derived controlling for level of economic development, so the RPE of .026 for Romania does not mean that Romania has the same political capacity as Finland's .029 in absolute terms. Rather it means that for its level of development, Romania has a 
higher than average political capacity, but not nearly the resources for policy that are available to the Dutch.

Table E.2: Mean Relative Political Extraction, By Country.

RPE Total Tax Revenue Minus Tariffs

\begin{tabular}{|c|c|c|c|c|c|}
\hline Country & Mean & $N$ & Country & Mean & $N$ \\
\hline Austria & 0.029 & 22 & Italy & 0.015 & 22 \\
\hline Belgium & 0.059 & 22 & Latvia & -0.043 & 13 \\
\hline Bulgaria & 0.044 & 13 & Lithuania & -0.040 & 11 \\
\hline Cyprus & -0.055 & 13 & Netherlands & 0.029 & 22 \\
\hline $\begin{array}{l}\text { Czech } \\
\text { Republic }\end{array}$ & 0.008 & 12 & Poland & -0.003 & 17 \\
\hline Denmark & 0.085 & 22 & Portugal & -0.057 & 22 \\
\hline Estonia & -0.027 & 10 & Romania & 0.026 & 13 \\
\hline Finland & 0.052 & 22 & Slovenia & 0.035 & 15 \\
\hline France & 0.036 & 22 & Spain & -0.045 & 22 \\
\hline Germany & -0.035 & 22 & Sweden & 0.092 & 22 \\
\hline Greece & -0.031 & 22 & Turkey & -0.038 & 22 \\
\hline Hungary & 0.057 & 17 & \begin{tabular}{|l|} 
United \\
Kingdom
\end{tabular} & -0.013 & 22 \\
\hline Ireland & -0.036 & 22 & & & \\
\hline
\end{tabular}

Sources: Gross Domestic Product by sector from OECD members SourceOECD, non-OECD members data from EUROSTAT tables using similar accounting methodology. Per Capita GDP from World Bank World Development Indicators database, using PPP at USD terms at year 2005 values. Revenue data is from SourceOECD database for OECD members, others from EUROSTAT. Oil production data is from the International Energy Agency, http:// www.iea.org/stats/index.asp. 


\section{APPENDIX F: Missing Data IN THE MOdeL}

The data were examined for missing values on the concept of intolerance and the components of social capital. Dummy variables of the each of the relevant indicators were created with the value of 0 indicating a valid response, and 1 indicating a missing response. The missing values dummy variable for the intolerance scale were then correlated with demographic variables and other indicators to identify significant deviations from a random distribution of missing values (McKnight, McKnight, Sidani and Figueredo 2007). The dataset was divided by each country and each wave of the survey in order to control for data missing from entire sub-samples, that would then manifest as a significant relationship between demographics and intolerance despite not being present in the model.

The results of the first test for influence of missing data on the intolerance scale are included in table F.1. The table reveals that the relationship between missing variables and Intolerance does show some associations, that is, the value of Intolerance is not associated with missing values at random. 
Table F.1: Test for Completely at Random Distribution Missing Data

\begin{tabular}{|c|c|c|c|c|}
\hline & Intolerance & $\begin{array}{l}\text { Bridging } \\
\text { Trust }\end{array}$ & $\begin{array}{c}\text { Confidence in } \\
\text { Civil } \\
\text { Government }\end{array}$ & $\begin{array}{l}\text { Overall proportion } \\
\text { missing }\end{array}$ \\
\hline Gender missing & 0.00 & $-.009 * *$ & 0.00 & 0.00 \\
\hline Age missing & 0.00 & -0.01 & -0.01 & 0.00 \\
\hline Income missing & $-.053 * *$ & $.010 * *$ & $-.012 * *$ & 0.18 \\
\hline $\begin{array}{l}\text { Self-identified political } \\
\text { position }\end{array}$ & $.064 * *$ & $.132 * *$ & $.068 * *$ & 0.20 \\
\hline Religiosity missing & $-.008 *$ & $.023 * *$ & $.023 * *$ & 0.06 \\
\hline Bridge trust missing & $-.011 * *$ & & & 0.07 \\
\hline $\begin{array}{l}\text { Confidence in Civ. Gov. } \\
\text { (Missing) }\end{array}$ & 0.00 & $.065 * *$ & & 0.06 \\
\hline \multicolumn{5}{|c|}{$\begin{array}{l}\text { Kendall's tau-b for non-parametric correlations. The row variables in the left column are all dummy } \\
\text { coded } 1=\text { missing, } 0=\text { recorded. } \\
\text { **. Correlation is significant at the } 0.01 \text { level ( } 2 \text {-tailed). } \\
\text { *. Correlation is significant at the } 0.05 \text { level (2-tailed). } \\
\text { a. Listwise } \mathrm{N}=74230\end{array}$} \\
\hline
\end{tabular}

In order to ensure that the relationships noted above are not simply artifacts of the data, the tau-b correlations were examined by country-year as well. While some of the correlations between missing data and the dependent variables, are artifacts of complete waves of missing data for a few countries, the two variables with the strongest relationship, are not. The relationships indicate that some steps to rectify the potential, albeit minor, distortion of parameters caused by missing 
data. As a further tests of missingness on components of social capital are also included as columns in the table. Finally the rate of missing data is included in the final column, illustrating the general very low rate of missing data. The one area with a high level of missing data was educational attainment.

\section{Missing Education}

For the 1989-1991 wave, a number of the European Values Survey countries only collected education data in terms of the age of completion of education instead of highest level of education achieved. The table below indicates the distribution of the missing variable by country and wave. Also in the table is the r-square of a regression equation that estimates the "highest level of education achieved" for years that the variables overlap in each country. The regression equation uses age, income level, gender, age of completion of education and intolerance as independent variables for the regression equation.

I used the application Amelia || (King, Honaker, Joseph and Scheve 2001), to estimate the missing educational attainment variables both within years for which the data was collected, and the waves and countries listed below in the years where the data on attainment were missing. Amelia II works by estimating a matrix for each of the variables, then once convergence has been achieved repeats this process with 5 times working each time with a data set created by random draws (with replacement) from the returned data. The program creates 5 
data sets with imputed responses in place of missing data (King et al 2001, ). This method reduces the missing information that would be worsened by listwise deletion, while preserving non-biased estimators for the model.

Table F.2: Imputed values for Educational Attainment

\begin{tabular}{|l|l|l|l|l|}
\hline Country - wave & $\begin{array}{l}\text { Educational Level } \\
\text { Attained, Mean } \\
\text { Imputed }\end{array}$ & $\begin{array}{l}\text { St. Dev } \\
\text { Educational } \\
\text { Attainment }\end{array}$ & $\begin{array}{l}\text { Reported Age } \\
\text { Education } \\
\text { Completed }\end{array}$ & $\begin{array}{l}\text { R-Square } \\
\text { OLS } \\
\text { Predictor }\end{array}$ \\
\hline Austria (2) & 4.03 & 1.97 & 16.84 & 0.628 \\
\hline Belgium (2) & 4.39 & 1.95 & 16.59 & \\
\hline Bulgaria (2) & 4.54 & 2 & 19.21 & 0.692 \\
\hline Czech Republic (2) & 3.9 & 1.94 & 16.46 & 0.465 \\
\hline Finland (2) & 5.7 & 1.91 & 21.78 & 0.323 \\
\hline France (2) & 4.32 & 2.1 & 17.62 & 0.698 \\
\hline Germany (2) & 4 & 2.23 & 16.84 & 0.525 \\
\hline Hungary (2) & 3.86 & 2.08 & 16.29 & \\
\hline Ireland (2) & 4.16 & 1.99 & 16.53 & 0.706 \\
\hline Italy (2) & 4.07 & 1.8 & 16.53 & 0.629 \\
\hline Malta (2) & 3.85 & 1.94 & 15.81 & 0.58 \\
\hline Netherlands (2) & 4.67 & 1.89 & 18.9 & 0.421 \\
\hline Poland (2) & 4.14 & 1.99 & 17.47 & 0.426 \\
\hline Portugal (2) & 3.5 & 2.38 & 15.2 & \\
\hline Slovakia (2) & 3.9 & 2.21 & 16.31 & 0.635 \\
\hline Slovenia (2) & 4.57 & 2.31 & 19.39 & 0.559 \\
\hline Spain (2) & 3.78 & 2.49 & 14.23 & 0.488 \\
\hline Sweden (2) & 5.28 & 21.62 & 0.413 \\
\hline Great Britain (2) & 4.05 & 16.47 & 0.352 \\
\hline Source: World Values Survey 1981-2008 Waves Official Combined $\ldots . .49$ & \\
\hline Using: Amelia II: A Program for Missing Data. (Honaker, King and Blackwell 2009) & \\
\hline & & & & \\
\hline
\end{tabular}


Overall, with the exception of item "educational attainment", the dataset has a very low rate of missing data. The missingness rate is low even for composite, or factor variables containing several component indicators. Despite the low rates of missing data for the data set, several significant relationships existed between the Intolerance measure and missing data in several of the demographic and theoretically important parts of the model. Because of this minor problem with data not missing completely at random, the Amelia II missing data Monte Carlo bootstrapping program was used to multiply impute the missing items. 


\section{APPENDIX G: DATA ASSUMPtions AND MOdel CONCERNS FOR MULTI-LEVEL MODELS}

The distributional and structural assumptions multi-level models reflect assumptions of other classes of multiple regression and maximum-likelihood models with a few unique caveats.

Data used in hierarchical linear models is expected to be normally distributed variables the same as for other OLS or maximum-likelihood estimators. Detection of violations of normal distributions will be necessary prior to estimating models. Variables that are found to not have a normal distribution will either be transformed to correct the violations or dropped from the model if there is no way to retain the information without compromising the analysis. Additionally, the transformed summed intolerance variable is closer to a gamma distribution, so transformation of the variable using Box-Cox estimators was required.

Effective sample size is also a concern when conducting a multi-level analysis. The level of intraclass correlation conditions the effective sample size of a multi-level model generally reducing the sample to something substantially lower than the raw N (Snijders and Bosker 1999). However, each participant in the World Values Survey has a national sample of at least 950 respondents providing some margin for inclusion of level 1 dependent variables. As of October 2011, there was only data for individuals nested in 25 European Union member and accession countries over several waves, meaning that the limit on available 
degrees of freedom for a group-level variables is a very tight 62 country-waves with 72 waves available for a more limited model. This small number of countrywave cases permits inclusion of only the few most salient group-level random effects variables for this analysis.

As this model will likely suffer from under-identification dealing with problems associated with missing data is critical. Missing data is examined to determine whether it is missing completely at random, or missing at random or missing not at random. Data missing completely at random has no detectable relationship with any other available data. Data missing at random has no detectable relationship with the value of the data itself but is related to other values in the dataset. Missing not at random is self-explanatory (McKnight, et al. 2007). Depending on the volume of missing data and the pattern of missingness, the decision to delete listwise or take advantage of a multiple imputation estimator to fill-in missing data and maintain the ever important sample-size. 
Noordijk

APPENDIX H: TABLE OF INTOLERANCE

Table H.1: Intolerance by Country and Wave 1989-2008

\begin{tabular}{|c|c|c|c|c|c|}
\hline \multicolumn{6}{|c|}{ Intolerance by summed race, immigrant status, AIDs and orientation } \\
\hline & 1989-1993 & 1994-1999 & 1999-2004 & 2005-2007 & 2008 \\
\hline Austria & 1.04 & & 0.62 & & 0.90 \\
\hline Belgium & 0.85 & & 0.65 & & 0.24 \\
\hline Bulgaria & 2.03 & & 1.59 & 1.38 & 1.34 \\
\hline Cyprus & & & & 1.27 & 1.15 \\
\hline Czech Republic & 1.46 & 0.86 & 0.70 & & 1.13 \\
\hline Denmark & & & 0.32 & & 0.20 \\
\hline Estonia & & 1.34 & 1.24 & & 1.46 \\
\hline Finland & 0.79 & 0.79 & & 0.68 & 0.53 \\
\hline France & 0.61 & & 0.45 & 1.20 & 0.16 \\
\hline Germany & 0.89 & 0.26 & 0.37 & 0.51 & 0.51 \\
\hline Great Britain & 0.75 & & & 0.48 & 0.40 \\
\hline Greece & & & 0.82 & & 0.88 \\
\hline Hungary & 1.86 & 1.36 & & & 0.85 \\
\hline Ireland & 0.79 & & 0.75 & & 0.65 \\
\hline Italy & 1.11 & & 0.92 & 0.83 & 0.84 \\
\hline Latvia & & 1.31 & 0.89 & & 1.10 \\
\hline Lithuania & & 1.86 & 1.56 & & 1.70 \\
\hline Luxembourg & & & 0.46 & & 0.59 \\
\hline Malta & & & 1.12 & & 1.09 \\
\hline Netherlands & 0.47 & & 0.24 & 0.31 & 0.46 \\
\hline Northern Cyprus & & & & & 1.68 \\
\hline Poland & 1.55 & & 1.40 & 1.15 & 1.34 \\
\hline Portugal & 1.19 & & 0.62 & & 0.56 \\
\hline Romania & & 1.61 & 1.58 & 1.35 & 1.37 \\
\hline Slovak Republic & 1.72 & 1.22 & 1.29 & & 0.96 \\
\hline Slovenia & 1.64 & 1.46 & 1.06 & 0.98 & 1.19 \\
\hline Spain & 0.84 & 0.59 & 0.57 & 0.37 & 0.26 \\
\hline Sweden & 0.51 & 0.27 & 0.18 & 0.12 & 0.27 \\
\hline Turkey & 2.43 & & 2.46 & 2.27 & 2.68 \\
\hline
\end{tabular}




\section{APPENDIX I: INTRACLASS CORRELATION}

Intraclass correlation and effective sample size for the summed intolerance dependent variable and the bridging social capital(diffuse trust and memberships)

Calculating the unconditional intraclass correlation is an important measure of the stratification structure of your data has an impact on the model. An unconditional intraclass coefficient for Intolerance as nested in country-wave groups is .133 indicating that $13 \%$ of variance in the intercept only model is accounted for by the respondents being nested in country-waves, this is effectively an ANOVA using country-wave as the classification variable. 13\% is sufficiently high to warrant a multilevel analysis.

The .133 intraclass correlation also provides a first look at the design impact of the World Values Surveys sample as stratified by country and nested in waves. Calculating the design effect with the unconditional intraclass correlation is accomplished by simply finding its product with the group sample size (Hox ). With this dataset weighted to 1000 cases per country per wave and 60 countrywaves there is an unadjusted sample of just under 60,000. The design effect with the unconditional intraclass correlation coefficient of .133 in this case by the 1000 per group is 133. The effective sample size of an OLS model without group-level explanatory variables is around 60000/133 $=451$. 
The unconditional intraclass correlation coefficient for the bridging form of social capital is a very high .25. Rendering a design effect of 250 , and an effective sample of 240 for OLS models without group level explanatory variables. Including the indicators of education, RPE and per cap GDP into the full path model results in a conditional intraclass correlation of .14, meaning that some of the intraclass variance is accounted for and that the effective sample size for the model used in the path analysis is over 7000 . 


\section{APPENDIX J: NOTES AND FIGURES FROM ANALYSIS Religiosity by Country and Correlation With Intolerance}

The correlation of religiosity to the summed measure of intolerance is .172 $(p<.05)$. Indicating that across countries and waves higher levels of religiosity are correlated with intolerance. The correlation also breaks down along the dimensions of intolerance that were reported in the intolerance section, with a higher correlation between religiosity and intolerance for the dimensions that specifically capture disapproval of social behavior while there is still substantial correlation between the types of intolerance themselves. In effect, religious people are only slightly more likely than their peers to report intolerance towards racial or immigration minorities, but far more likely to report intolerance of homosexuals or AIDS sufferers than their fellows.

Table J.1: Correlations of Religiosity and Selected Intolerance Indicators.

\begin{tabular}{|c|c|c|c|}
\hline & Religiosity & $\begin{array}{l}\text { Neighbors: People of a } \\
\text { Different Race. }\end{array}$ & $\begin{array}{l}\text { Neighbors: } \\
\text { Homosexuals }\end{array}$ \\
\hline Religiosity & 1 & $.084^{* *}$ & $205^{* \star}$ \\
\hline Intolerance Scale & $.172^{\star \star}$ & $.567^{\star \star}$ & $.81^{\star \star}$. \\
\hline $\begin{array}{l}\text { Neighbors: People of a } \\
\text { different race }\end{array}$ & $.084^{* \star}$ & 1 & $.275^{\star \star}$ \\
\hline $\begin{array}{l}\text { Neighbors: } \\
\text { Homosexuals }\end{array}$ & $.205^{* *}$ & $.275^{\star \star}$ & 1 \\
\hline $\begin{array}{l}\text { Behavior vs. race } \\
\text { Intolerance }\end{array}$ & -0.036 & $.51^{* *}$ & $-.24^{\star \star}$ \\
\hline
\end{tabular}

Analysis in the regression indicates that the correlations between religiosity and the different forms of intolerance is largely an artifact of the grouping of 
intolerant and religious individuals within the same societies and the covariance

between religiosity and other indicators such as age in societies with weaker

distinctions between intolerance toward lifestyle versus racism and homophobia.

The hierarchical analysis of bridging social capital indicates that religiosity is

positively correlated with bridging social capital, but that indirect path is more than

suppressed by the reverse correlation in the indirect path.

Table J.2: Education Path by RPE with GDP Per Capita

\begin{tabular}{|l|l|}
\hline OLS & $\beta$ \\
\hline Intercept & 2.76 \\
\hline RPE & $0.102(1.2)$ \\
\hline Ln GDP/cap & $0.018(.86)$ \\
\hline$R^{2}$ & 0.01 \\
\hline $\begin{array}{l}\text { Dependent Variable= Educational Attainment } \\
\text { N= 82839, Deff= 85, Adjusted N=974 for Educational attainment. } \\
\text { All Standardized Regression Coefficients, t-scores from group level. } \\
\text { *significant at } p<.05 \\
\text { Source: World Values Survey 1980-2005 combined dataset. World Values Association. }\end{array}$ \\
\hline
\end{tabular}

Table 4.4 presents the coefficients of the GDP per capita and relative

Table J.3: Regression Test of RPE and Bonding Capital

\begin{tabular}{|l|l|}
\hline & $\beta$ \\
\hline Intercept & 0.121 \\
\hline Study & $-0.046(-1.9)$ \\
\hline Education & $-0.025(-1.14)$ \\
\hline RPE & $-0.075(-.37)$ \\
\hline GDP per cap & $-0.087(-.55)$ \\
\hline
\end{tabular}




\begin{tabular}{|l|l|}
\hline Religiosity & $-0.156(-6.8)$ \\
\hline Is Minority & $0.026(1.2)$ \\
\hline$R^{2}$ & 0.029 \\
\hline
\end{tabular}

$\mathrm{N}=$ 79983, Deff $=40$, Adjusted $\mathrm{N}=1999$

t-scores for group-level variables estimated using $\mathrm{N}$ for degrees of freedom at each level. Bonding Social Capital is on a scale of $-1=$ intense $<->1=$ weak.

Source: World Values Survey 1980-2005 combined dataset. World Values Association. 
Table J.4: Multi-level regression results

\begin{tabular}{|c|c|c|c|c|c|}
\hline Model & $\begin{array}{l}\text { Random } \\
\text { Intercept }\end{array}$ & Model 1 & Model 2 & Model 3 & Model 4 \\
\hline \multicolumn{6}{|l|}{ Fixed Effects } \\
\hline Intercept ү00 & -0.20 & -0.17 & 10.80 & 11.40 & 11.90 \\
\hline Gender $(0=$ female, $1=$ male $)$ & & $.27^{* *}$ & $.28^{* *}$ & $.28^{* *}$ & $.28^{* *}$ \\
\hline Minority Religion ( $0=\min , 1=$ maj $)$ & & 0.01 & & & \\
\hline Religiosity & & $.039^{* *}$ & $.038^{* *}$ & $.038^{* *}$ & $.037^{* *}$ \\
\hline Education & & $-.088^{* *}$ & $-089^{* *}$ & $-089^{* *}$ & $-087^{* *}$ \\
\hline Right-Left Political & & $.05^{\star *}$ & $.078^{* *}$ & $.078^{* *}$ & $.08^{* *}$ \\
\hline Income & & $-.018^{* *}$ & $-.018^{* *}$ & $-.017^{* *}$ & $-.017^{* *}$ \\
\hline Bridging Social Capital & & $-.31^{* *}$ & $-.31^{* *}$ & $-.29^{* *}$ & $-.29^{* *}$ \\
\hline Official Trust & & $.018^{* *}$ & & & \\
\hline Age (uncentered) & & $0.01^{* *}$ & $.013^{* *}$ & $0.13^{* *}$ & $0.13^{* *}$ \\
\hline Town Size (uncentered) & & $-.035^{* *}$ & $-.034^{* *}$ & $-.035^{\star *}$ & $-.035^{\star *}$ \\
\hline Unem (uncentered) & & & $-2.7^{* *}$ & $-2.8^{* *}$ & \\
\hline Relative Political Extraction & & & 1.20 & 1.14 & 1.50 \\
\hline In GDP/Capita & & & $-1.1^{* *}$ & -1.09 & $-1.13^{* *}$ \\
\hline Soc Security Spending/GDP & & & $-3.9^{*}$ & -3.87 & $-4^{* *}$ \\
\hline In-Migration Rate & & & $-2.6^{*}$ & & \\
\hline Right-Wing Gov (5-year MA) & & & 0.00 & & \\
\hline RPE x Bridging Capital & & & & & $-1.3^{*}$ \\
\hline \multicolumn{6}{|l|}{ Random Effects } \\
\hline Residual & 3.4 & 3.14 & 3.14 & 3.13 & 3.13 \\
\hline Random Intercept & $.7^{\star \star}$ & $.54^{* *}$ & $.19^{* *}$ & $.20^{\star \star}$ & $.20^{\star \star}$ \\
\hline Random Slope Bridging & & & & $.04^{\star \star}$ & $.03^{\star \star}$ \\
\hline \multicolumn{6}{|l|}{ Model Fit (smaller is better) } \\
\hline $\mathrm{AIC}$ & 227193.00 & 222738.00 & 222684.00 & 222574.00 & 222605.00 \\
\hline $\mathrm{BIC}$ & 227210.00 & 222756.00 & 222702.00 & 222600.00 & 222632.00 \\
\hline R2 estimated & & 0.10 & 0.19 & 0.18 & 0.18 \\
\hline Model Chi-square Difference & & 0.00 & 0.00 & 0.00 & Worse fit \\
\hline \multicolumn{6}{|c|}{$\begin{array}{l}\text { Individual N=77,015, Group-level N = } 72 \text {. Mixed Regression, unstructured Random Effects } \\
\text { (variance components). Right-wing parties in percentage of total cabinet posts, weighted by days. } \\
\text { Source: own calculations for Turkey based on Schmidt and Beyer (1992); } 1991 \text { onwards: Political } \\
\text { Data Yearbook(s), EJPR. } \\
\text { Source: World Values Survey 1980-2005 combined dataset. World Values Association. }\end{array}$} \\
\hline
\end{tabular}




\begin{tabular}{|c|c|c|}
\hline Fixed Effects & Model 5 & Model 6 \\
\hline Intercept y00 & -0.04 & -0.21 \\
\hline Religiosity (centered) & $0.03^{\star \star}$ & $.04^{\star \star}$ \\
\hline Gender (male) & & $.27^{\star \star}$ \\
\hline Education (centered) & $-0.087^{\star \star}$ & $-.09^{\star \star}$ \\
\hline Right-Left Political (centered) & $0.082^{\star \star}$ & $.08^{\star \star}$ \\
\hline Income (centered) & $-0.01^{\star \star}$ & $-.017^{\star \star}$ \\
\hline Bridging Social Capital (centered) & $-0.28^{\star \star}$ & $-.33^{\star \star}$ \\
\hline Age (centered) & $0.013^{\star \star}$ & $.013^{\star \star}$ \\
\hline Town Size & $-0.037^{\star \star}$ & $-.04^{\star \star}$ \\
\hline Relative Political Extraction & 1.87 & 1.90 \\
\hline In GDP/Capita (centered) & $-1.22^{\star \star}$ & $-1.03^{\star \star}$ \\
\hline Mig. rate & & -2.24 \\
\hline Soc. Security Spending/GDP & -2.09 & -2.9 \\
\hline Local expenditure/total expenditure & & -0.036 \\
\hline RPE x Bridging Capital & $-1.03^{*}$ & $-1.39^{*}$ \\
\hline Ln GDP x Bridging & $-.15^{\star \star}$ & $-.15^{\star \star}$ \\
\hline Local Exp x Bridging & & 0.12 \\
\hline \multicolumn{3}{|l|}{ Random Effects } \\
\hline Residual & 3.18 & 3.13 \\
\hline Random Intercept & $.23^{\star \star}$ & $.22^{*}$ \\
\hline Random Slope Bridging & $-.025^{\star \star}$ & $-.025^{\star \star}$ \\
\hline Slopes by Intercepts Bridging & -0.005 & -0.006 \\
\hline \multicolumn{3}{|l|}{ Model Fit (smaller is better) } \\
\hline $\mathrm{AIC}$ & 269040.00 & 226570.00 \\
\hline $\mathrm{BIC}$ & 269077.00 & 226606.00 \\
\hline Pseudo $R^{2}$ & 0.18 & 0.19 \\
\hline
\end{tabular}

Individual $\mathrm{N}=77,015$, Group-level $\mathrm{N}=72$. Mixed Regression, Unstructured Random Effects (variance components). Right-wing parties in percentage of total cabinet posts, weighted by days. Source: own calculations for Turkey based on Schmidt and Beyer (1992); 1991 onwards: Political Data Yearbook(s), EJPR.

Source: World Values Survey 1980-2005 combined dataset. World Values Association. 


\begin{tabular}{|c|c|c|c|c|c|c|}
\hline $\begin{array}{l}\text { Fixed Effects of } \\
\text { Standardized }\end{array}$ & Model 7 & $t$ & Model 8 & $t$ & Model 9 & $t$ \\
\hline Intercept & 0.61 & 26.64 & 0.61 & 26.47 & 0.61 & 26.55 \\
\hline Male & 0.08 & 20.15 & 0.08 & 20.15 & 0.08 & 20.16 \\
\hline $\begin{array}{l}\text { Bridging Social } \\
\text { Capital }\end{array}$ & -0.07 & -12.33 & -0.07 & -11.85 & -0.07 & -11.52 \\
\hline Religiosity & 0.03 & 15.31 & 0.03 & 15.31 & 0.03 & 15.30 \\
\hline $\begin{array}{l}\text { Political Self- } \\
\text { Placement }\end{array}$ & 0.05 & 26.90 & 0.05 & 26.89 & 0.05 & 26.90 \\
\hline Age & 0.07 & 35.48 & 0.07 & 35.48 & 0.07 & 35.48 \\
\hline Education & -0.08 & -38.24 & -0.08 & -38.24 & -0.08 & -38.23 \\
\hline Ln GDP/cap & -0.24 & -10.35 & -0.23 & -10.22 & -0.24 & -10.38 \\
\hline RPE & -0.02 & -0.71 & -0.01 & -0.57 & -0.02 & -0.81 \\
\hline Bridging * GDP & -0.01 & 2.21 & -0.01 & 2.36 & -0.01 & 2.52 \\
\hline $\begin{array}{l}\text { Gov-right } 5 \\
\text { year MA }\end{array}$ & 0.04 & 1.85 & 0.04 & 1.74 & 0.04 & 1.86 \\
\hline Bridging * RPE & & & -0.01 & -0.97 & & \\
\hline $\begin{array}{l}\text { RPE by Gov } \\
\text { right }\end{array}$ & & & -0.02 & -0.72 & & \\
\hline Bridging Group & & & & & 0.04 & 1.14 \\
\hline $\begin{array}{l}\text { Bridging Group } \\
\text { * Bridging Ind. }\end{array}$ & & & & & -0.01 & -1.57 \\
\hline \multicolumn{7}{|l|}{ Time EU } \\
\hline $\begin{array}{l}\text { Random } \\
\text { Effects }\end{array}$ & Est. & Wald Z & Est. & Wald Z & Est. & Wald Z \\
\hline Residual & 0.376 & 231.42 & 0.376 & 231.42 & 0.376 & 231.428 \\
\hline $\begin{array}{l}\text { Random } \\
\text { Intercept }\end{array}$ & 0.042 & 6.238 & 0.042 & 6.198 & 0.042 & 6.237 \\
\hline $\begin{array}{l}\text { Bridging by } \\
\text { Intercept }\end{array}$ & 0.001 & 1.046 & 0.001 & 0.944 & 0.002 & 1.241 \\
\hline $\begin{array}{l}\text { Bridging } \\
\text { Random Slope }\end{array}$ & 0.002 & 4.556 & 0.002 & 4.518 & 0.002 & 4.517 \\
\hline
\end{tabular}


Noordijk

APPENDIX K: GROUP-LEVEL SCATteRPLOT OF INTOLERANCE By GDP/CAP

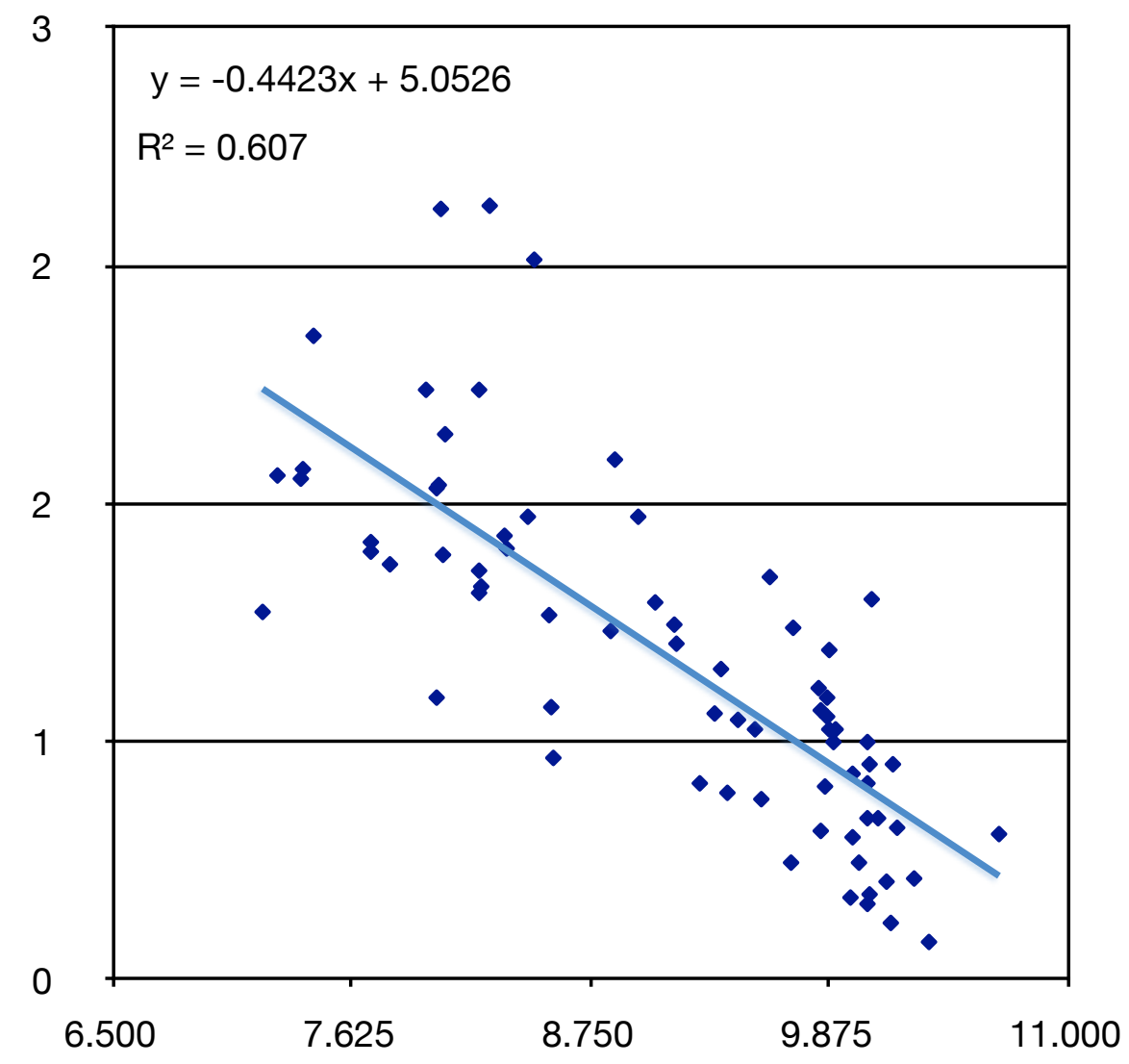

Figure K.1: Ln of per capita GDP by group mean Summed Intolerance, uncentered. 
APPENDIX L: PARTICIPATIE LADDER LEVELS

\begin{tabular}{|c|c|}
\hline Dutch & English \\
\hline $\begin{array}{l}\text { Niveau 1: Geïsoleerd } \\
\text { - Heeft niet of nauwelijks contact met anderen dan } \\
\text { huisgenoten EN } \\
\text { - de contacten buiten de huisgenoten beperken } \\
\text { zich tot functionele contacten (winkelpersoneel, } \\
\text { hulpverleners, buschauffeurs etc.) } \\
\text { Voorbeelden niveau 1: } \\
\text { - Nauwelijks contacten buiten de deur } \\
\text { - Mantelzorg voor huisgenoten } \\
\text { - Alleen actieve contacten via internet/email } \\
\text { - Dakloos zonder contacten met niet-daklozen, } \\
\text { behalve hulpverleners }\end{array}$ & $\begin{array}{l}\text { Level 1: Isolated } \\
\text { - Has little or no contact with people other than } \\
\text { household members AND } \\
\text { - contacts outside the household limited to } \\
\text { functional contacts (Shop assistants, social } \\
\text { workers, bus drivers, etc.) } \\
\text { Level } 1 \text { Examples: } \\
\text { - Hardly any contacts outside the home } \\
\text { - Care for family members } \\
\text { - Only active contacts via internet / email } \\
\text { - Homeless; no contacts with non-homeless, } \\
\text { except emergency }\end{array}$ \\
\hline $\begin{array}{l}\text { Niveau 2: Sociale contacten buiten de deur } \\
\text { - Heeft minimaal één keer per week fysiek contact } \\
\text { met mensen die geen huisgenoten zijn EN } \\
\text { - die contacten vinden niet plaats in } \\
\text { georganiseerd verband EN } \\
\text { - voert geen taken uit met verantwoordelijkheden } \\
\text { naar anderen (d.w.z. het is geen werk) EN } \\
\text { - die contacten beperken zich niet alleen tot } \\
\text { functioneel contact met winkelpersoneel, } \\
\text { hulpverleners et cetera } \\
\text { Voorbeelden niveau 2: } \\
\text { - Mensen ontmoeten zoals buren, buurtbewoners } \\
\text { en ouders van vriendjes van kinderen } \\
\text { - Regelmatig activiteiten buiten de deur } \\
\text { ondernemen, zoals bezoek van vrienden, } \\
\text { bioscoopbezoek, museumbezoek etc. } \\
\text { - Regelmatige mantelzorg voor niet-huisgenoten } \\
\text { (die niet via een organisatie is georganiseerd) } \\
\text { - Individuele sporten zoals sportschool } \\
\text { - Neemt deel aan activiteiten in georganiseerd } \\
\text { verband maar minder dan } 1 \text { x per week } \\
\text { - Regelmatig kerk/moskeebezoek (minimaal 1x } \\
\text { per week) }\end{array}$ & $\begin{array}{l}\text { Level 2: Social contacts outside the } \\
\text { Household } \\
\text { - Has physical contact with people who are not } \\
\text { household members at least once a week } \\
\text { AND } \\
\text { - these contacts do not occur in an organized } \\
\text { context AND } \\
\text { - does not perform tasks with responsibilities to } \\
\text { others (I.e., it is not work) AND } \\
\text { - these contacts are not restricted to contact with } \\
\text { store clerks, workers etc. } \\
\text { Level } 2 \text { Examples: } \\
\text { - Meeting people like neighbors, neighbors } \\
\text { parents and friends of children } \\
\text { - Regular activities, including visits from friends, } \\
\text { cinema, museum visits, etc. } \\
\text { - Regular care for non-household members (Not } \\
\text { organized by an organization) } \\
\text { - Individual sports such as gym or fitness } \\
\text { - Participates in organized activities but less than } \\
1 \text { x per week } \\
\text { - Regular church / mosque attendance (at least } \\
1 \times \text { per week) }\end{array}$ \\
\hline
\end{tabular}




\begin{tabular}{|c|c|}
\hline Dutch & English \\
\hline $\begin{array}{l}\text { Niveau 3: Deelname georganiseerde } \\
\text { activiteiten } \\
\text { - Neemt deel aan activiteiten in } \\
\text { georganiseerd verband zoals verenigingen of } \\
\text { opleidingen EN } \\
\text { - voert geen taken uit met verantwoordelijkheden } \\
\text { naar anderen (d.w.z. het is geen werk) EN } \\
\text { - neemt minimaal eens per week deel aan die } \\
\text { activiteit waarbij hij/zij in fysiek contact komt met } \\
\text { anderen } \\
\text { Voorbeelden niveau 3: } \\
\text { - Volgen van een } \\
\text { inburgeringsaanbod, } \\
\text { educatieaanbod of re-integratie-instrument zonder } \\
\text { werkcomponent } \\
\text { - Volgen van andere cursussen of opleidingen } \\
\text { zonder werkcomponent } \\
\text { - Lidmaatschap vereniging (regelmatig een } \\
\text { activiteit volgen waarbij je in contact komt met } \\
\text { andere mensen) } \\
\text { - Regelmatige sport beoefenen in georganiseerd } \\
\text { verband } \\
\text { - Vrijwilligerswerk (minder dan 1x per week } \\
\text { contact) }\end{array}$ & $\begin{array}{l}\text { Level 3: Participation in organized activities } \\
\text { - Participates in organized activities such as } \\
\text { associations or training AND } \\
\text { - does not perform tasks with responsibilities to } \\
\text { others (I.e., it is not work) AND } \\
\text { - take part in that activity in which he / she is in } \\
\text { physical contact come with others at least once a } \\
\text { week. } \\
\text { Level } 3 \text { Examples: } \\
\text { - Tracking a range of integration, offer education } \\
\text { or rehabilitation tool without Work Component } \\
\text { - Tracking other courses or training } \\
\text { unemployed component } \\
\text { - Association Membership (regular activity } \\
\text { follow where you come into contact with other } \\
\text { people) } \\
\text { - Regular organized sport in link } \\
\text { - Volunteering (less than } 1 x \text { per week contact) }\end{array}$ \\
\hline $\begin{array}{l}\text { Niveau 4: Onbetaald werk } \\
\text { - Doet onbetaald werk; dat wil zeggen: } \\
\text { - heeft geen arbeidscontract EN } \\
\text { - voert taken uit en heeft daarbij } \\
\text { verantwoordelijkheden naar anderen EN } \\
\text { - heeft minimaal eens per week fysiek contact met } \\
\text { anderen bij het uitvoeren van het onbetaalde } \\
\text { werk.Voorbeelden niveau 4: } \\
\text { - Werken met behoud van uitkering (Work First, } \\
\text { participatiebanen e.d.) } \\
\text { - Duale inburgeringstrajecten met een } \\
\text { werkcomponent } \\
\text { - Re-integratie-instrument met werkcomponent } \\
\text { - Stages }\end{array}$ & $\begin{array}{l}\text { Level 4: Unpaid Work } \\
\text { - Doing unpaid work, ie: } \\
\text { - has no employment contract, } \\
\text { AND } \\
\text { - performs tasks and thereby responsibilities to } \\
\text { others AND } \\
\text { - has at least once a week physical contact with } \\
\text { others when performing unpaid work. } \\
\text { Examples of level 4: } \\
\text { - Working with conservation benefits (Work First, } \\
\text { participation jobs e.d.) } \\
\text { - Dual integration programs with a Work } \\
\text { Component } \\
\text { - Re-integration tool with work component } \\
\text { - Internships } \\
\text { - Volunteer work (at least } 1 \text { x per week contact) } \\
\text { - Bol-training (training course with occasional } \\
\text { internship) } \\
\text { - GIT-projects (Integrated Pathways - vocational } \\
\text { training projects where a with training is combined } \\
\text { with learning the Dutch language) }\end{array}$ \\
\hline
\end{tabular}




\begin{tabular}{|c|c|}
\hline Dutch & English \\
\hline $\begin{array}{l}\text { Niveau 5: Betaald werk met ondersteuning } \\
\text { - Heeft een arbeidscontract met een } \\
\text { werkgever of is zzp'er en ontvangt daarbij } \\
\text { ondersteuning, dat wil zeggen: } \\
\text { - maakt gebruik van gemeentelijke } \\
\text { participatie-instrumenten OF } \\
\text { - ontvangt een aanvullende uitkering OF } \\
\text { - werkt in WSW-verband (intern, } \\
\text { gedetacheerd of begeleid werken) OF } \\
\text { - volgt een reguliere opleiding met } \\
\text { arbeidscomponent, onder het niveau van de } \\
\text { startkwalificatie. } \\
\text { Voorbeelden niveau 5: } \\
\text { - WSW (intern/gedetacheerd/begeleid werken) } \\
\text { - Werk (parttime) met aanvullende uitkering van } \\
\text { gemeente of UWV } \\
\text { - Werkt met loonkostensubsidie } \\
\text { - Werk waarbij uitkering wordt verloond (o.a. } \\
\text { bepaalde vormen van Work First) } \\
\text { - Werk met apart ingekochte instrument nazorg } \\
\text { waarbij sprake is van echte ondersteuning } \\
\text { - Werk met externe begeleiding/jobcoach } \\
\text { - Werk en volgt daarnaast een inburgeringsaanbod }\end{array}$ & $\begin{array}{l}\text { Level 5: Paid work supports } \\
\text { - Has a contract with a employer or SOHO and } \\
\text { will then issue support, ie: } \\
\text { - uses municipal participation instruments OR } \\
\text { - receive an additional allowance OR } \\
\text { - work in connection WSW (internal, seconded or } \\
\text { supported employment) OR } \\
\text { - follows a regular training labor component, } \\
\text { below the level of the basic qualification. } \\
\text { Level } 5 \text { Examples: } \\
\text { - WSW (internal / seconded / supported } \\
\text { employment) } \\
\text { - Work (part time) with additional payment of } \\
\text { municipality or the UWV } \\
\text { - Works with wage } \\
\text { - Work with distribution is verloond (inter alia } \\
\text { certain types of Work First) } \\
\text { - Work with separately purchased tool aftercare } \\
\text { involving real support } \\
\text { - Work with external assistance / job coach } \\
\text { - Work and follows also an integration range } \\
\text { - Work and follows also an educational offer } \\
\text { - Bbl training (four days working in a teaching } \\
\text { facility and training days) } \\
\text { - Working with allowance and without } \\
\text { supplementary benefit }\end{array}$ \\
\hline $\begin{array}{l}\text { Niveau 6: Betaald werk } \\
\text { - Heeft een arbeidscontract met een } \\
\text { werkgever of is zzp'er EN } \\
\text { - ontvangt geen aanvullende uitkering van } \\
\text { gemeente of andere uitkeringsinstantie } \\
\text { EN } \\
\text { - wordt niet door anderen dan } \\
\text { leidinggevende of collega's begeleid bij het } \\
\text { uitvoeren van het werk EN } \\
\text { - maakt geen gebruik van WSW of } \\
\text { gemeentelijke participatie-instrumenten. } \\
\text { Voorbeelden niveau 6: } \\
\text { - Baan met arbeidscontract } \\
\text { - Baan met arbeidscontract en pro forma nazorg1 } \\
\text { - Zzp'ers } \\
\text { - Ondernemers }\end{array}$ & $\begin{array}{l}\text { Level 6: Paid work } \\
\text { - Has a contract with a } \\
\text { employer or SOHO and } \\
\text { - does not receive additional payment of } \\
\text { municipality or other benefits agency AND } \\
\text { - will not be other than } \\
\text { supervisor or colleagues assisted in } \\
\text { perform the work and } \\
\text { - does not use or WSW } \\
\text { municipal participation instruments. } \\
\text { Examples of Level 6: } \\
\text { - Course of employment } \\
\text { - Course of employment and pro forma nazorg1 } \\
\text { - Self-employed } \\
\text { - Entrepreneurs }\end{array}$ \\
\hline
\end{tabular}

